\title{
ipen
}

INSTITUTO DE PESQUISAS ENERGÉTICAS E NUCLEARES

Autarquia associada à Universidade de São Paulo

\section{UTILIZAÇÃO DE REDES NEURAIS ARTIFICIAIS NA MONITORAÇÃO E DETECÇÃO DE FALHAS EM SENSORES DO REATOR IEA-R1}

ELAINE INACIO BUENO

Dissertação apresentada como parte dos requisitos para obtenção do Grau de Mestre em Ciências na Área de Tecnologia Nuclear - Reatores.

Orientador: Dr. Daniel Kao Sun Ting 
Dedico este trabalho aos meus pais, Gilberto e Marinezia e aos meus irmãos, Wellington e Lucineide 


\section{AGRADECIMENTOS}

Ao Prof ${ }^{0}$ Dr. Daniel Kao Sun Ting pela orientação, amizade e pela confiança depositada para a realização deste trabalho.

À Iraci Martinez P. Gonçalves pela amizade, dedicação, paciência e pela coorientação neste trabalho.

Ao CNPq pelo suporte financeiro fornecido durante a realização deste trabalho, sem o qual o mesmo não seria possível.

À todos os meus amigos e colegas do IPEN, que colaboraram direta ou indiretamente para a realização deste trabalho.

Aos colegas Roberto Carlos dos Santos e Margaret Damy, pelas palavras de incentivo.

À toda equipe de operação do reator IEA-R1 pela capacidade e disposição na aquisição de dados operacionais.

Ao meu irmão Wellington e à minha irmã Lucineide, pela dedicação e amizade nesta jornada.

Aos meus pais, Marinezia e Gilberto pelas palavras de incentivo e pelo apoio emocional recebido durante todo o mestrado.

Aos amigos da CPG pelo apoio recebido durante todo o mestrado.

Aos meus amigos Gustavo, Simone, Elaine e Marcelo, e a todos outros que também colaboraram direta ou indiretamente para este trabalho. 
Paciência e perseverança têm o efeito mágico de fazer as dificuldades desaparecerem e os obstáculos sumirem.

(John Quincy Adams) 


\title{
UTILIZAÇÃO DE REDES NEURAIS ARTIFICIAIS NA MONITORAÇÃO E DETECÇÃO DE FALHAS EM SENSORES DO REATOR IEA-R1
}

\author{
Elaine Inacio Bueno
}

\begin{abstract}
RESUMO
Os estudos na área de Monitoração e Diagnóstico de Falhas têm sido estimulados devido ao aumento crescente em qualidade, confiabilidade e segurança nos processos de produção, onde a interrupção da produção por alguma anomalia imprevista pode colocar em risco a segurança do operador, além de provocar perdas econômicas, aumentando os custos com a reparação de algum equipamento danificado. Tendo em vista estes dois fatores, o fator econômico e a própria questão de segurança do operador, tornase necessário a implementação de Sistemas de Monitoração e Detecção de Falhas.

Neste trabalho foi desenvolvido um Sistema de Monitoração e Detecção de Falhas usando a metodologia de Redes Neurais Artificiais que foi aplicado ao reator de pesquisas IEA-R1. O desenvolvimento deste sistema foi dividido em três etapas: sendo a primeira etapa dedicada à monitoração, a segunda a detecção, e a terceira ao diagnóstico de falhas. Na primeira etapa, foram treinadas diversas Redes Neurais Artificiais para a monitoração das variáveis de temperatura, potência e taxa de dose. Para tanto foram utilizadas duas bases dados: uma contendo dados gerados por um modelo teórico do reator, e outra contendo dados referentes a uma semana típica de operação. Na segunda etapa, as redes treinadas para realizar a monitoração das variáveis, foram testadas com uma base de dados contendo falhas inseridas artificialmente nos sensores de temperatura. Como o limite máximo de erro de calibração para termopares especiais é de $\pm 0,5^{\circ} C$, foram inseridas falhas de $\pm 1^{\circ} \mathrm{C}$ nos sensores responsáveis pela leitura das variáveis T3 e T4. Na terceira etapa foi desenvolvido um Sistema Fuzzy para realizar o diagnóstico de falhas, onde foram consideradas 3 condições possíveis de falhas: condição normal, falha de $-1^{\circ} C$, e falha de $+1^{\circ} C$, sendo que o sistema desenvolvido indicará qual o sensor de temperatura está com falha.
\end{abstract}




\title{
DEVELOPMENT OF AN ARTIFICIAL NEURAL NETWORK FOR MONITORING AND DIAGNOSIS OF SENSOR FAULT AND DETECTION IN THE IEA-R1 RESEARCH REACTOR AT IPEN
}

\author{
Elaine Inacio Bueno
}

\begin{abstract}
The increasing demand on quality in production processes has encouraged the development of several studies on Monitoring and Diagnosis Systems in industrial plant, where the interruption of the production due to some unexpected change can bring risk to the operator's security besides provoking economic losses, increasing the costs to repair some damaged equipment. Because of these two points, the economic losses and the operator's security, it becomes necessary to implement Monitoring and Diagnosis Systems.

In this work, a Monitoring and Diagnosis Systems was developed based on the Artificial Neural Networks methodology. This methodology was applied to the IEA-R1 research reactor at IPEN. The development of this system was divided in three stages: the first was dedicated to monitoring, the second to the detection and the third to diagnosis of failures. In the first stage, several Artificial Neural Networks were trained to monitor the temperature variables, nuclear power and dose rate. Two databases were used: one with data generated by a theoretical model and another one with data to a typical week of operation of the IEA-R1 reactor. In the second stage, the neural networks used to monitor the variables was tested with a fault database. The faults were inserted artificially in the sensors signals. As the value of the maximum calibration error for special thermocouples is $\pm 0,5^{\circ} C$, it had been inserted faults of $\pm 1^{\circ} C$ in the sensors for the reading of the variables T3 and T4. In the third stage a Fuzzy System was developed to carry out the faults diagnosis, where were considered three conditions: a normal condition, a fault of $-1^{\circ} C$, and a fault of $+1^{\circ} C$. This system will indicate which thermocouple is faulty.
\end{abstract}




\section{SUMÁRIO}

1. INTRODUÇÃ

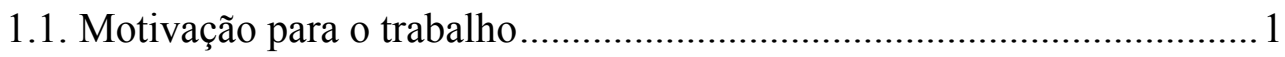

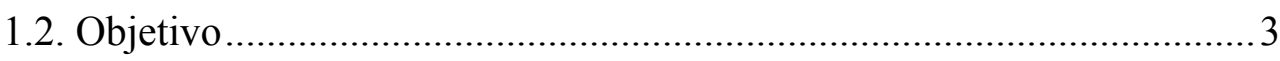

1.3. Aspectos relevantes e contribuições do trabalho ..................................... 4

1.4. Organização da dissertação .................................................................. 4

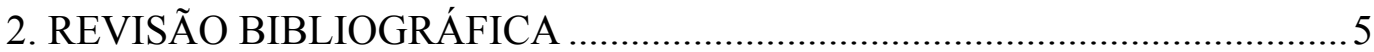

3. PRINCIPAIS ASPECTOS DO REATOR IEA-R1 ......................................... 8

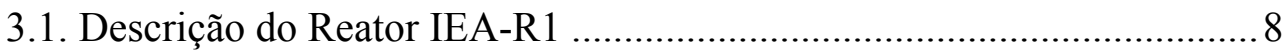

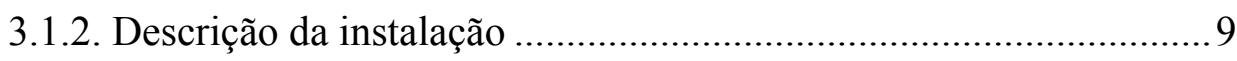

3.2. Sistema de Aquisição de Dados (SAD) ............................................. 11

3.2.1. Organização do Banco de Dados do SAD ....................................... 14

3.3. Modelo Teórico do reator IEA-R1 ….................................................... 17

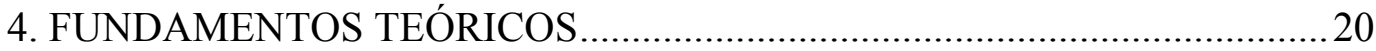

4.1. Redes Neurais Artificiais ......................................................................2 20

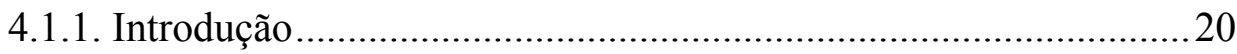

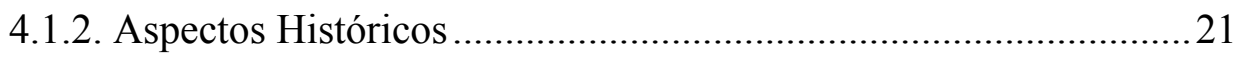

4.1.3. Modelo de Neurônio Biológico ......................................................23

4.1.4. Arquiteturas de Redes Neurais Artificiais (RNA's) .....................22

4.1.4.1. Redes do tipo Multilayer Perceptron (MLP) .............29

4.1.5. Principais Algoritmos de Treinamento........................................... 30

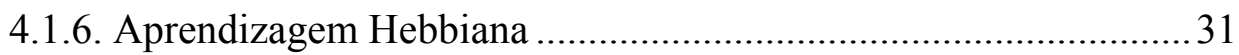

4.1.7. Aprendizagem por Correção de Erro............................................. 31

4.1.8. Regra Delta ou Método do Gradiente Descendente ....................... 33

4.1.9. Algoritmo de Retropropagação ..................................................... 34

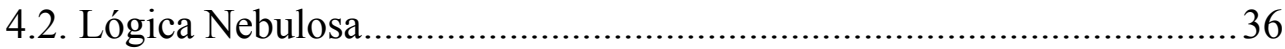

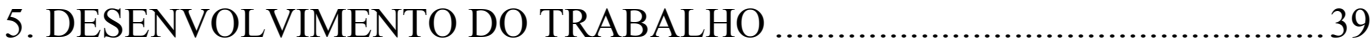

5.1. Base de dados para treinamento das Redes Neurais ............................42

5.2. Desenvolvimento das Redes Neurais ...................................................4 43

5.3. Arquitetura das redes MLP desenvolvidas neste trabalho .................... 43

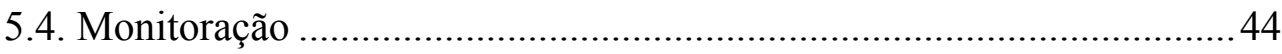

5.4.1. Treinamento da Rede com dados do modelo teórico do reator......44

5.4.2. Treinamento da Rede com dados de operação do reator ................46 
5.5. Deteç̧ão de falhas. 46

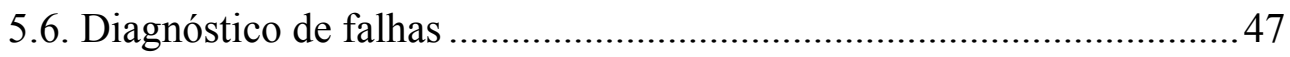

6. RESULTADOS OBTIDOS NA MONITORAÇÃO …................................... 48

6.1. Base de dados do Modelo teórico .......................................................48

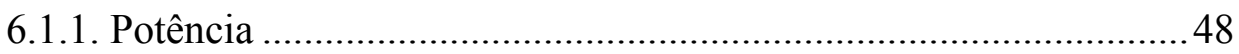

6.1.2. Monitoração das temperaturas......................................................49

6.1.3. Análise dos resultados do Modelo Teórico ....................................55

6.2. Resultados obtidos com dados de operação do reator...........................57

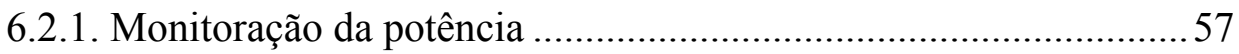

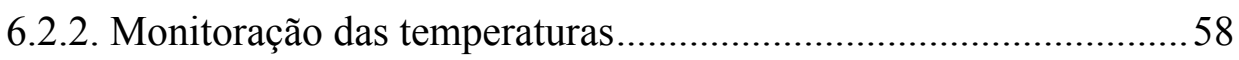

6.2.3. Monitoração da Taxa de Dose.......................................................66

6.2.4. Análise dos resultados com dados de operação do reator ..............67

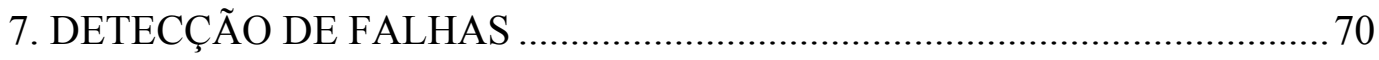

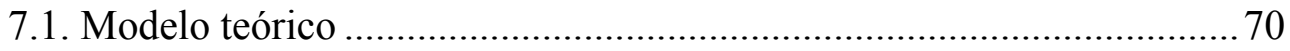

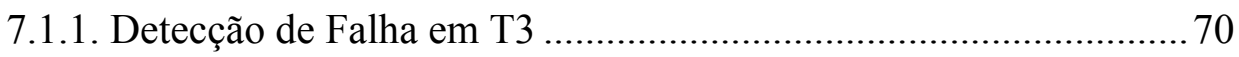

7.1.2. Deteç̧ão de Falha em T4 …........................................................ 74

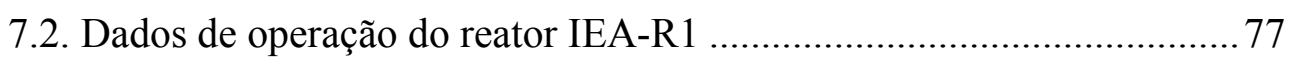

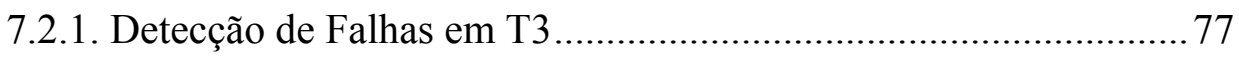

7.2.2. Detecção de Falhas em T4 ............................................................ 80

7.3 Discussão e análise dos resultados obtidos ............................................ 83

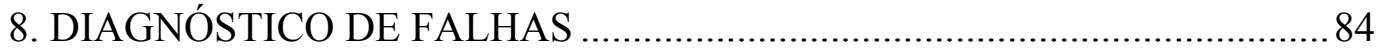

8.1. Modelagem Fuzzy do Conhecimento Especialista ................................85

8.2. Modelagem das Variáveis de Entrada................................................ 85

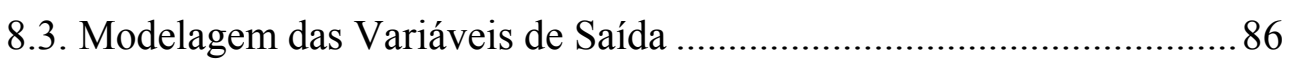

8.4. A base de regras do Sistema Fuzzy .................................................... 87

8.5. Implementação do Sistema Fuzzy ......................................................... 90

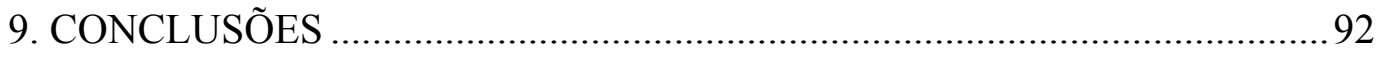

9.1. Recomendações para trabalhos futuros ..................................................93

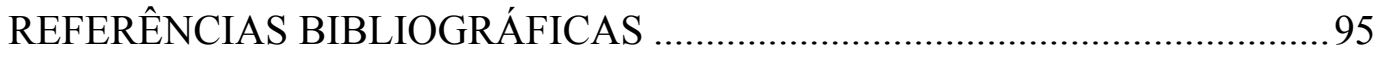




\section{LISTA DE TABELAS}

Tabela Título

Página

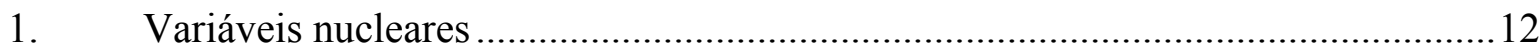

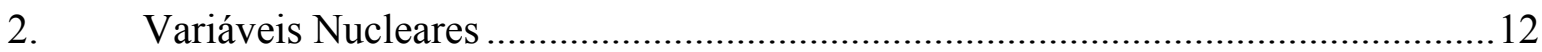

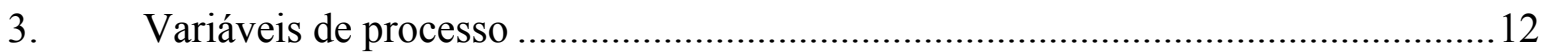

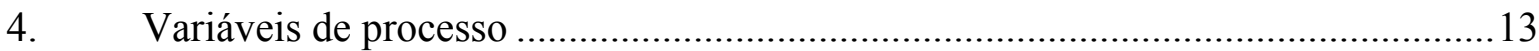

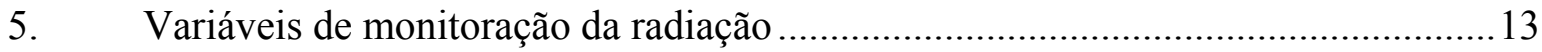

6. Variáveis de monitoração da radiação ................................................................... 13

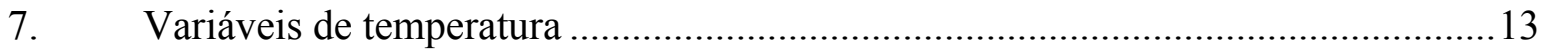

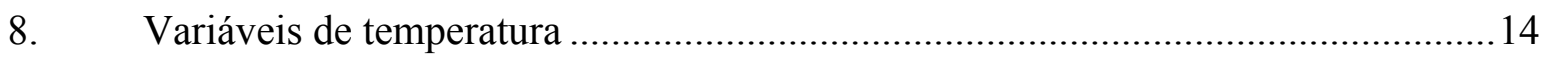

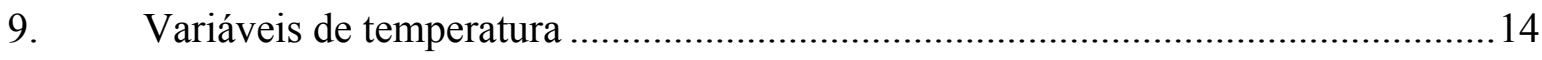

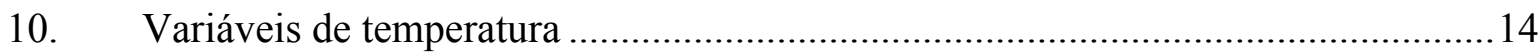

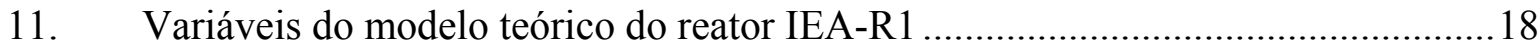

12. Descrição das variáveis utilizadas no trabalho .....................................................42

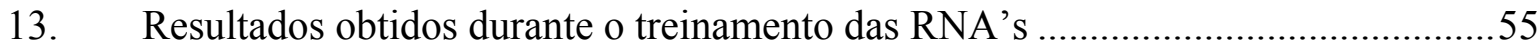

14. Resultados obtidos durante o treinamento das RNA's ............................................67

15. Resumo dos resultados obtidos na detecção e na monitoração de falhas .................83 


\section{LISTA DE FIGURAS}

Figura Título

Página

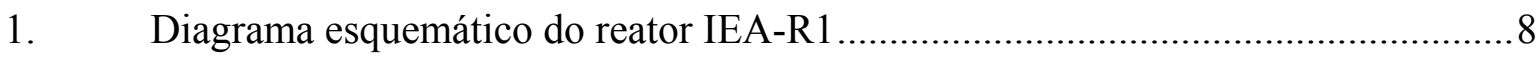

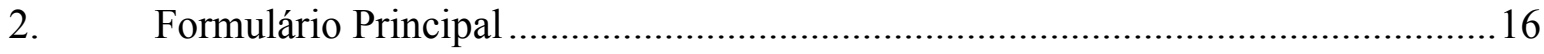

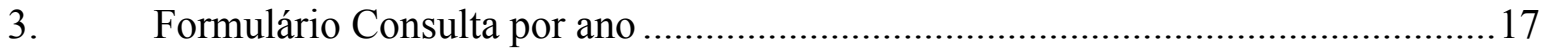

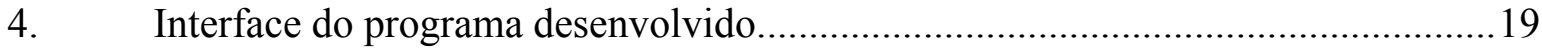

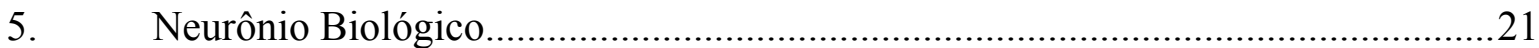

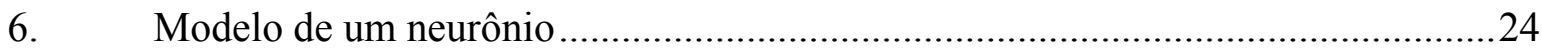

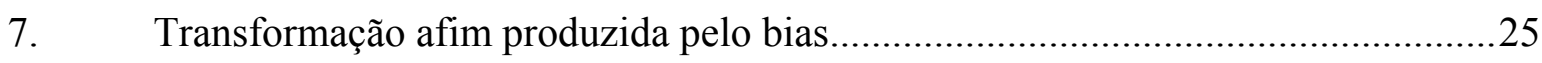

8 (a) Função limiar, (b) Função linear por partes (c) Função sigmóide com parâmetro

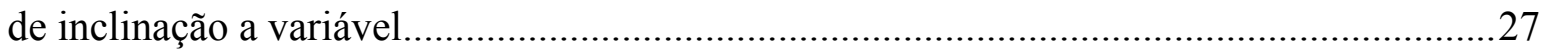

9. Redes com propagação para frente de uma camada ............................................28

10. Redes do tipo MLP (Múltiplas camadas com propagação para frente) ....................28

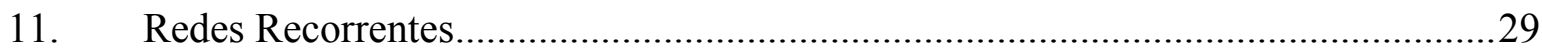

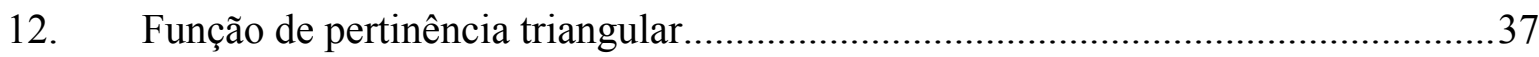

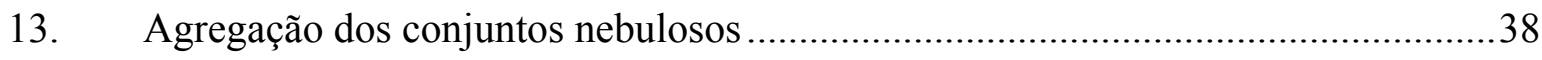

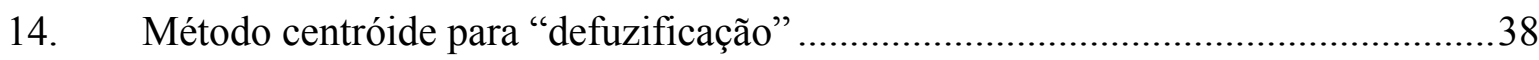

15. Etapas da implementação do Sistema de Monitoração e Detecção de Falhas.........39

16. Primeira etapa desenvolvida: Monitoração das variáveis .......................................40

17. Segunda etapa desenvolvida: Detecção de Falhas ....................................................41

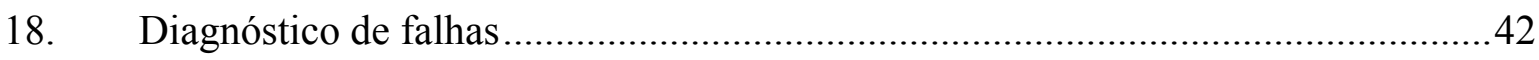

19. Resíduo da rede com 10 neurônios na camada oculta ...........................................49

20. Resíduo da rede com 8 neurônios na camada oculta ...............................................50

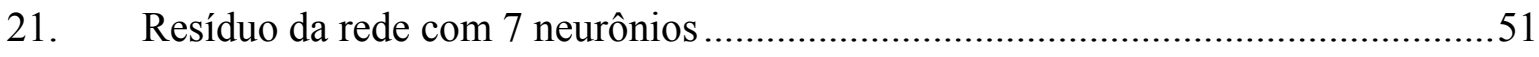

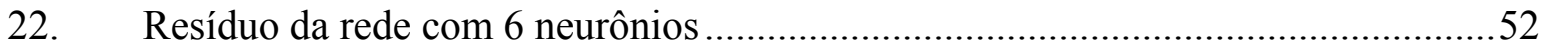

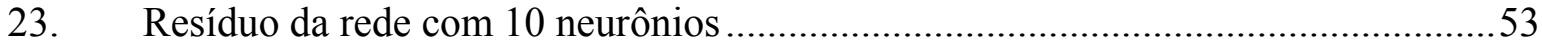

24. Saída desejada comparada com a saída obtida pela RNA …....................................53

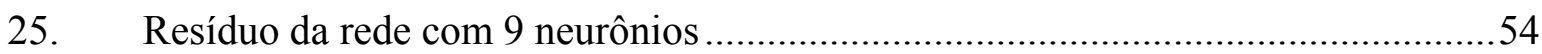

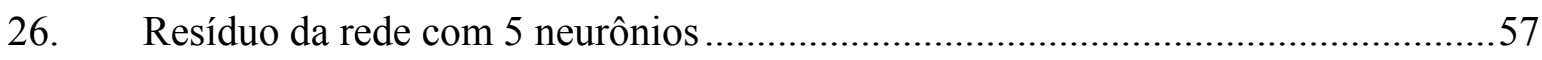

27. Saída desejada comparada à saída da rede com 5 neurônios na camada oculta ......58

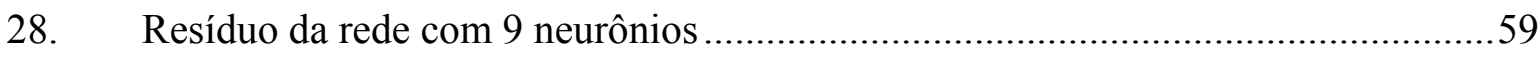

29. Saída desejada comparada à saída da rede com 9 neurônios na camada oculta .......59 
30. Resíduo da rede com 5 neurônios .60

31. Saída desejada comparada à saída da rede com 5 neurônios na camada oculta ......61

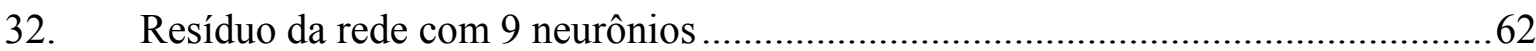

33. Saída desejada comparada à saída da rede com 9 neurônios na camada oculta ......62

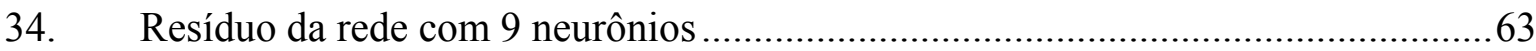

35. Saída desejada comparada à saída da rede com 9 neurônios na camada oculta ......64

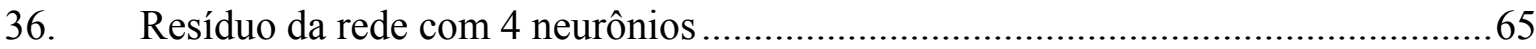

37. Saída desejada comparada à saída da rede com 4 neurônios na camada oculta ......65

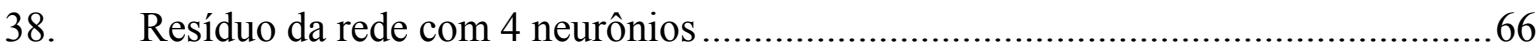

39. Saída desejada comparada à saída da rede com 4 neurônios na camada oculta ......67

40. Detecção de falha em T3 - Falha de $+1^{\circ} \mathrm{C}$ em T3 …...........................................71

41. Resíduo obtido na detecção de falha em T3 ......................................................72

41. Detecção de falhas em T3 - Falha de $-1^{\circ} \mathrm{C}$ em T3 .............................................73

42. Resíduo obtido na detecção de falha em T3 ..........................................................73

43. Detecção de Falha em T4 - Falha de $+1^{\circ} \mathrm{C}$ em T4 ..............................................74

44. Resíduo obtido na detecção de falha em T4 …......................................................75

45. Detecção de falhas em $\mathrm{T} 4-$ Falha de $-1^{\circ} \mathrm{C}$ em T4 .................................................76

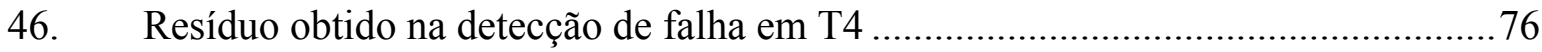

47. $\quad$ Detecção de falhas em T3 - Falha de $+1^{\circ} \mathrm{C}$ em T3 ..............................................77

48. $\quad$ Resíduo obtido na detecção de falha em T3 ..........................................................78

49. Detecção de falha em T3 - Falha de $-1^{\circ} \mathrm{C}$ em T3 .................................................79

50. Resíduo obtido na detecção de falha em T3 ...........................................................79

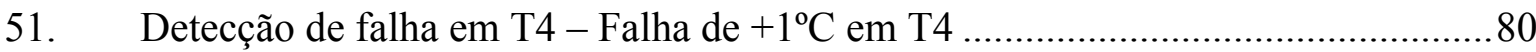

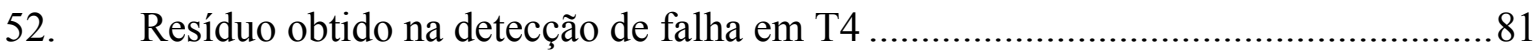

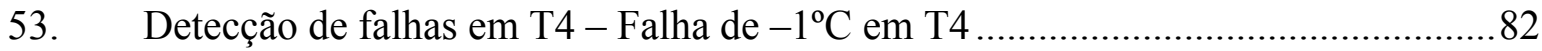

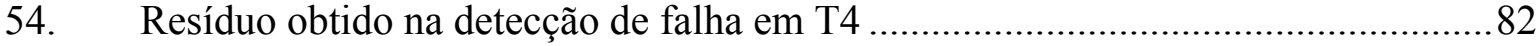

55. Sistema Fuzzy desenvolvido para o diagnóstico de Falhas .....................................84

56. Função de Pertinência da variável de entrada T3 ……........................................... 86

57. Função de pertinência da variável de saída T3 …..................................................87

58. Simulação de falha no termopar responsável pela leitura de T3 ….........................91 




\section{INTRODUÇÃO}

\subsection{Motivação para o trabalho}

A demanda crescente em qualidade, confiabilidade e segurança nos processos de produção tem encorajado o desenvolvimento de métodos e estudos na detecção e localização de falhas nas plantas nucleares e industriais. Este aumento crescente tem sido estimulado pela complexidade de alguns processos industriais, como os das indústrias químicas, centrais elétricas, indústrias petroquímicas, etc. Nestes processos, a interrupção da produção por alguma anomalia imprevista pode colocar em risco a segurança do operador, além de provocar perdas econômicas e aumentar os custos com a reparação de algum equipamento danificado. Perdas econômicas e questões de segurança fazem com que seja desejável a implementação de sistemas de controle confiáveis e tolerantes a falhas.

O termo "falha" pode ser definido como uma mudança inesperada na funcionalidade de um sistema, podendo ocorrer de forma abrupta obrigando a interrupção do processo para a manutenção e/ou reparação do instrumento danificado; ou então ocorrer gradualmente, onde a identificação da falha no seu estágio inicial, permite a substituição e/ou reparo do instrumento falho, antes que problemas mais sérios ocorram, ou a continuidade da operação até a próxima manutenção [1].

As tarefas de um sistema de Monitoração e Diagnóstico podem englobar desde a simples supervisão das variáveis, verificando se os seus valores estão dentro de um limite pré-estabelecido, até a detecção de uma falha. Sistemas de monitoração e diagnóstico mais sofisticados podem ainda realizar a identificação do componente responsável pela irregularidade observada no sistema. Neste trabalho estudaremos as falhas de sensores e atuadores de um sistema.

Em sistemas de monitoração e diagnóstico de falhas tradicionais utiliza-se a chamada redundância física (ou redundância por hardware), onde dois ou mais sensores similares realizam a mesma medida. Um esquema de votação lógica pode então ser utilizado para identificar um instrumento falho. Embora este seja um método confiável, há uma série de desvantagens, tais como o custo elevado de instalar e manter um maior 
número de sensores. Além disso, nem sempre há disponibilidade de espaço para a instalação de sensores redundantes.

Em oposição à redundância física (ou por hardware) tem-se a chamada redundância analítica (ou redundância por software) que faz uso da estimativa de sinais gerados por um modelo matemático do sistema considerado. Este modelo matemático pode ser elaborado a partir das equações matemáticas que descrevem o fenômeno real (conhecido como "first principle model"), ou o modelo é gerado a partir dos dados ("datadriven model") [2]. Estas estimativas são comparadas com as medidas dos sensores do sistema. Devido aos recentes avanços na computação, tem crescido muito o número de sistemas de monitoração baseados nessa nova filosofia. A principal vantagem do emprego de redundância analítica é que não há a necessidade de acrescentar novos componentes ao sistema existente para implementar o algoritmo monitoração e detecção de falhas. Normalmente, a instrumentação existente para controlar o processo é suficiente para isso.

As técnicas de Inteligência Artificial também estão sendo muito utilizadas em sistemas de monitoração e detecção de falhas, destacando-se entre elas as que utilizam sistemas inteligentes, como: a Lógica Nebulosa (Fuzzy Logic) e as Redes Neurais Artificiais (RNA's). As RNA's, em particular, têm sido empregadas em uma infinidade de áreas, como: nas centrais elétricas, nas indústrias químicas, na agricultura, na medicina, e em muitas outras áreas [3] [4] [5] [6].

A solução de diversos problemas de engenharia através de Redes Neurais Artificiais é muito interessante, tanto pela forma como estes problemas são representados internamente pela rede, como também pelos resultados gerados. Em Redes Neurais Artificiais, o procedimento usual na solução de problemas passa inicialmente por uma fase de aprendizagem, em que um conjunto de exemplos é apresentado para a rede, que extrai automaticamente dos mesmos as características necessárias para representar a informação fornecida. Essas características são utilizadas posteriormente para gerar respostas a problemas com características similares às dos exemplos.

A possibilidade de aprender através de exemplos e generalizar a informação aprendida são, sem dúvida, os principais atrativos na solução de problemas através de Redes Neurais Artificiais. A generalização, que está associada à capacidade da rede aprender através de um conjunto reduzido de exemplos, e posteriormente dar respostas coerentes para dados não conhecidos, é uma demonstração de que a capacidade das Redes Neurais Artificiais não se limita apenas em mapear relações de entrada e saída. As Redes Neurais Artificiais são capazes de extrair informações não apresentadas de forma explícita, 
através de exemplos. Uma vantagem obtida no uso de RNA's na monitoração e no diagnóstico de falhas de sensores e atuadores, é a sua capacidade de modelar o sistema monitorado servindo, portanto, como um simulador do sistema e fornecendo um apoio importante ao operador durante a operação do sistema.

\subsection{Objetivo}

O objetivo deste trabalho é demonstrar a viabilidade de aplicação da metodologia de Redes Neurais Artificiais (RNA's) e Lógica Nebulosa, na monitoração e detecção de falhas em sensores e atuadores. Esta metodologia será aplicada no reator de pesquisas do IPEN IEA-R1, onde será utilizada uma base de dados contendo os valores das variáveis de processo da instrumentação, coletados e armazenados pelo SAD (Sistema de Aquisição de Dados) do reator.

Para a monitoração dos instrumentos de processo, utilizou-se Redes Neurais Artificiais (RNA's) com o propósito de realizar a modelagem das variáveis do sistema. Na detecção de falhas, também se utilizou Redes Neurais Artificiais, porém o modelo desenvolvido na monitoração, foi testado com uma base de dados contendo falha, para verificar a capacidade de generalização das redes usadas no desenvolvimento do modelo. Já o diagnóstico de falhas foi realizado por um Sistema Fuzzy, composto por uma série de regras "SE ENTÃO (if - then)", que foi implementado usando-se Lógica Nebulosa. Este Sistema Fuzzy desenvolvido foi testado no diagnóstico da descalibração dos sensores de temperatura.

A metodologia desenvolvida foi implementada inicialmente usando dados de um modelo teórico, e depois foram utilizados dados referentes a uma semana típica de operação do reator. O modelo teórico do reator IEA-R1 permite gerar dados para diferentes condições de operação, além de dados com falhas. Os dados gerados pelo modelo teórico, em diferentes condições de operação, permitiram a realização de um estudo exaustivo da metodologia de Redes Neurais na monitoração de instrumentos de processo. Após este estudo, foram utilizados dados referentes a uma semana típica de operação do reator. A função de monitoração é independente das indicações dos painéis de Instrumentação e Controle instalados na Sala de Controle, e, portanto a instalação do Sistema de Monitoração e Detecção de Falhas não irá interferir na operação do reator. 


\subsection{Aspectos relevantes e contribuições do trabalho}

As principais contribuições deste trabalho são:

Proposta de aplicação da metodologia de Redes Neurais Artificiais (RNA's) na monitoração e detecção de falhas nos instrumentos de processo do reator, demonstrada através do uso primeiramente, de uma base de dados teórica, onde se iniciou um estudo do comportamento do sistema. Após esse estudo, foram utilizados dados típicos de uma semana de operação do IEA-R1;

\subsection{Organização da dissertação}

* Capítulo 1: Neste capítulo é feita uma introdução teórica, que situa o tema da dissertação e define os objetivos do trabalho.

* Capítulo 2: São abordados os principais aspectos históricos das diferentes tecnologias utilizadas nos Sistemas de Monitoração e Detecção de Falhas.

* Capítulo 3: Descrição dos principais aspectos do reator IEA-R1 e da base de dados utilizada no trabalho.

* Capítulo 4: Teoria sobre Redes Neurais Artificiais e Lógica Nebulosa.

* Capítulo 5: Desenvolvimento do trabalho, onde são descritos em detalhes, as etapas de monitoração, detecção e diagnóstico de falhas.

* Capítulo 6: Apresenta os resultados obtidos na monitoração de falhas dos sensores.

- Capítulo 7: Resultados obtidos na detecção de falhas dos sensores.

* Capítulo 8: Resultados obtidos no diagnóstico de falhas dos sensores.

* Capítulo 9: Apresenta as conclusões obtidas e também recomendações para trabalhos futuros. 


\section{REVISÃO BIBLIOGRÁFICA}

A utilização de Sistemas de Monitoração e Detecção de Falhas teve início na década de 70 [7] [8] [9], onde foi verificada a necessidade de avaliar a confiabilidade dos instrumentos de processo, através da detecção e do isolamento de instrumentos falhos.

A redundância física começou a ser utilizada para monitorar e detectar instrumentos falhos, onde se utilizava mais de um instrumento redundante para realizar a mesma medida [10] [11]. Na redundância física, usando-se dois instrumentos redundantes, era possível detectar falhas; já com o uso de três instrumentos, era possível isolar a mesma [12].

Com o avanço da tecnologia, da computação numérica e do processamento de sinais, passou-se a utilizar o primeiro método de monitoração e detecção de falha, a redundância analítica que faz uso da estimativa dos sinais gerados por um modelo matemático do sistema considerado [13]. Podem ser citadas diversas aplicações de redundância analítica, na área de monitoração e detecção de falhas, entre elas: a detecção de filtros [14] [15], uso de filtros de Kalman [16] [10], a aproximação de espaço [17], a técnica de estimação de parâmetros [18] e algumas aplicações usando sistemas especialistas [12].

Pode-se encontrar diversas aplicações dos sistemas inteligentes na monitoração e no diagnóstico de falhas, dentre as quais podemos citar: as aplicações nas indústrias químicas, nas centrais elétricas, e em uma infinidade de áreas, como pode ser visto nas referências [19] [20]. Entretanto, os sistemas baseados no conhecimento são muito específicos, pois seu poder de representação é muito limitado e é extremamente difícil a sua atualização [21].

A bibliografia revisada mostra que as Redes Neurais Artificiais também estão sendo muito utilizadas na Monitoração e na Detecção de falhas, como pode ser visto na descrição de alguns trabalhos citados abaixo.

SORSA e KOIVO (1991) [22] estudaram várias arquiteturas de redes para a monitoração e detecção de falhas em um trocador de calor e em um tanque de mistura contínua. Foi utilizado um processo bem próximo do real como estudo de caso, onde existiam 14 medidas com ruído e 10 faltas típicas. Nesta aplicação, a melhor arquitetura foi 
a Multilayer Perceptron (MLP) que foi capaz de identificar todas as falhas.

BERNIERI et al. (1994) [23], propôs uma metodologia para detecção e isolamento de falhas em instrumentos, baseada em Redes Neurais Artificiais. Foram testados as falhas que podem ocorrer em motores de indução e os resultados obtidos foram extremamente satisfatórios.

SELIGER e FRANK (1995) [24], introduziram o conceito de Redes Neurais Artificiais na detecção de falhas e no isolamento das mesmas nos processos industriais. Foram discutidas três possibilidades diferentes de utilização das RNA'S. A primeira possibilidade seria a utilização de uma RNA ao invés de um modelo matemático, na geração de resíduos; a segunda seria o treinamento de uma RNA para realizar uma tarefa de classificação da evolução residual, e depois o isolamento da falha; a última possibilidade seria realizar a detecção em uma única etapa, onde a RNA seria treinada para detectar e isolar possíveis falhas de todas as medidas disponíveis sem a necessidade de uma geração a priori de sinais residuais intermediários.

KEYAN e NAGARAJ (1997) [25], desenvolveram um protótipo de um Sistema de Monitoração usando RNA's. O sistema possuía uma excelente interface gráfica, era extremamente amigável, e permitia que o usuário escolhesse os sinais e os parâmetros de seu interesse. Além disso, este sistema mostrava o estado ou condição dos sinais testados em condições normais e com falha. Na presença de falhas, o sistema através do uso de uma base de dados integrada, identificava a falha e indicava o progresso da falta relativa em relação à condição normal e vice-versa. Todos os sinais utilizados no desenvolvimento do sistema foram coletados de um Sistema de Aquisição de Dados de um reator nuclear.

MAKI e LOPARO (1997) [26], usaram uma rede do tipo MLP para a monitoração e detecção de falhas em processos industriais. Esta metodologia foi testada em uma estação de medidas complexas para realizar testes em um motor de indução. $\mathrm{O}$ principal aspecto desse estudo foi que a detecção de falhas ocorreu em regime transiente de operação do processo. Foi proposta uma RNA de dois estágios como estrutura básica do sistema de detecção. O primeiro estágio da rede detectava a direção dinâmica de cada medida; já o segundo detectava e monitorava as falhas. Este método conseguiu detectar e monitorar com grande sucesso as falhas treinadas em regime de transiente.

ABO-SHOSHA et. al. (1997) [27], usaram RNA's do tipo MLP para identificar possíveis falhas em plantas nucleares e propuseram um sistema de alarmes para auxiliar o operador na tomada de decisões. 
SIMANI e FANTUZZI (2000) [1], propuseram uma metodologia de monitoração de duas fases: na primeira fase, a falha era detectada com base nos resíduos gerados por um banco de filtros Kalman; na segunda, a identificação da falha era feita através de técnicas de reconhecimento de padrões, implementadas por RNA's.

ROSSI (2001) [28], usou redes neurais do tipo MLP e Radial Basis Function (RBF) para a monitoração da potência do reator IEA-R1, visando o desenvolvimento de uma interface homem-máquina inteligente, onde a informação fosse devidamente priorizada. Os resultados obtidos após o treinamento da rede foram mostrados em uma tela de informações, juntamente com o resultado obtido através de outras formas de medida de potência, auxiliando desta maneira os operadores da instalação na eventual necessidade de calibração dos instrumentos medidores de Potência Nuclear.

SEKER et. al.(2003) [29], estudaram o problema de utilização de RNA's para detectar possíveis anomalias, assim como os parâmetros físicos de uma planta nuclear durante sua operação em tempo real.

O Sistema de Monitoração e Diagnóstico de Falhas desenvolvido neste trabalho diferencia-se de outros trabalhos realizados nesta área, por utilizar primeiramente uma base de dados de um modelo teórico, que será detalhada nos próximos capítulos, e também por utilizar dados referentes a uma semana típica de operação do reator IEA-R1. Além disso, nos trabalhos realizados anteriormente, a única variável monitorada era a Potência Nuclear, e no Sistema desenvolvido neste trabalho, foram monitoradas além da Potência Nuclear, 5 variáveis de temperatura, além da taxa de dose. Outro aspecto interessante deste trabalho, é que após o treinamento das Redes Neurais estabeleceu-se um modelo de monitoração, e o mesmo foi testado com uma base de dados com falha, para verificar a capacidade de generalização das redes treinadas; além disso, foi desenvolvido um Sistema Fuzzy para diagnosticar a descalibração dos sensores de temperatura do reator IEA-R1.

A bibliografia revisada apresenta os resultados obtidos com a aplicação da metodologia de Redes Neurais Artificiais na Monitoração e Detecção de Falhas em sistemas de processos, mostrando a viabilidade de aplicação da mesma no reator IEA-R1. 


\section{PRINCIPAIS ASPECTOS DO REATOR IEA-R1}

\subsection{Descrição do Reator IEA-R1}

O Reator IEA-R1 foi projetado e construído pela "Babcok \& Wilcox", em 1956. É um reator tipo piscina, refrigerado e moderado a água leve, que utiliza berílio como refletor. Sua primeira criticalidade foi atingida em 16 de setembro de 1957, onde passou a operar a $2 \mathrm{MW}$ de potência, de segunda a sexta-feira, das 8:00h às 17:00h, com uma parada a cada 15 dias, nas segundas-feiras, para manutenção preventiva e corretiva. A partir de 1995, o reator teve seu regime de operação modificado para 64 horas ininterruptas visando a produção de radioisótopos e o desenvolvimento de pesquisas. A Figura 1 mostra um diagrama esquemático do reator IEA-R1.

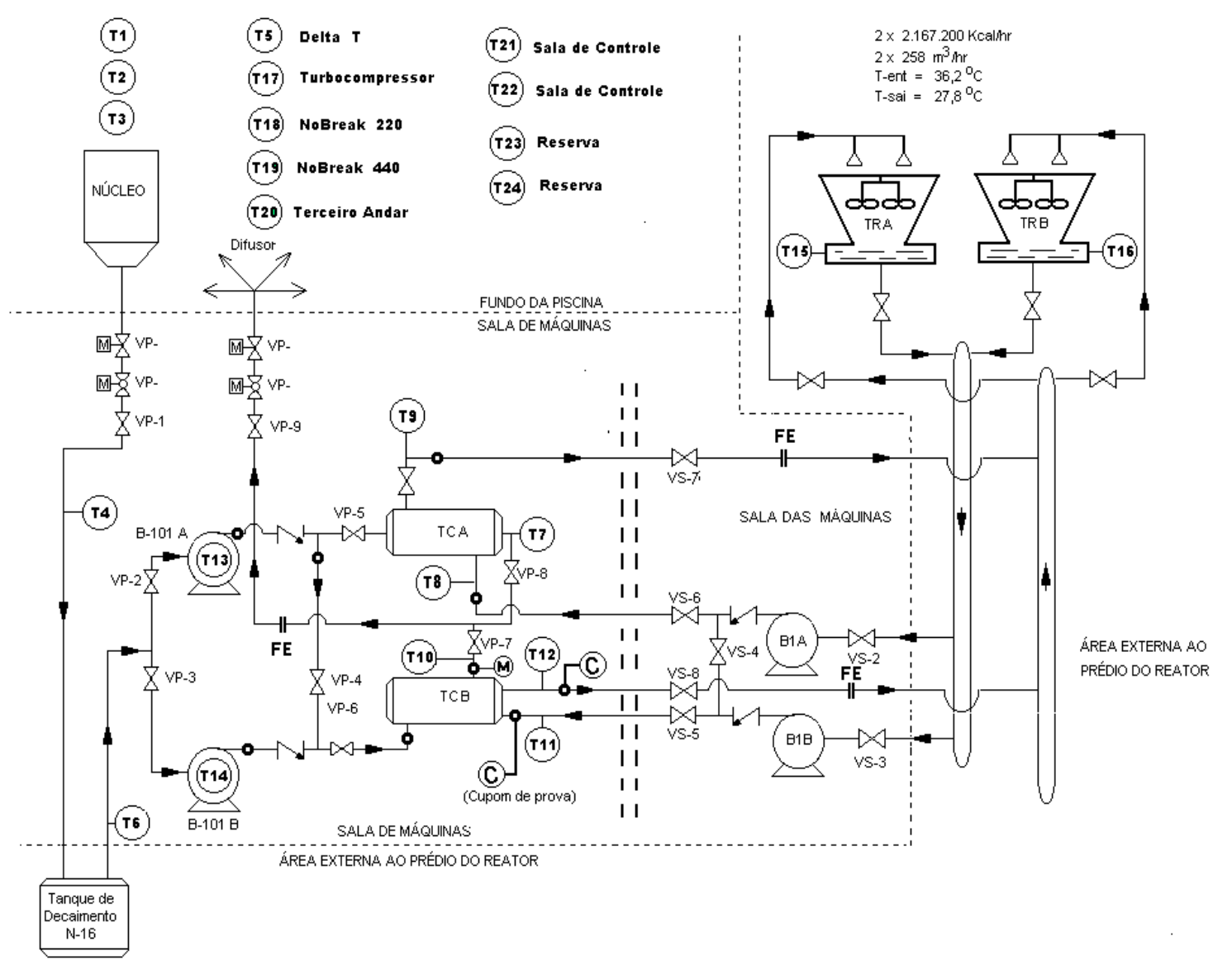

Figura 1. Diagrama esquemático do reator IEA-R1 
O reator IEA-R1 é utilizado para: [30]

* Produção de radioisótopos para aplicações na medicina, indústria, agricultura e para pesquisas;

Treinamento e formação de operadores do reator;

Teste de materiais;

Pesquisa em física e química nuclear;

Realização de experimentos visando a obtenção de parâmetros nucleares

\subsubsection{Descrição da instalação}

O prédio do reator IEA-R1 é composto por cinco pavimentos:

* No subsolo: a Casa das Máquinas;

No $1^{\circ}$ andar: o Salão de Experimentos;

No $2^{\circ}$ andar: Sala de Ventilação e Ar-Condicionado, Almoxarifados e o acesso principal do prédio;

* No $3^{\circ}$ andar: Saguão da Piscina do Reator, a Sala de Controle e as Oficinas de Apoio;

* No $4^{\circ}$ andar encontra-se a Sala de Exaustão, com filtros e chaminé do Sistema de Exaustão do Reator.

O núcleo do reator encontra-se dentro da piscina e está montado em uma placa matriz com oitenta orifícios, onde é possível que os combustíveis sejam dispostos em vários arranjos experimentais. Além disso, essa placa matriz é sustentada por uma treliça conectada a uma plataforma móvel, onde estão montados os quatro mecanismos de acionamento das barras e detectores que enviam sinais para a mesa de controle.

A piscina do reator é dividida em dois compartimentos: o primeiro compartimento é usado para estocar e manusear materiais radioativos e elementos combustíveis; já o segundo, é destinado à operação do reator por conter o núcleo do mesmo.

A redundância física é utilizada nos circuitos de resfriamento do núcleo, onde apenas um circuito de resfriamento é suficiente em casos de acidentes. Além disso, a 
maneira em que foram projetados permite alternar circuitos e alinhamentos dos seus diversos componentes.

Cada circuito de resfriamento é composto por:

* 1 bomba do circuito primário;

* 1 bomba do circuito secundário;

* 1 trocador de calor;

* 1 torre de resfriamento do circuito secundário;

* Válvulas de fechamento automático são posicionadas na saída e no retorno da água, isolando o circuito primário em caso de perda do refrigerante, além disso, existe um outro sistema que permite o resfriamento do núcleo em caso de exposição do mesmo.

O tanque de decaimento (localizado no circuito primário de resfriamento), é responsável por atrasar o retorno da água para a piscina, possibilitando o decaimento do ${ }^{16} \mathrm{~N}$ formado na água.

A reatividade do reator é controlada usando-se três barras de segurança e uma barra de controle, que são movimentadas por um mecanismo de acionamento constituído de motores síncronos. Essas barras são sustentadas por magnetos que são desenergizados, na ocorrência de algum evento não usual, fazendo-as cair por ação da gravidade, desligando o reator.

A instrumentação nuclear é composta por:

2 câmaras de ionização não compensadas;

* 1 câmara de ionização compensada;

* 1 câmara de fissão.

Esses instrumentos nucleares enviam sinais para a mesa de controle localizada na sala de controle. Na sala de controle estão instalados os seguintes instrumentos de apoio à operação:

* Monitores de radiação de área, dutos e contaminação de ar;

* Sistema de Alarmes de Radiação;

* Comando das bombas dos circuitos: primário e secundário, e os ventiladores das torres de resfriamento; 
- Comandos do Sistema de Ventilação e Exaustão do Ar-Condicionado;

* Alarme de incêndio;

* Comando do Sistema de Resfriamento de Emergência;

* Comando das válvulas de isolação do circuito primário;

* Iluminação de emergência;

* Indicação de condutividade da água da piscina e da água de reposição;

- Sistema de análise de vibração dos mancais dos volantes de inércia;

* Comunicação interna e externa.

O Sistema de Ventilação e Ar-Condicionado é responsável por manter o prédio despressurizado nas áreas com maior risco de contaminação, tais como: Saguão da Piscina, Casa de Máquinas e Salão de Experimentos.

A água da piscina do reator mantém-se em boa qualidade através do uso de sistemas de resinas trocadoras de íons, que são os Sistemas de Tratamento e Retratamento da Água. O Sistema de Tratamento é responsável por completar o nível de água da piscina com a pureza necessária aos níveis operacionais; já o Sistema de Retratamento opera continuamente e tem como objetivo manter a qualidade da água da piscina, minimizando os efeitos de corrosão e os níveis de dose de radiação na superfície da piscina.

A energia elétrica é fornecida por meio da rede elétrica da concessionária local, e se ocorrer uma interrupção no fornecimento de energia, um conjunto de quatro motogeradores fornecerá energia elétrica aos sistemas vitais e essenciais para manter o reator em operação.

Além disso, os principais sistemas do reator enviam sinais à mesa de controle, garantindo que o mesmo seja desligado, na ocorrência de alguma anormalidade durante a operação do mesmo.

Todos os aspectos de instalação descritos acima têm como objetivo garantir a segurança máxima do reator IEA-R1, protegendo assim os indivíduos, a sociedade e o meio ambiente de acidentes nucleares.

\subsection{Sistema de Aquisição de Dados (SAD)}

O Sistema de Aquisição de Dados SAD é responsável pela monitoração de 58 variáveis operacionais, incluindo temperatura, vazão, nível, pressão, radiação, potência nuclear e posição de barras. O SAD permite armazenar a história temporal de todas as 
variáveis de processo monitoradas, fornecendo assim um conjunto de informações que foram utilizados para a elaboração do Sistema de Monitoração e Detecção de Falhas.

Inicialmente, os dados eram distribuídos em 10 arquivos, cujo conteúdo são mostrados nas Tabelas de 1 a 10:

Tabela 1. Variáveis nucleares

\begin{tabular}{|l|l|}
\hline Z1 & Posição da barra de controle [0 a $1000 \mathrm{~mm}]$ \\
\hline Z2 & Posição da barra de segurança 1 [0 a $999 \mathrm{~mm}]$ \\
\hline Z3 & Posição da barra de segurança 2 [0 a $999 \mathrm{~mm}]$ \\
\hline Z4 & Posição da barra de segurança $3[0$ a $999 \mathrm{~mm}]$ \\
\hline PERIODO & Período [seg] \\
\hline N2 & \% de potência (canal de segurança 1) [\%] \\
\hline
\end{tabular}

Tabela 2. Variáveis Nucleares

\begin{tabular}{|l|l|}
\hline N3 & $\%$ de potência (canal de segurança 2$)[\%]$. \\
\hline N4 & $\%$ de potência (canal de segurança 3) [\%]. \\
\hline N5 & Potência logarítmica (canal log) [\%]. \\
\hline N6 & $\%$ de potência (canal linear) [\%]. \\
\hline N7 & \% de demanda (modo automático) [\%]. \\
\hline N8 & Potência do N16 (canal N16) [\%]. \\
\hline
\end{tabular}

Tabela 3. Variáveis de processo

\begin{tabular}{|l|l|}
\hline F1M3 & Vazão do primário [gpm]. \\
\hline F2M3 & Vazão do secundário (trocador A) [gpm]. \\
\hline F3M3 & Vazão do secundário (trocador B) [gpm]. \\
\hline F23 & Vazão de água de emergência [gpm]. \\
\hline DP & Delta P do núcleo [V]. \\
\hline C1 & Condutividade da água da piscina após o tratamento $[\mu \mathrm{mho}]$. \\
\hline C2 & $\begin{array}{l}\text { Condutividade da água da piscina antes da entrada no sistema } \\
\text { de retratamento [ } \mu \text { mho]. }\end{array}$ \\
\hline
\end{tabular}


Tabela 4. Variáveis de processo

\begin{tabular}{|l|l|}
\hline L1 & Nível da piscina [\%]. \\
\hline
\end{tabular}

Tabela 5.Variáveis de monitoração da radiação

\begin{tabular}{|l|l|}
\hline R1M3 & Ponte de sustentação do núcleo, lado esquerdo [mR/h]. \\
\hline R2M3 & Ponte de sustentação do núcleo, lado direito $[\mathrm{mR} / \mathrm{h}]$. \\
\hline R3M3 & Parede do prédio do saguão da piscina, face norte $[\mathrm{mR} / \mathrm{h}]$. \\
\hline R4M3 & $\begin{array}{l}\text { Parede da piscina, face sul, sobre o tubo de irradiação } \mathrm{n}^{\circ} 8 \\
{[\mathrm{mR} / \mathrm{h}] .}\end{array}$ \\
\hline R5M3 & $\begin{array}{l}\text { Parede da piscina, face oeste, sobre os tubos de irradiação } \mathrm{n}^{\circ} 3 \\
\text { e } 4[\mathrm{mR} / \mathrm{h}] .\end{array}$ \\
\hline R6M3 & $\begin{array}{l}\text { Parede do prédio do reator, face leste, sobre os tubos de } \\
\text { armazenamento de material radioativo }[\mathrm{mR} / \mathrm{h}] .\end{array}$ \\
\hline R7M3 & Poço de coleta de água da piscina (poço $\mathrm{SUMP})[\mathrm{mR} / \mathrm{h}]$. \\
\hline
\end{tabular}

Tabela 6. Variáveis de monitoração da radiação

\begin{tabular}{|l|l|}
\hline R8M3 & Sistema de retratamento de água - Coluna de resinas [mR/h]. \\
\hline R9M3 & Trocador de calor A [mR/h]. \\
\hline R10M3 & $\begin{array}{l}\text { Parede ao fundo do porão, encostada ao duto de exaustão entre } \\
\text { os trocadores de calor A e B [cps]. }\end{array}$ \\
\hline R11M3 & $\begin{array}{l}\text { Sala do ar condicionado, junto ao duto de exaustão de ar do } 1^{\text {o }} \\
\text { andar [cps]. }\end{array}$ \\
\hline R12M3 & Saguão da piscina, junto ao duto de exaustão de ar [cps]. \\
\hline R13M3 & Duto de exaustão de ar da chaminé [cps]. \\
\hline R14M3 & Tanque de retenção [cps]. \\
\hline
\end{tabular}

Tabela 7. Variáveis de temperatura

\begin{tabular}{|l|l|}
\hline T1 & Temperatura na superfície da piscina $\left[{ }^{\circ} \mathrm{C}\right]$. \\
\hline T2 & Temperatura a meia altura da piscina $\left[{ }^{\circ} \mathrm{C}\right]$. \\
\hline T3 & Temperatura sobre o núcleo do reator $\left[{ }^{\circ} \mathrm{C}\right]$. \\
\hline T4 & Temperatura na entrada do tanque de decaimento $\left[{ }^{\circ} \mathrm{C}\right]$. \\
\hline T5 & Temperatura delta T (T4-T3) $\left[{ }^{\circ} \mathrm{C}\right]$. \\
\hline T6 & Temperatura na saída do tanque de decaimento $\left[{ }^{\circ} \mathrm{C}\right]$. \\
\hline
\end{tabular}




\begin{tabular}{|l|l|}
\hline T7 & Temperatura na saída do primário (trocador $\mathrm{A})\left[{ }^{\circ} \mathrm{C}\right]$. \\
\hline
\end{tabular}

Tabela 8. Variáveis de temperatura

\begin{tabular}{|l|l|}
\hline T8 & Temperatura na entrada do secundário (trocador $\mathrm{A})\left[{ }^{\circ} \mathrm{C}\right]$. \\
\hline T9 & Temperatura na saída do secundário (trocador $\mathrm{A})\left[{ }^{\circ} \mathrm{C}\right]$. \\
\hline T10 & Temperatura na saída do primário (trocador $\mathrm{B})\left[{ }^{\circ} \mathrm{C}\right]$. \\
\hline T11 & Temperatura na entrada do secundário (trocador $\mathrm{B})\left[{ }^{\circ} \mathrm{C}\right]$. \\
\hline T12 & Temperatura na saída do secundário (trocador $\mathrm{B})\left[{ }^{\circ} \mathrm{C}\right]$. \\
\hline T13 & Temperatura na carcaça do motor da bomba $\mathrm{B} 101-\mathrm{A}\left[{ }^{\circ} \mathrm{C}\right]$. \\
\hline T14 & Temperatura na carcaça do motor da bomba $\mathrm{B} 102-\mathrm{A}\left[{ }^{\circ} \mathrm{C}\right]$. \\
\hline
\end{tabular}

Tabela 9. Variáveis de temperatura

\begin{tabular}{|l|l|}
\hline T15 & Temperatura externa na torre de refrigeração $\mathrm{A}\left[{ }^{\circ} \mathrm{C}\right]$. \\
\hline T16 & Temperatura externa na torre de refrigeração $\mathrm{B}\left[{ }^{\circ} \mathrm{C}\right]$. \\
\hline T17 & Temperatura na carcaça do motor do turbo compressor $\left[{ }^{\circ} \mathrm{C}\right]$. \\
\hline T18 & Temperatura no NO-BREAK $-220 \mathrm{~V}\left[{ }^{\circ} \mathrm{C}\right]$. \\
\hline T19 & Temperatura no NO-BREAK $-440 \mathrm{~V}\left[{ }^{\circ} \mathrm{C}\right]$. \\
\hline T20 & Temperatura ambiente $\left[{ }^{\circ} \mathrm{C}\right]$. \\
\hline T21 & Temperatura ambiente $\left[{ }^{\circ} \mathrm{C}\right]$. \\
\hline
\end{tabular}

Tabela 10. Variáveis de temperatura

\begin{tabular}{|l|l|}
\hline T22 & Temperatura ambiente $\left[{ }^{\circ} \mathrm{C}\right]$. \\
\hline T23 & Temperatura ambiente $\left[{ }^{\circ} \mathrm{C}\right]$. \\
\hline T24 & Temperatura ambiente $\left[{ }^{\circ} \mathrm{C}\right]$. \\
\hline
\end{tabular}

Atualmente os dados do SAD são fornecidos em outro formato, onde todas as variáveis são agrupadas em um único arquivo. Além disso, é possível importar facilmente esse arquivo para a plataforma Excel.

\subsubsection{Organização do Banco de Dados do SAD}

Os dados do SAD são coletados semanalmente, sendo que anteriormente, os dados eram armazenados em pastas de acordo com o ciclo de operação correspondente, no formato prn, que é um formato para emitir relatórios em impressoras. Para uma semana 
típica de operação do reator, eram necessários 10 arquivos do tipo prn para armazenar a história temporal de operação do reator. Com a finalidade de evitar duplicações de nomes de pastas e arquivos, os dados eram separados inicialmente em pastas correspondente ao ano, e depois em uma pasta cujo nome correspondia ao dia e mês de início de operação do ciclo.

Para auxiliar o acesso aos dados do SAD, primeiramente todos os 10 arquivos no formato prn foram importados para um único arquivo na plataforma Excel, e posteriormente, foi elaborado um banco de dados na plataforma Access [31]. O banco de dados foi organizado da seguinte forma: todas as tabelas do Excel foram importadas para o Access, e em seguida, foram elaborados formulários para as respectivas tabelas, para facilitar a visualização dos dados.

Após a importação das tabelas e da elaboração de seus respectivos formulários, foi criada uma interface gráfica, como pode ser visto na Figura 2. Nesta tela inicial, é possível escolher uma das seguintes opções: consulta por ano, variáveis do SAD, ou sair. Se for escolhida a opção Sair, o Microsoft Access será encerrado; se for escolhida a opção Variáveis do $S A D$, será mostrada em uma tela de informações os significados das variáveis operacionais do reator; por outro lado, se a escolha for Consulta por ano, será possível escolher o ano em que se deseja realizar a pesquisa, como mostra a Figura 3.

Após a escolha do ano, é possível ainda escolher o mês em que se deseja pesquisar as informações do SAD, sendo que após a escolha, uma janela do Excel se abrirá, mostrando a informação desejada, facilitando assim o acesso aos dados de operação desde o ano 2000 até o ano de 2002. A implementação de dados atuais no banco de dados é extremamente fácil, visto que os mesmos já estão disponíveis. Este banco de dados, além de ser utilizado neste trabalho e outros, contém o registro do histórico operacional da instalação e poderá ser utilizado como um apoio a operação e manutenção da instalação. 


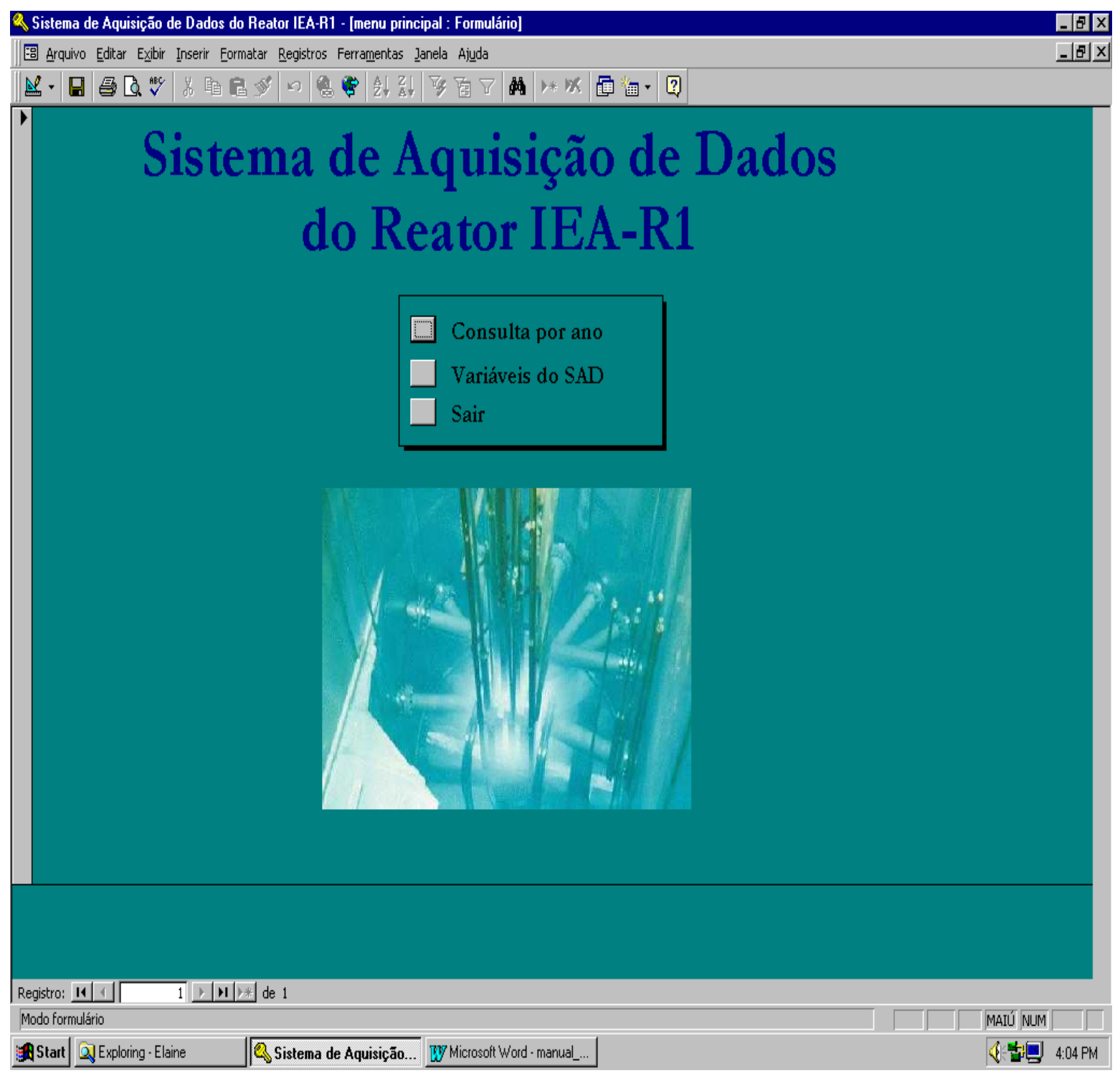

Figura 2. Formulário Principal 


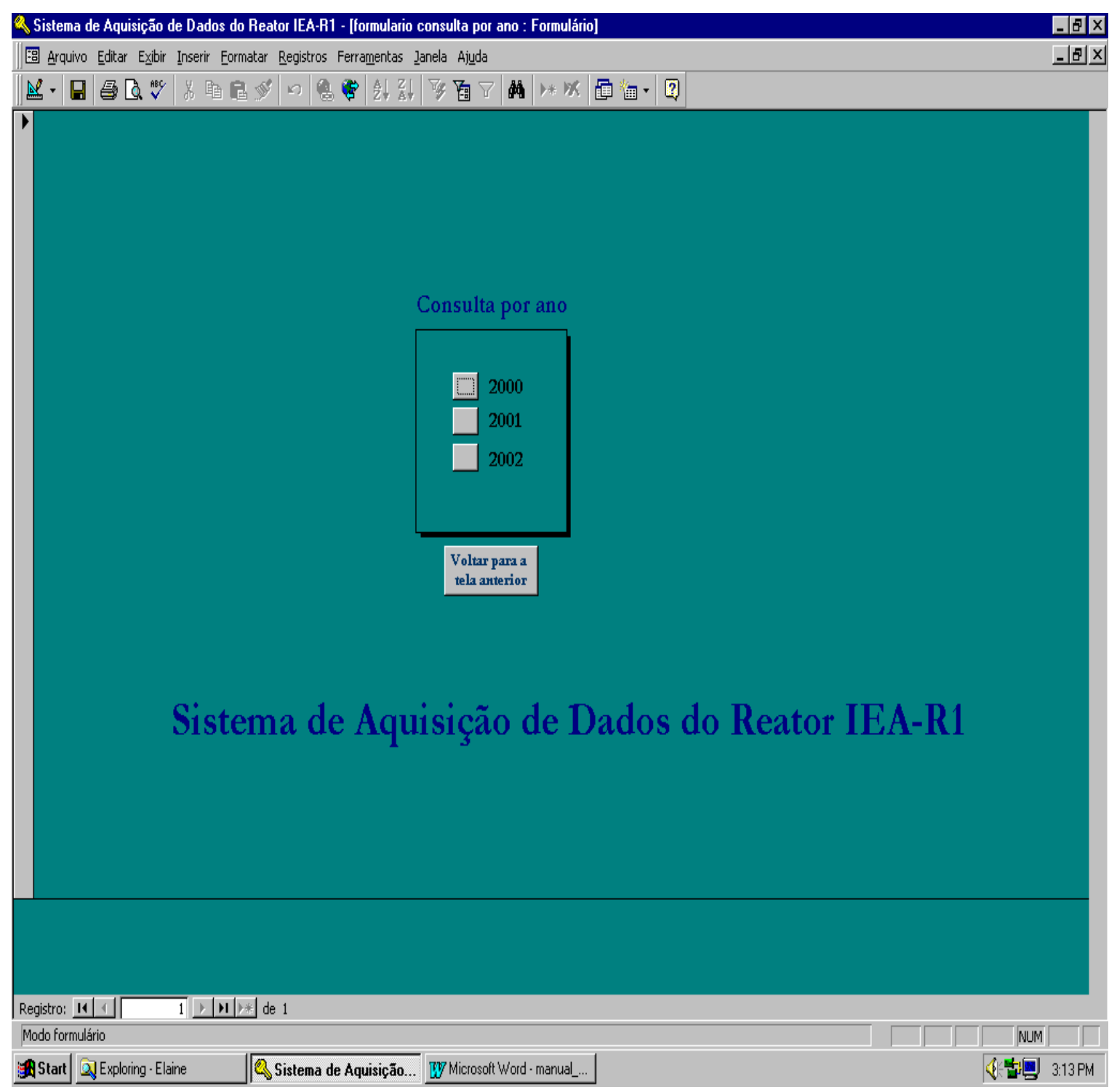

Figura 3. Formulário Consulta por ano

\subsection{Modelo Teórico do reator IEA-R1}

Com o objetivo de iniciar os estudos de Monitoração e Detecção de Falhas usando Redes Neurais Artificiais, foi utilizado um modelo teórico do reator IEA-R1, usando a ferramenta GUIDE do Matlab [32], que é composta por um conjunto de funções projetadas para desenvolver interfaces de forma fácil e rápida. Além disso, esta ferramenta possibilita o desenvolvimento de interfaces com gráficos e botões que executam determinadas funções do Matlab quando são pressionados.

O modelo teórico do reator é uma ferramenta que permite gerar dados em diversas condições de operação do reator, permitindo trabalhar com situações que não são 
possíveis de se obter experimentalmente, devido às restrições de operação do reator nuclear.

Este modelo representa as relações básicas entre as diferentes variáveis de processo. O reator IEA-R1 possui dois circuitos de refrigeração, e neste modelo foi representado apenas um circuito de refrigeração. As equações que regem o comportamento das variáveis de processo foram baseadas no balanço de massa e energia do reator IEA-R1, levando-se em consideração todos os aspectos físicos e operacionais, tais como, comprimento e diâmetro das tubulações, relações entre os valores de vazão, temperaturas e perda de carga [32]. Na Tabela 11, segue uma descrição detalhada das variáveis do reator IEA-R1 representadas no modelo teórico.

Tabela 11. Variáveis do modelo teórico do reator IEA-R1

\begin{tabular}{|l|l|}
\hline Variável & Descrição \\
\hline T1 & Temperatura na superfície da piscina $\left[{ }^{\circ} \mathrm{C}\right]$ \\
\hline T2 & Temperatura a meia altura da piscina $\left[{ }^{\circ} \mathrm{C}\right]$ \\
\hline T3 & Temperatura sobre o núcleo do reator $\left[{ }^{\circ} \mathrm{C}\right]$ \\
\hline T4 & Temperatura na entrada do tanque de decaimento $\left[{ }^{\circ} \mathrm{C}\right]$ \\
\hline T6 & Temperatura na saída do tanque de decaimento $\left[{ }^{\circ} \mathrm{C}\right]$ \\
\hline T7 & Temperatura na saída do primário $\left[{ }^{\circ} \mathrm{C}\right]$ \\
\hline T8 & Temperatura na entrada do secundário $\left[{ }^{\circ} \mathrm{C}\right]$ \\
\hline T9 & Temperatura na saída do secundário $\left[{ }^{\circ} \mathrm{C}\right]$ \\
\hline FE01 (mp) & Vazão do primário $($ gpm) \\
\hline FE02 (ms) & Vazão do secundário $(\mathrm{gpm})$ \\
\hline
\end{tabular}

A interface do programa foi criada de forma a lembrar o fluxograma de processo do reator IEA-R1, como pode ser visto na Figura 4. Nessa interface é possível visualizar os valores da potência térmica (em MW), calculados no núcleo e no lado primário do trocador de calor.

Neste modelo é possível adicionar falhas às variáveis, sendo que a escolha das variáveis com falha são feitas a partir de uma lista que contêm todas as variáveis do modelo. Existe ainda a opção de gerar dados "sem falha", ou seja, na condição normal de operação do reator. 
Pode-se ainda atribuir níveis de ruídos das variáveis de entrada através de uma janela, sendo o seu valor determinado em \%.

Além disso, é possível determinar o número total de pontos que serão gerados para as condições estabelecidas, onde o programa calcula para um ponto, atualiza os valores necessários, e reinicia o cálculo para o próximo ponto.

Para gerar uma base de dados, pode-se digitar diretamente os valores desejados nas caixas de edição da interface, e em seguida pressionar o botão calcular, onde será calculado o valor da potência de acordo com as equações do balanço térmico.

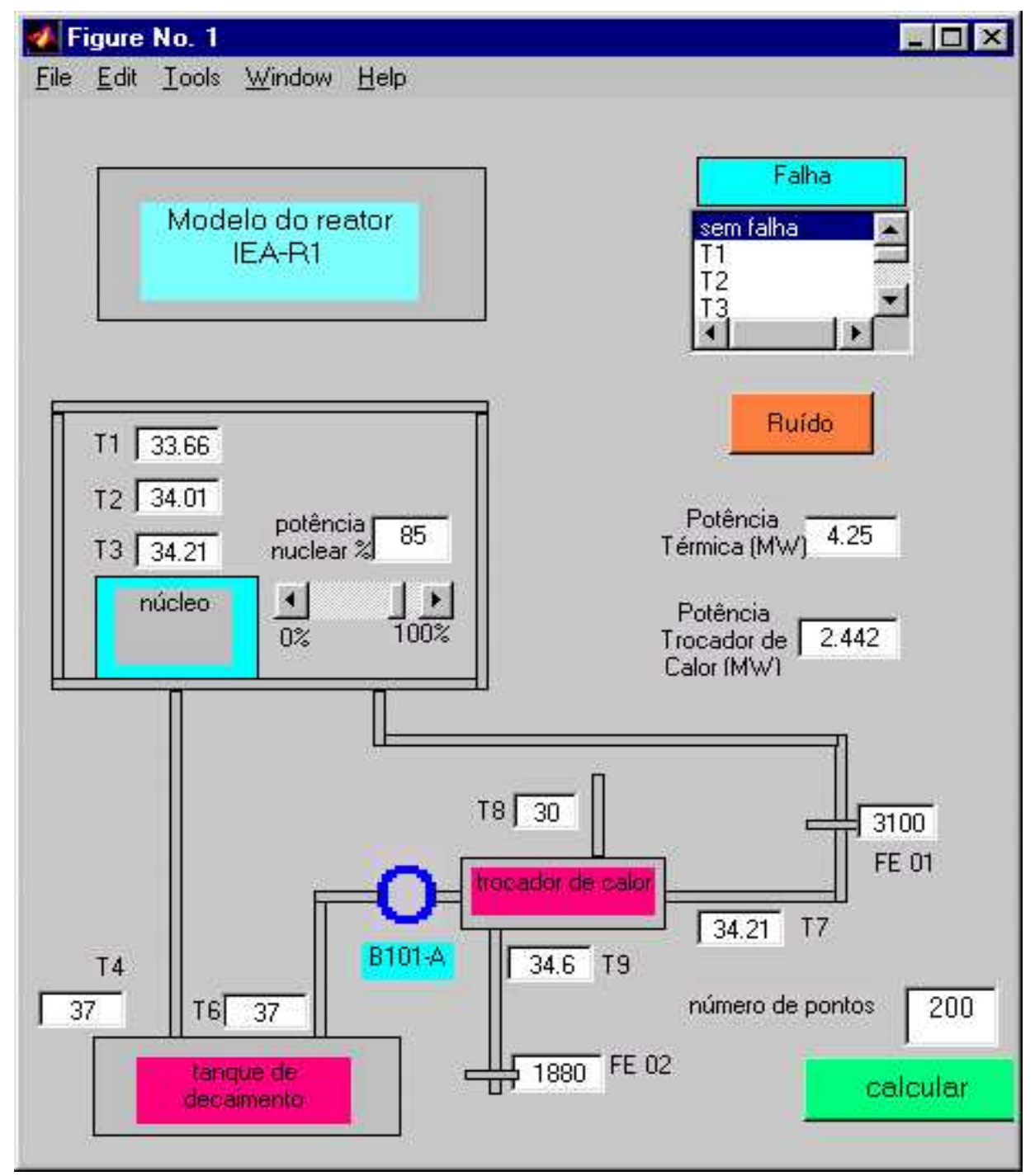

Figura 4. Interface do programa desenvolvido 


\section{FUNDAMENTOS TEÓRICOS}

\subsection{Redes Neurais Artificiais}

\subsubsection{Introdução}

Recentes avanços em neurofísiologia têm desvendado vários mecanismos sobre o fluxo e o processamento de informações que ocorrem no cérebro humano. Alguns destes mecanismos foram modelados matematicamente permitindo a elaboração de algoritmos computacionais que simulam, ainda que de modo simplificado, a mais básica das estruturas cerebrais: o neurônio.

A capacidade de implementar computacionalmente versões simplificadas de neurônios biológicos deu origem a uma subespecialidade da inteligência artificial, conhecida como Redes Neurais Artificiais (RNA's), que podem ser definidas como sistemas paralelos compostos por unidades de processamento simples, dispostas em camadas e altamente interligadas, inspiradas no cérebro humano [33].

A origem da teoria de RNA's remonta aos modelos matemáticos e aos modelos de engenharia de neurônios biológicos. Os neurônios biológicos podem ser divididos em três seções: o corpo celular (soma), os dendritos e o axônio, como mostra a Figura 5 [34].

* No corpo celular (soma), as informações são processadas e novos impulsos nervosos são gerados;

- No axônio, os impulsos nervosos são transmitidos a outros neurônios;

* Os dendritos recebem os impulsos nervosos, provenientes de outros neurônios, e os conduz até o corpo celular. $\mathrm{O}$ ponto de contato entre a terminação axônica de um neurônio e o dendrito de outro neurônio é denominado sinapse. 


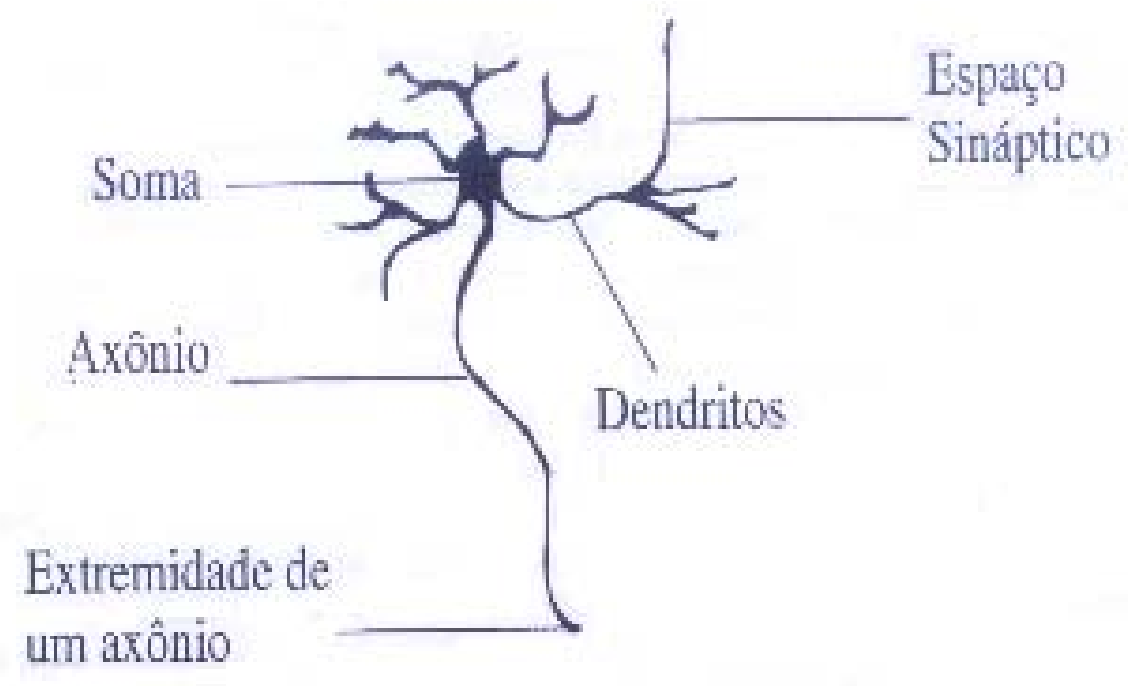

Figura 5. Neurônio Biológico

A sinapse é o ponto da estrutura de uma rede de neurônios através da qual ocorrem os processos de comunicação entre os mesmos, por meio de processos eletroquímicos específicos decorrentes de características particulares da sua constituição.

As sinapses são regiões eletroquimicamente ativas, compreendidas entre duas membranas celulares: a membrana pré-sináptica e a membrana pós-sináptica. Na membrana pré-sináptica chegam estímulos provenientes de uma outra célula; e a póssináptica, e a membrana do dendrito. O estímulo nervoso que chega à sinapse, nesta região, é transferido à membrana dendrital pelos neurotransmissores. Essa transferência provoca uma alteração no potencial elétrico da membrana pós-sináptica. A conexão sináptica poderá ser excitatória ou inibitória, dependendo do neurotransmissor. $\mathrm{Na}$ conexão excitatória ocorrerá uma alteração no potencial da membrana, que contribuirá para a formação de um impulso nervoso no axônio de saída, enquanto que a conexão inibitória agirá no sentido oposto.

\subsubsection{Aspectos Históricos}

As pesquisas na área de Redes Neurais Artificiais se iniciaram após a publicação de um artigo intitulado "A logical calculus of the ideas immanent in nervous activity (Um cálculo lógico das idéias imanentes na atividade nervosa)”, por Mc Culloch e Pitts [35]. Neste artigo foi proposto um modelo simplificado de neurônio biológico, que em um determinado instante de tempo, ficaria ativo ou inativo. O trabalho de Mc Culloch e 
Pitts propiciou uma disseminação do entendimento de possíveis modelos neurais, atraindo e influenciando muitos pesquisadores famosos.

Hebb, em 1949, publicou um livro intitulado "The Organization of Behavior (A Organização do Comportamento)" onde foi proposta pela primeira vez uma regra de aprendizagem para a modificação dos pesos sinápticos [36].

Em 1956, John von Neumann introduziu o conceito de redundância, originando a geração dos atuais computadores digitais [33].

Rosenblatt, em 1958, forneceu várias idéias a respeito do Perceptron. Entre 1960 e 1962, Rosenblatt e seu grupo de pesquisas estavam concentrados no problema do treinamento do Perceptron, onde conseguiram provar a convergência de um algoritmo de aprendizado [33].

Widrow e Hoff (1960) desenvolveram um modelo neural denominado Adaline “Adaptive Linear Element (Elemento Linear Adaptativo)”. Com ele definiram, em 1962, uma das primeiras redes construídas com elementos adaptativos, o Madaline "Multiple Adaline (Múltiplos Adalines)". O Adaline/Madaline usou saídas lineares ao invés das binárias originalmente propostas por Mc Culloch e Pitts. Adicionalmente, Widrow e Hoff desenvolveram um algoritmo de aprendizado de grande importância na área das Redes Neurais, utilizando o conceito de minimização do desvio médio quadrático (Least Mean Square algorithm - LMS). Esta técnica ficou conhecida como regra delta ou método do gradiente descendente para a minimização do erro [33].

Em 1969, Minsky e Papert lançaram o polêmico livro Perceptrons, onde foi demonstrado matematicamente que o teorema desenvolvido por Rosenblatt só era aplicável a problemas linearmente separáveis. Ainda neste mesmo trabalho, Minsky e Papert afirmaram que não havia motivo aparente para acreditar que redes formadas por múltiplas camadas de Perceptrons, pudessem herdar as boas qualidades do Perceptron simples. Estas colocações desestimularam os pesquisadores que atuavam na área, fazendo com que houvesse um grande desinteresse pelas pesquisas na área de Redes Neurais durante a década de 70 e início dos anos 80 [33].

Apesar das poucas atividades de pesquisa nesse período, alguns trabalhos tiveram destaque, especialmente na pesquisa das redes auto-organizáveis utilizando algoritmos competitivos, como foi o caso do trabalho de Kohonen (1972) [37] que desenvolveu modelos de memórias associativas, utilizando o conceito de aprendizado competitivo, nos quais as unidades competem para responder a determinada entrada, e a 
unidade vencedora tem os pesos de sua entrada modificados, convergindo para responder com mais força a valores próximos do desejado [33].

Em 1976, Grossberg estabeleceu os princípios para uma nova classe de redes neurais junto com Carpenter denominadas de ART (Adaptive Ressonance Theory) [37].

Hopfield (1982) utilizou a idéia de uma função energia para uma nova maneira de funcionamento das redes recorrentes com conexões sinápticas simétricas, onde os elementos são ligados buscando o aprendizado com um mínimo de energia, tendo dado origem às Redes de Hopfield [33].

Somente em 1986 tiveram início as atividades de desenvolvimento de Redes Neurais Artificiais, com o desenvolvimento do algoritmo de retropropagação por Rumelhart, Hinton e Williams, embora este algoritmo já tivesse sido proposto em 1974, por Werbos em sua tese de doutorado; e por Parker e LeCun (1985). Com o lançamento do livro denominado Parallel Distributed Processing: Explorations in the Microstructures of Cognition, editado por Rumelhart e McClelland, o qual apresenta de uma forma organizada todo o progresso das redes neurais, ressurgiu o grande interesse pelas pesquisas nessa área [38].

\subsubsection{Modelo de Neurônio Biológico}

Em 1943, Warren McCulloch e Walter Pitts propuseram o primeiro modelo artificial de um neurônio biológico [35]. O neurônio de McCulloch era um dispositivo binário, sendo que sua saída poderia ser pulso ou não pulso, e suas entradas tinham ganhos arbitrários, podendo ser excitatórias ou inibitórias. A Figura 6 mostra o neurônio artificial proposto por eles. É possível identificar três elementos básicos em um neurônio: um conjunto de sinapses, onde um sinal $x_{j}$ na entrada da sinapse $j$, conectada ao neurônio $k$, é multiplicado por um peso sináptico $w_{k j}$; um somador que é responsável pela somatória dos sinais de entrada que são multiplicados pelos respectivos pesos sinápticos dos neurônios; e de uma função de ativação para limitar a amplitude da saída do neurônio. O bias - " $b_{k}$ ", têm como objetivo promover um deslocamento de curva da função de ativação, ou seja, é aumentar ou diminuir a entrada da função de ativação. 


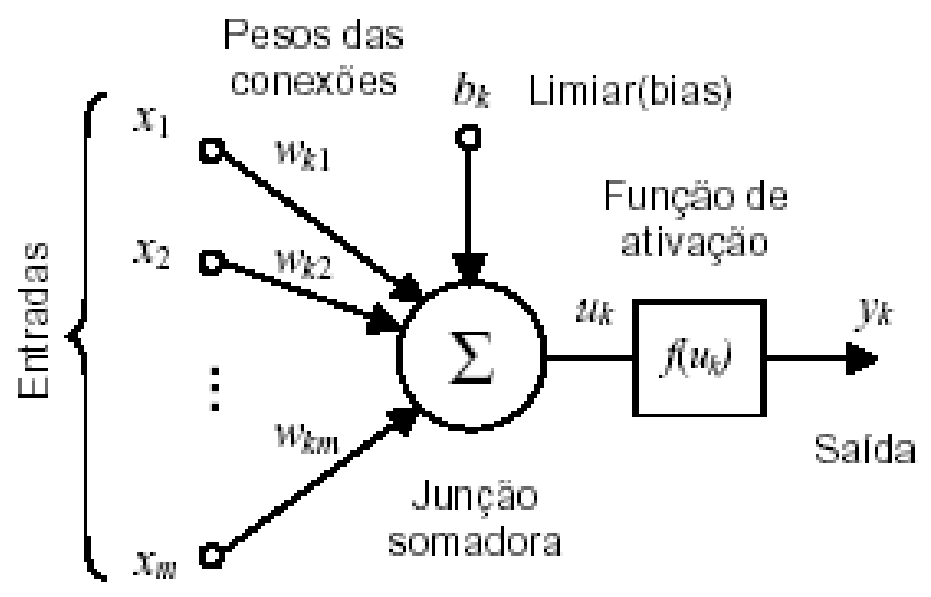

Figura 6. Modelo de um neurônio

Em termos matemáticos, podemos descrever o neurônio $k$ através das equações (1) e (2):

$$
\mu_{k}=\sum_{j=1}^{m} w_{k j}+x_{j}
$$

e

$$
y_{k}=\varphi\left(u_{k}+b_{k}\right)
$$

Onde $x_{1}, x_{2}, \ldots, x_{m}$ são os sinais de entrada; $w_{k l}, w_{k 2}, \ldots, w_{k m}$ são os pesos sinápticos do neurônio $k$; $u_{k}$ é o integrador linear de saída devido aos sinais de entrada; $b_{k}$ é o bias; $\varphi_{k}($.) é a função de ativação; e $y_{k}$ é o sinal de saída do neurônio. O bias tem o papel de promover uma transformação afim à saída $u_{k}$ do combinador linear do neurônio da Figura 7, como pode ser visto na equação (3):

$$
v_{k}=u_{k}+b_{k}
$$

Se o bias $b_{k}$ for positivo ou negativo, a relação entre o potencial de ativação $v_{k}$ do neurônio $k$ e do integrador de saída $u_{k}$ é modificado de acordo com a Figura 7 . 


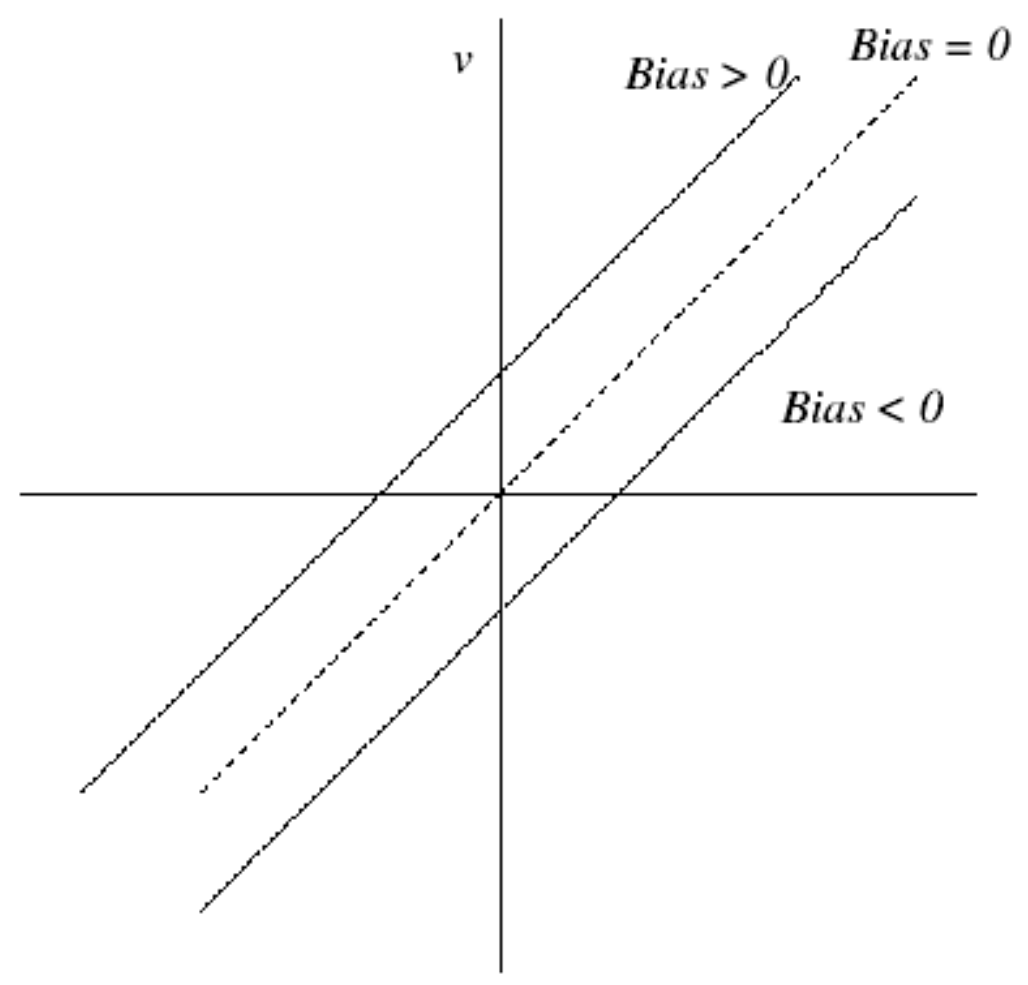

Figura 7. Transformação afim produzida pelo bias

São três os tipos de função de ativação mais utilizados, cujos gráficos são mostrados na Figura 8:

- Função de limiar: A saída do neurônio é igual a zero, quando seu valor for negativo e 1, quando seu valor for positivo, como mostra a Figura 8 a.

$$
\varphi(v)=\left\{\begin{array}{l}
1 \text { se } v \geq 0 \\
0 \text { se } v<0
\end{array}\right.
$$


- Função de limiar por partes: Esse tipo de função pode ser visto como uma aproximação de um amplificador não linear, como mostra a Figura $8 b$.

$$
\varphi(v)=\left\{\begin{aligned}
1, & v & \geq 0,5 \\
v, & +0,5 & >v>-0,5 \\
0, & v & \leq-0,5
\end{aligned}\right.
$$

口 Função sigmóide: É o tipo de função de ativação mais utilizada em redes neurais artificiais. É definida como uma função extremamente crescente, que apresenta um balanço entre o comportamento linear e não-linear, como pode ser visto na Figura 8c. Um exemplo de função sigmóide é a função logística, definida pela equação (6):

$$
\varphi(v)=\frac{1}{1+e^{-a v}}
$$

Onde a é o parâmetro de inclinação da função. 


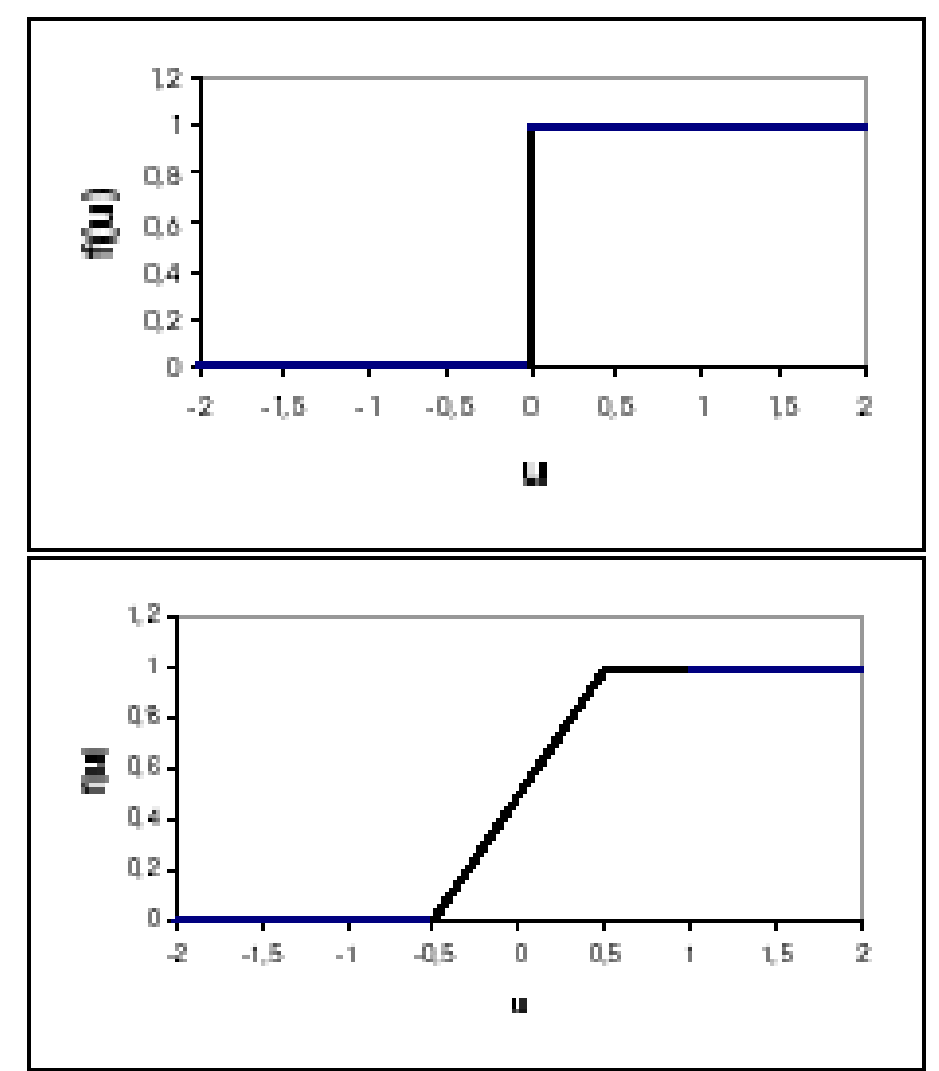

(a)

(b)

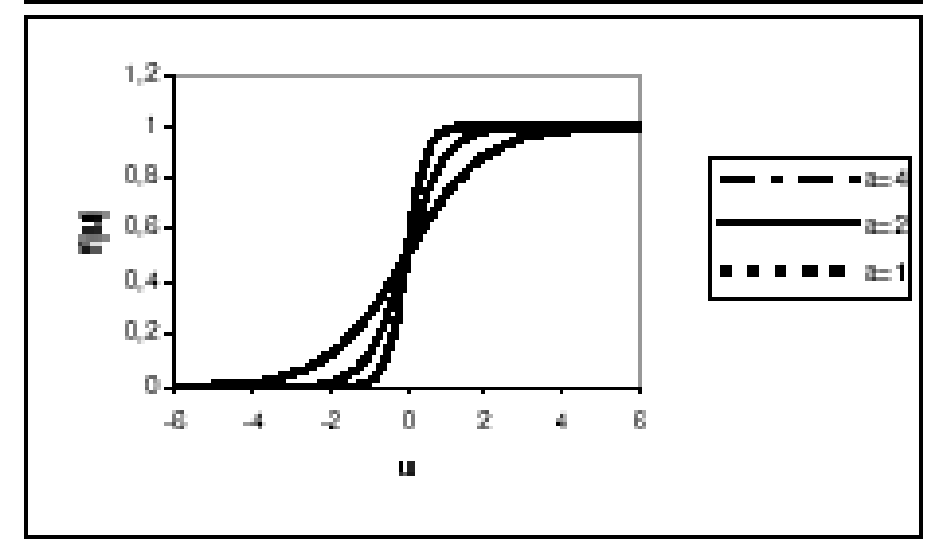

(c)

Figura 8. (a) Função limiar, (b) Função linear por partes (c) Função sigmóide com parâmetro de inclinação a variável

\subsubsection{Arquiteturas de Redes Neurais Artificiais (RNA's)}

As formas em que os neurônios da rede neural estão organizados, estão intimamente ligadas ao algoritmo de aprendizado utilizado no treinamento da rede. Geralmente, podemos identificar três tipos de arquiteturas de RNA's [33]:

Redes com propagação para frente de uma camada: são compostas por uma camada de entrada e outra de saída, como mostra a Figura 9; 
* Redes com propagação para frente de múltiplas camadas: são compostas por uma camada de entrada, uma ou mais camadas ocultas e uma camada de saída, como mostra a Figura 10;

* Redes Recorrentes: contêm realimentação das saídas para as entradas, sendo suas saídas determinadas pelas entradas atuais e pelas saídas anteriores, como pode ser visto na Figura 11.

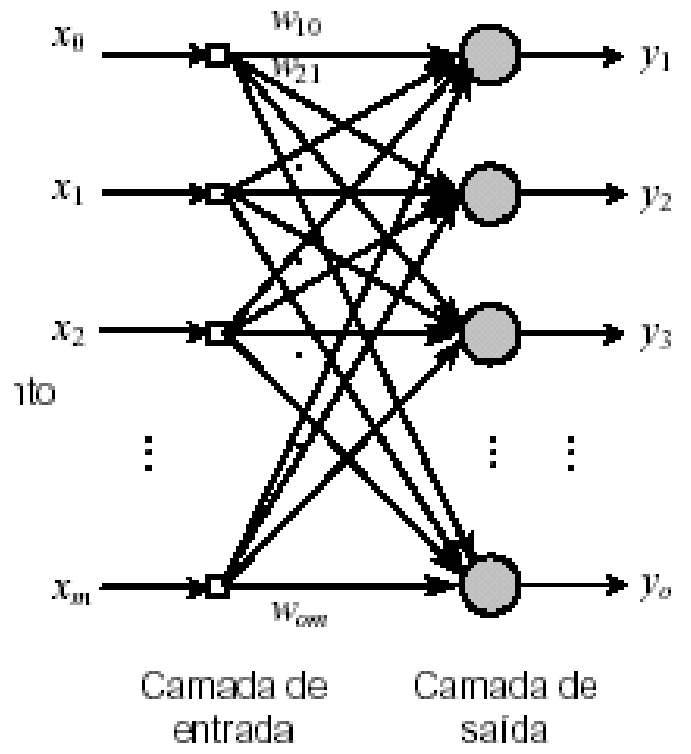

Figura 9. Redes com propagação para frente de uma camada

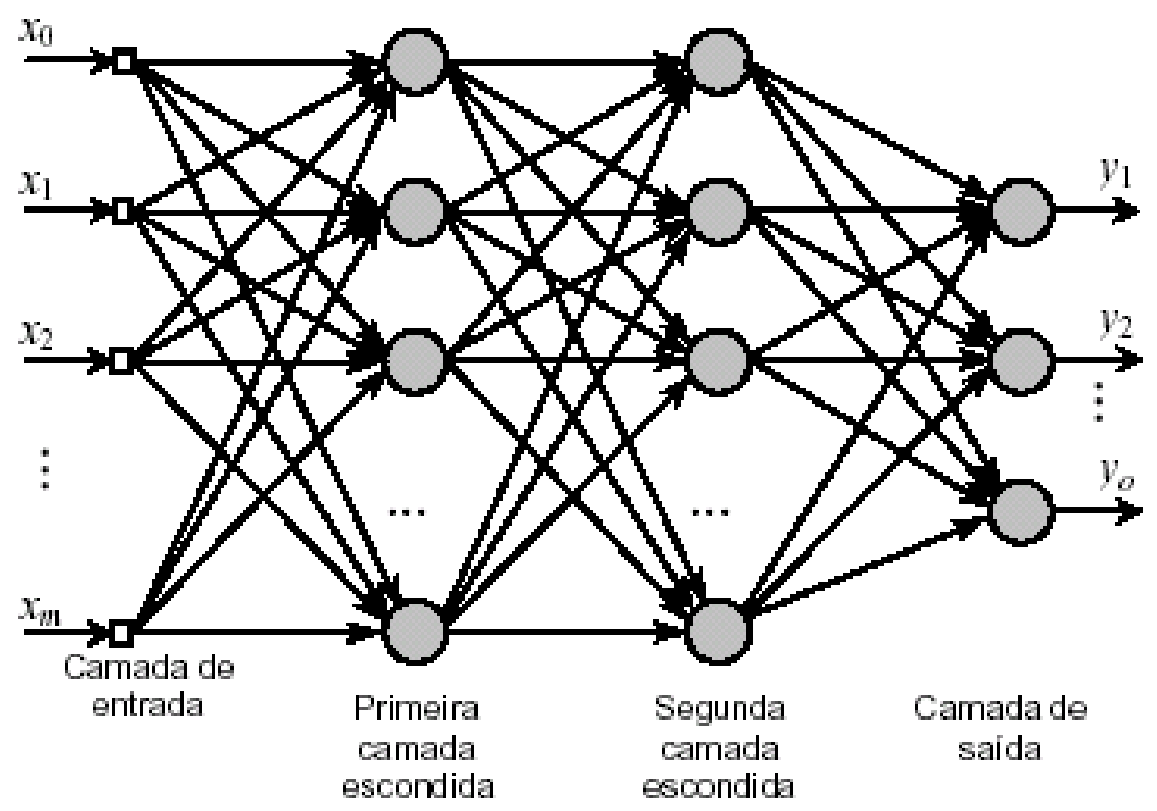

Figura 10. Redes do tipo MLP (Múltiplas camadas com propagação para frente) 


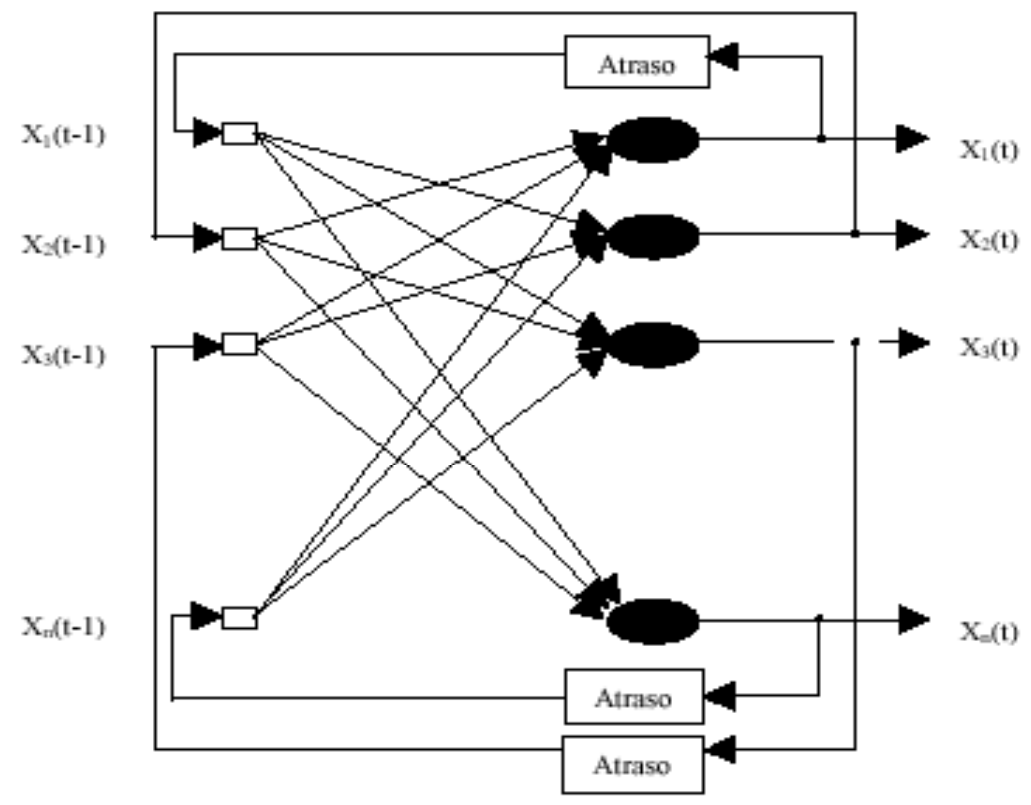

Figura 11.Redes Recorrentes

A arquitetura de rede usada neste trabalho foi a rede com propagação para frente de múltiplas camadas, também conhecida como Multilayer Perceptron (MLP), que será descrita em detalhes no próximo tópico.

\subsubsection{Redes do tipo Multilayer Perceptron (MLP)}

As redes do tipo MLP são redes multicamadas, formadas por uma camada de entrada, uma ou mais camada oculta, e uma camada de saída, como pode ser visto na Figura 10. Cada neurônio de uma camada recebe os sinais de todos os neurônios da camada anterior, e propaga sua saída a todos os neurônios da camada posterior.

A camada de entrada é utilizada para receber os dados de entrada da rede. Essa camada, portanto, não efetua qualquer tipo de processamento, servindo apenas para receber e armazenar o vetor de entrada. O número de neurônios nessa camada corresponde ao vetor de entrada.

A camada de saída tem a função de armazenar as respostas obtidas pela rede. $\mathrm{O}$ número de neurônios nessa camada corresponde ao vetor saída.

Entre a camada de entrada e a de saída, podemos ter uma ou mais camadas ocultas. As camadas ocultas proporcionam complexidade e não-linearidade para a rede. Não existe um método que determine o número ideal de camadas ocultas e de neurônios nessa camada, porém a escolha desses parâmetros é muito importante e influencia diretamente o desempenho do sistema, pois o tempo computacional para o cálculo da 
resposta e para o treinamento da rede, aumenta significativamente com o aumento das conexões e de neurônios nas camadas ocultas.

No próximo tópico serão apresentados os principais algoritmos de treinamento.

\subsubsection{Principais Algoritmos de Treinamento}

"O aprendizado pode ser definido como um processo onde os parâmetros livres da rede neural são adaptados através de um processo de estimulação do ambiente onde a mesma está envolvida".

(Haykin, 1999).

O principal objetivo do treinamento de uma RNA é fazer com que a aplicação de um conjunto de entradas produza um conjunto de saídas desejadas ou no mínimo um conjunto de saídas consistentes. Cada conjunto de entrada ou saída é denominado vetor.

O treinamento é realizado pela aplicação seqüencial dos vetores de entradas (e em alguns casos também os de saída), enquanto os pesos da rede são ajustados de acordo com um procedimento de treinamento pré-determinado. Durante o treinamento, os pesos da rede gradualmente convergem para determinados valores, de maneira tal que a aplicação dos vetores de entrada produzam as saídas necessárias. Os procedimentos de treinamento das RNA's podem ser classificados em duas classes:

* Supervisionado

* Não supervisionado

O treinamento supervisionado necessita de um vetor de entrada e um vetor de saída, conhecido como vetor alvo. Esses dois vetores são então utilizados para o treinamento da RNA. O procedimento de treinamento funciona da seguinte maneira: o vetor de entrada é aplicado, a saída de rede é calculada e comparada com o correspondente vetor alvo. O erro encontrado é então realimentado através da rede e os pesos são atualizados de acordo com um algoritmo determinado a fim de minimizar este erro. Este processo de treinamento é repetido até que o erro para os vetores de treinamento alcance valores pré-determinados.

O treinamento não-supervisionado, por sua vez, não requer vetor alvo para as saídas e, obviamente, não faz comparações para determinar a resposta ideal. O conjunto de 
treinamento modifica os pesos da rede de forma a produzir saídas que sejam consistentes. O processo de treinamento extrai as propriedades estatísticas do conjunto de treinamento e agrupa os vetores similares em classes, onde a aplicação de um vetor de uma determinada classe à entrada da rede produzirá um vetor de saída específico.

Os principais algoritmos de treinamento descritos neste trabalho são: aprendizagem Hebbiana, aprendizagem por Correção de Erro e aprendizagem pelo Método do Gradiente Descendente.

\subsubsection{Aprendizagem Hebbiana}

A regra de aprendizado de Hebb's é a mais antiga de todas as regras de aprendizado [36]. Hebb's postulou que a adaptação das sinapses do sistema nervoso é proporcional à atividade dos neurônios pré e pós - sinápticos. A partir desse postulado, Hebb's desenvolveu um algoritmo para a atualização dos pesos, descrito pela equação (7):

$$
\Delta w_{i j}=\eta y_{j}(n) x_{j}(n)
$$

Onde:

$$
\begin{aligned}
& \eta \quad \text { : é uma constante que expressa a taxa de aprendizado } \\
& x_{j}(n) \text { : entrada da rede } \\
& y_{j}(n) \text { : saída da rede }
\end{aligned}
$$

\subsubsection{Aprendizagem por Correção de Erro}

Nesse processo de aprendizado têm-se como objetivo minimizar a diferença entre a saída calculada pela rede e a saída desejada, como mostra a equação (8):

$$
e(n)=y_{d j}(n)-y_{j}(n)
$$

Onde:

$e_{j}(n)$ : representa o erro da rede

$j$ : neurônio 
$y_{d j}(n):$ saída desejada

$y_{j}(n)$ : saída calculada pela rede.

O erro $e_{j}(n)$ atua como um mecanismo de controle através da aplicação de uma seqüência de atualizações aos pesos sinápticos no neurônio j. As atualizações dos pesos sinápticos têm como objetivo aproximar a saída $y_{j}(n)$ da saída desejada $y_{d j}(n)$, através da minimização da energia do erro, $\varepsilon(n)$, definida em função do erro $e_{j}(n)$, como mostra a equação (9):

$$
\varepsilon(n)=\frac{1}{2} e_{j}^{2}(n)
$$

Onde :

$\varepsilon(n)$ : energia do erro

A equação (10) mostra como é feita a atualização dos pesos:

$$
w_{i j}(n+1)=w_{i j}(n)+\Delta w_{i j}(n)
$$

Onde:

$w_{i j}(n+1):$ peso atualizado

$w_{i j}(n)$ : peso antigo

O ajuste aos pesos sinápticos no neurônio $k$ continua, até que o sistema atinja a estabilidade. Logo após, o processo de aprendizado é interrompido. 


\subsubsection{Regra Delta ou Método do Gradiente Descendente}

O método do Gradiente Descendente tem como propósito principal minimizar uma função de erro, que é definida pela soma dos erros quadráticos, como mostra a equação (11):

$$
E=\frac{1}{2} \sum_{m=1}^{m}\left(y_{d j}(n)-y_{j}(n)\right)^{2}
$$

Onde:

$$
\begin{aligned}
& E: \text { representa o erro } \\
& m: \text { número de neurônios na camada de saída } \\
& y_{d j}: \text { saída desejada } \\
& y_{j}: \text { saída calculada pela rede }
\end{aligned}
$$

No método do gradiente descendente verifica-se que com o decréscimo do erro, o peso tende a aumentar o que fortalece a ligação entre os neurônios. Quando ocorre a aumento do erro, o peso tende a diminuir, conforme a equação (12).

$$
w_{i j}(n+1)=w_{i j}(n)-\eta \frac{\partial E}{\partial w_{i j}}
$$

Onde:

$$
\begin{aligned}
& w_{i j}(n+1): \text { peso atualizado } \\
& w_{i j}(n): \text { peso antigo } \\
& \eta: \text { taxa de aprendizado } \\
& \frac{\partial E}{\partial w_{i j}}: \text { gradiente }
\end{aligned}
$$

O algoritmo de retropropagação, que foi utilizado no treinamento das RNA's deste trabalho, utiliza a regra delta generalizada. Este algoritmo será descrito em detalhes, no próximo tópico. 


\subsubsection{Algoritmo de Retropropagação}

O algoritmo de retropropagação é utilizado no treinamento das RNA's do tipo MLP, descrita no item 4.1.4.1. Além disso, esse algoritmo foi um dos principais responsáveis pelo reinício das pesquisas na área de redes neurais, como pode ser visto no item 4.1.2.

O algoritmo de retropropagação é um algoritmo supervisionado que utiliza pares (entrada, saída desejada) para, por meio de um mecanismo de correção, ajustar os pesos sinápticos da rede neural. O treinamento ocorre em duas fases distintas conhecidas como "forward" e "backward". Na fase forward, é definida a saída da rede para um dado padrão de entrada, e na fase backward, a diferença entre a saída desejada e a saída atual é utilizada pela rede para atualizar os pesos de suas conexões.

A implantação computacional do algoritmo de retropropagação apresenta os seguintes passo: [34]

Passo 1: Inicialização de todos os pesos e parâmetros.

Passo 2: Fase forward, consiste em:

* Dadas as entradas, calcular as saídas para todas as camadas da rede;

* Calcular o erro de saída da rede.

Passo 3: Fase backward, consiste em:

Efetuar o cálculo das atualizações dos pesos entre as camadas da rede, iniciando a partir da última camada, até chegar a camada de entrada;

O algoritmo de retropropagação consiste na utilização dos pesos, considerando a propagação do erro da saída da rede para a sua entrada. Este algoritmo é também conhecido como regra delta generalizada.

Embora o erro total E seja definido pela soma dos erros dos neurônios de saída para todos os padrões, será considerado sem perda de generalidade, que a minimização do erro para cada padrão individualmente levará à minimização do erro total para todos os padrões. Portanto, o erro passa a ser definido conforme a equação (11), descrita anteriormente. 
Como na regra delta a variação dos pesos é definida de acordo com o gradiente decrescente, partindo-se da equação (12) é calculada matematicamente a equação (13), sendo $\Delta w=w(n+1)-w(n)$ :

$$
\Delta w_{i j}=-\eta \frac{\partial E}{\partial w_{i j}}
$$

Logo:

$$
\begin{aligned}
& \Delta w_{i j}=-\eta \frac{\partial E}{\partial w_{i j}}=-\eta \times \frac{\partial E}{\partial y_{j}} \times \frac{\partial y_{j}}{\partial w_{i j}} \\
& y_{j}=\left(\sum_{m=1}^{m} x_{j} w_{i j}\right) \\
& \Delta w_{i j}=-\eta \cdot\left[2 \cdot \frac{1}{2} \cdot\left(y_{d j}-y_{j}\right) \cdot(-1)\right] \cdot x_{j} \\
& \Delta w_{i j}=-\eta \cdot\left\lfloor-\left(y_{d j}-y_{j}\right)\right] \cdot x_{j} \\
& \Delta w_{i j}=x_{j} \cdot \eta \cdot\left(y_{d j}-y_{j}\right)
\end{aligned}
$$

Onde:

$w$ : indica o valor dos pesos

$y_{d j}:$ saída desejada

$y_{j}:$ saída calculada pela rede

$\eta$ : taxa de aprendizado

$x_{j}$ : entrada da rede 


\subsection{Lógica Nebulosa}

O conceito de lógica nebulosa foi introduzido em 1965 por Lofti Zadeh [39], onde a idéia básica foi de ampliar os conceitos da lógica clássica, onde uma proposição pode ter apenas dois valores: verdadeira ou falsa. Na lógica nebulosa, os conceitos se aproximam mais das variáveis lingüísticas, sendo que o valor de uma proposição pode variar entre os valores verdadeiro e falso com determinado peso. Entre outras diferenças básicas entre a lógica clássica e a lógica nebulosa, é que a lógica clássica trata conceitos como categorias discretas, enquanto que na lógica nebulosa pode-se atribuir a um mesmo conceito diversos valores lingüísticos com graus de certeza associados. O conceito principal da teoria da lógica nebulosa é o da função de pertinência, que numericamente representa o grau no qual um elemento pertence a um determinado conjunto.

Em 1973, Zadeh [40] estabeleceu que os elementos contidos em um pensamento tipicamente humano não são números, e sim rótulos de conjuntos nebulosos. As pessoas são mais eficientes em avaliações qualitativas do que em análises quantitativas. Provavelmente, o uso de variáveis lingüísticas e de lógica nebulosa, são as formas nas quais o cérebro humano consegue armazenar informações. A teoria de conjuntos nebulosos possibilita quantificar e manipular situações qualitativas, conceitos vagos ou subjetividade de opiniões.

As variáveis lingüísticas se comportam da mesma maneira que no caso de variáveis numéricas em um modelo matemático convencional, mas adotando palavras ou sentenças no lugar dos valores destas variáveis. Os valores das variáveis lingüísticas são então obtidos através de operações específicas de conjuntos nebulosos.

O grau com que um elemento pertence ao conjunto nebuloso é chamado grau de pertinência (membership), e é representado por:

$\mu_{\mathbf{A}}(\mathbf{x})$ é o grau de pertinência do elemento x ao conjunto A.

Tradicionalmente, os elementos pertencem ou não a um conjunto. Por exemplo, o número 1 é um elemento do conjunto de números ímpares.

Em um conjunto nebuloso, $\mathrm{x}$ pode pertencer ao conjunto A com um certo grau de pertinência, que pode variar de 0 a 1 , inclusive.

A curva que define como cada ponto no espaço de entrada é mapeado com um valor do grau de pertinência variando de 0 a 1, é chamada de função de pertinência. Esta 
função pode ser trapezoidal, triangular, gaussiana, sigmoidal, ou baseada em algum polinômio. A Figura 12 apresenta um exemplo de função de pertinência.

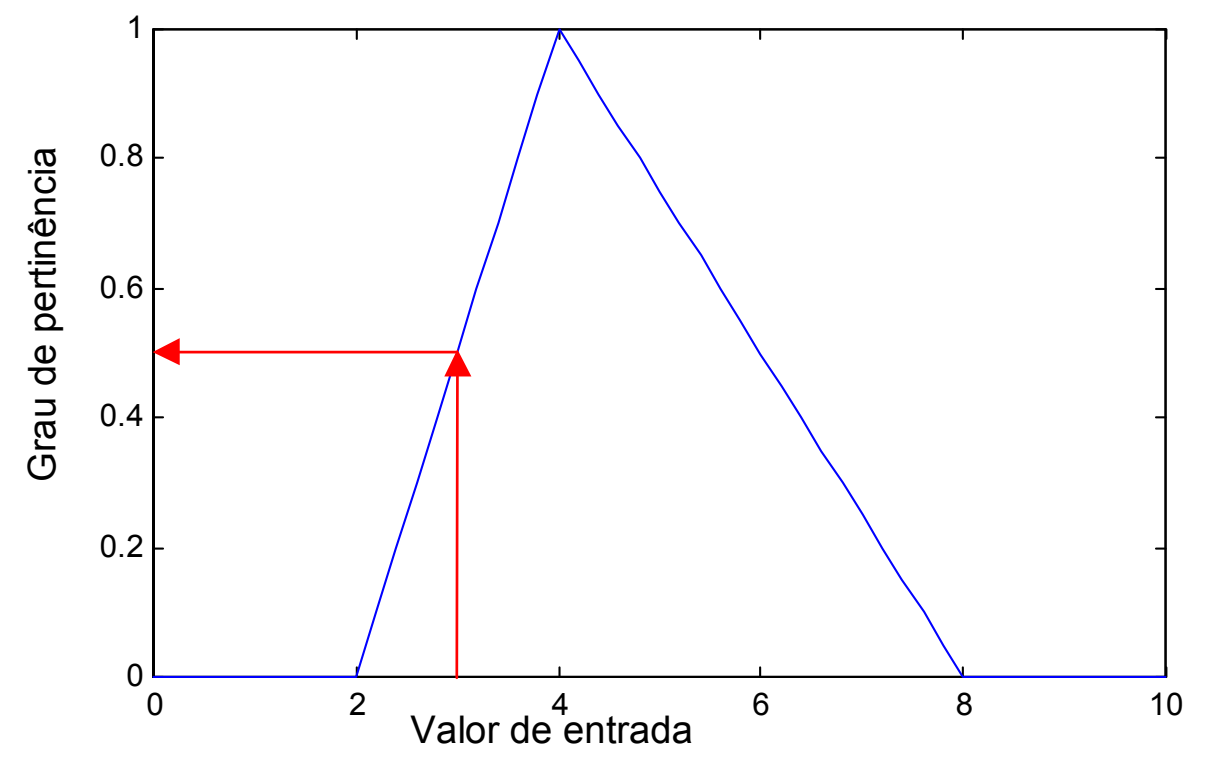

Figura 12. Função de pertinência triangular

São cinco os passos para aplicação de Lógica Nebulosa [41]:

* Transformação dos dados de entrada em valores nebulosos, ou seja, transformação de valores numéricos em valores nebulosos (fuzzificação das entradas);

* Aplicação de operadores nebulosos (E, OU, NÃO);

* Aplicação de métodos de inferência (pode-se usar valor mínimo ou produto);

* Agregação das variáveis de saída (combina as saídas de cada regra em um conjunto nebuloso), como pode ser visto na Figura 13;

* Transformação das variáveis nebulosas em valores numéricos (defuzzificação). O método mais comum é o método de centróide, como pode ser visto na Figura 14.

No Sistema Fuzzy desenvolvido neste trabalho, os antecedentes foram relacionados com o conetivo $e(A N D)$, e o operador de intersecção foi aplicado, levando-se em consideração o valor mínimo entre os antecedentes. Para cada regra, o grau de ativação da ação de controle foi calculado a partir da união (operador máximo) das contribuições de 
cada regra ativada, gerando uma única e nova função. Finalmente, para transformar as variáveis nebulosas em valores numéricos (defuzzificação), utilizou-se o método do centro de área (CDA) que calcula o centro da área da função inferida. No capítulo 5 será explicado em detalhes o Sistema Fuzzy desenvolvido, e no capítulo 7 serão mostrados os resultados obtidos.

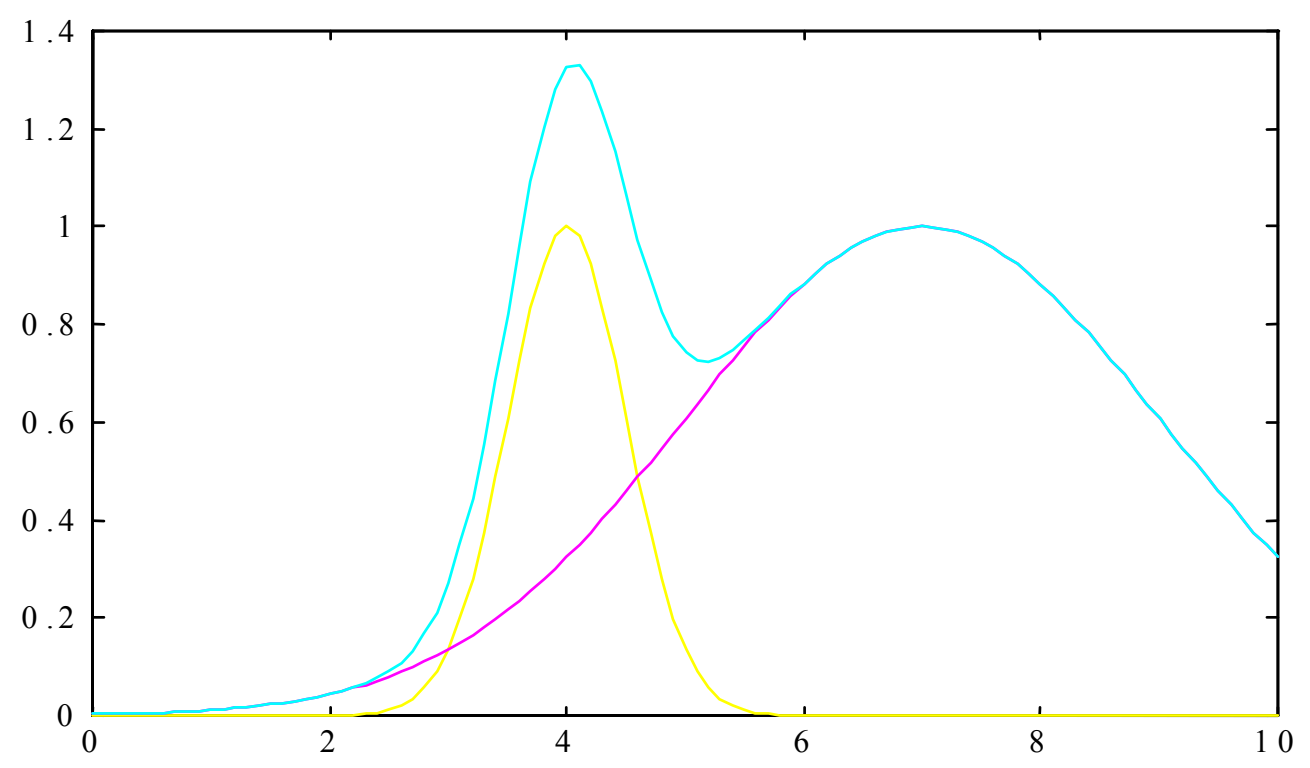

Figura 13. Agregação dos conjuntos nebulosos

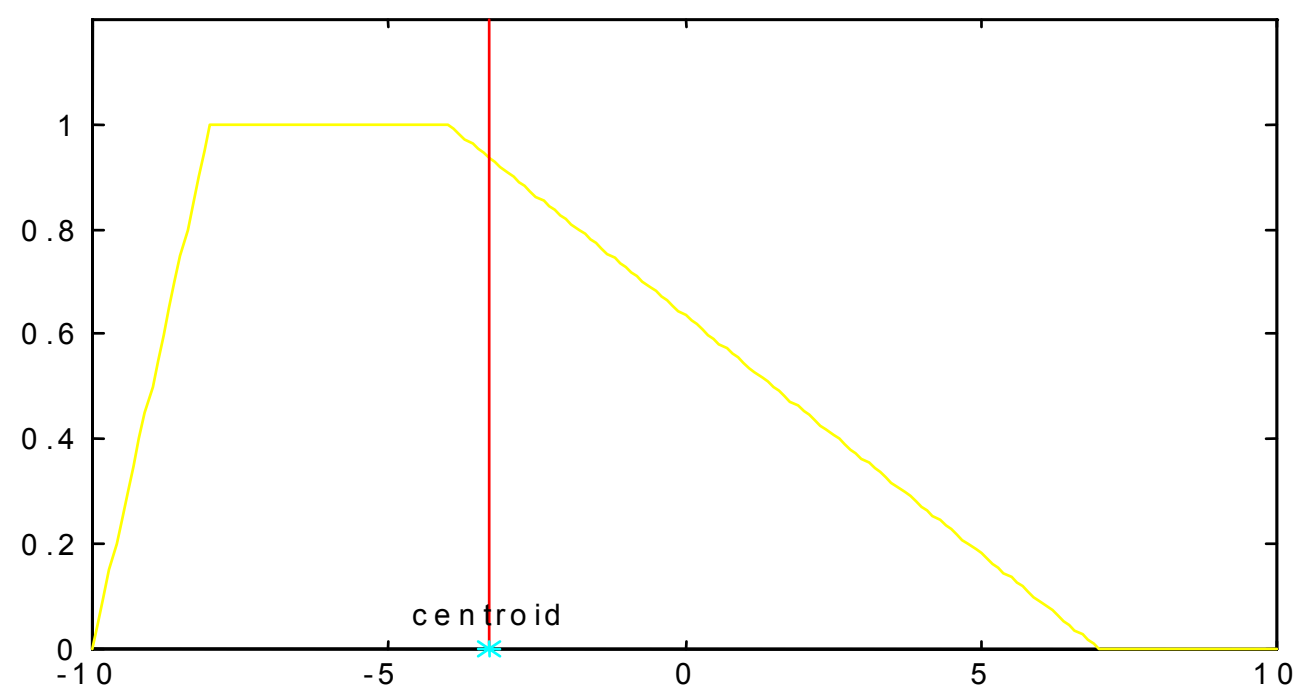

Figura 14. Método centróide para "defuzificação" 


\section{DESENVOLVIMENTO DO TRABALHO}

A implementação do Sistema de Monitoração e Detecção de Falhas foi dividia em duas etapas: na primeira etapa, a Monitoração dos sensores e atuadores do reator, e na segunda etapa, a Detecção e o Diagnóstico de Falhas. A Figura 15 apresenta um diagrama esquemático das etapas de implantação desse Sistema.

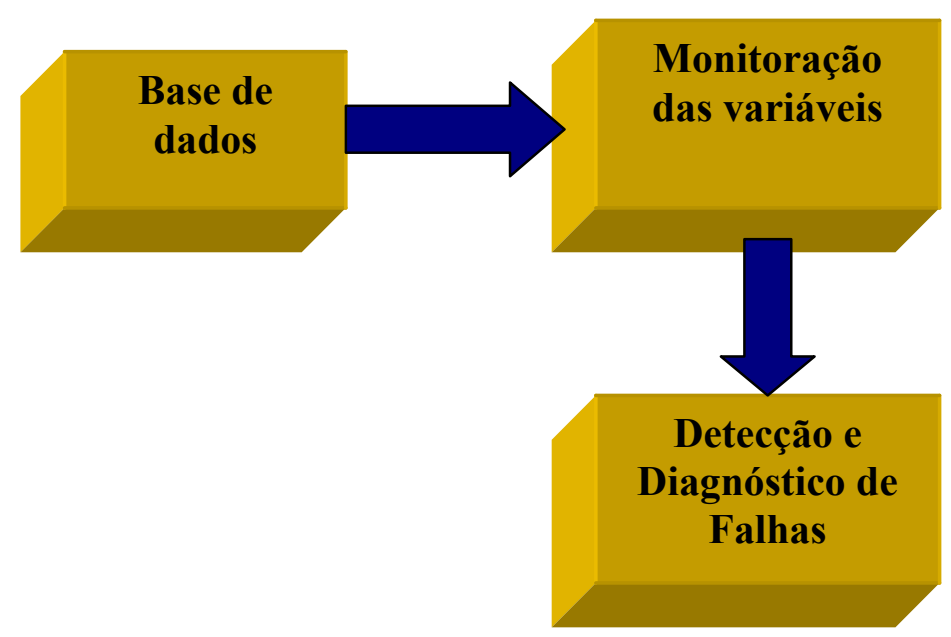

Figura 15. Etapas da implementação do Sistema de Monitoração e Detecção de Falhas

A monitoração dos sensores e atuadores do reator foi implementada através da utilização de Redes Neurais Artificiais. Para tanto, foi escolhido um grupo de variáveis consideradas importantes para a operação do reator.

A escolha desse grupo de variáveis não foi feita de forma aleatória, e sim através de um estudo exaustivo que mostrou a influência das mesmas na operação do reator. Além disso, procurou-se utilizar as mesmas variáveis do trabalho de Monitoração e Detecção de Falhas usando GMDH [42], para realizar estudos comparativos entre a metodologia GMDH e a de Redes Neurais Artificiais.

Para o treinamento das Redes Neurais, foram utilizadas duas bases de dados: uma base de dados gerada pelo modelo teórico e a outra contendo dados de uma semana típica de operação do reator. A Figura 16 apresenta resumidamente as etapas envolvidas na etapa de monitoração. 


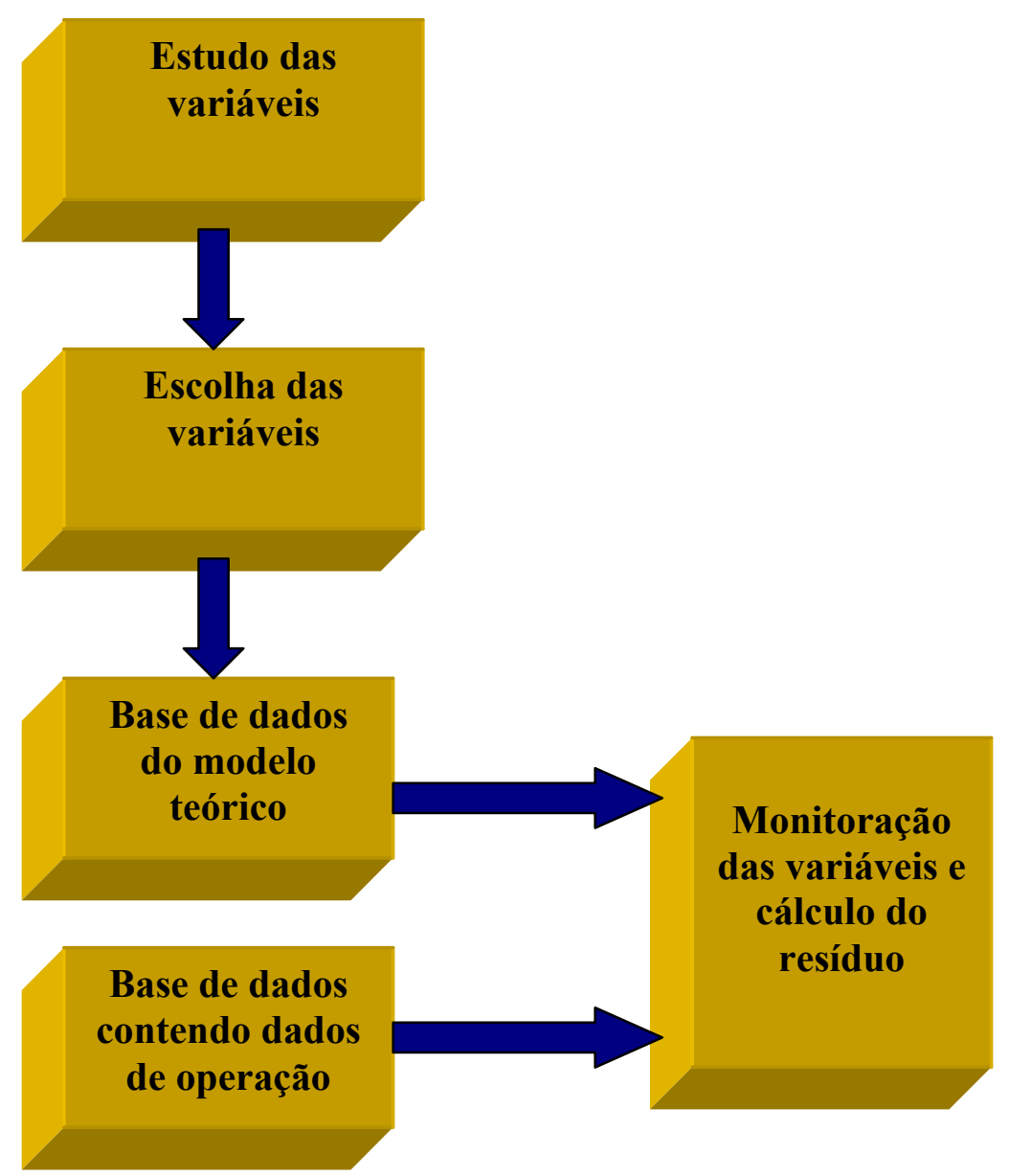

Figura 16. Primeira etapa desenvolvida: Monitoração das variáveis

A detecção de falhas foi implementada usando Redes Neurais Artificiais para verificar a descalibração de termopares. Assim como foi feito na monitoração, foram utilizadas duas bases de dados: uma base de dados com falha gerada pelo modelo teórico e outra contendo dados de operação, onde foram inseridas falhas para simular a descalibração dos termopares. A Figura 17 apresenta um diagrama esquemático da etapa de Detecção de Falhas. 


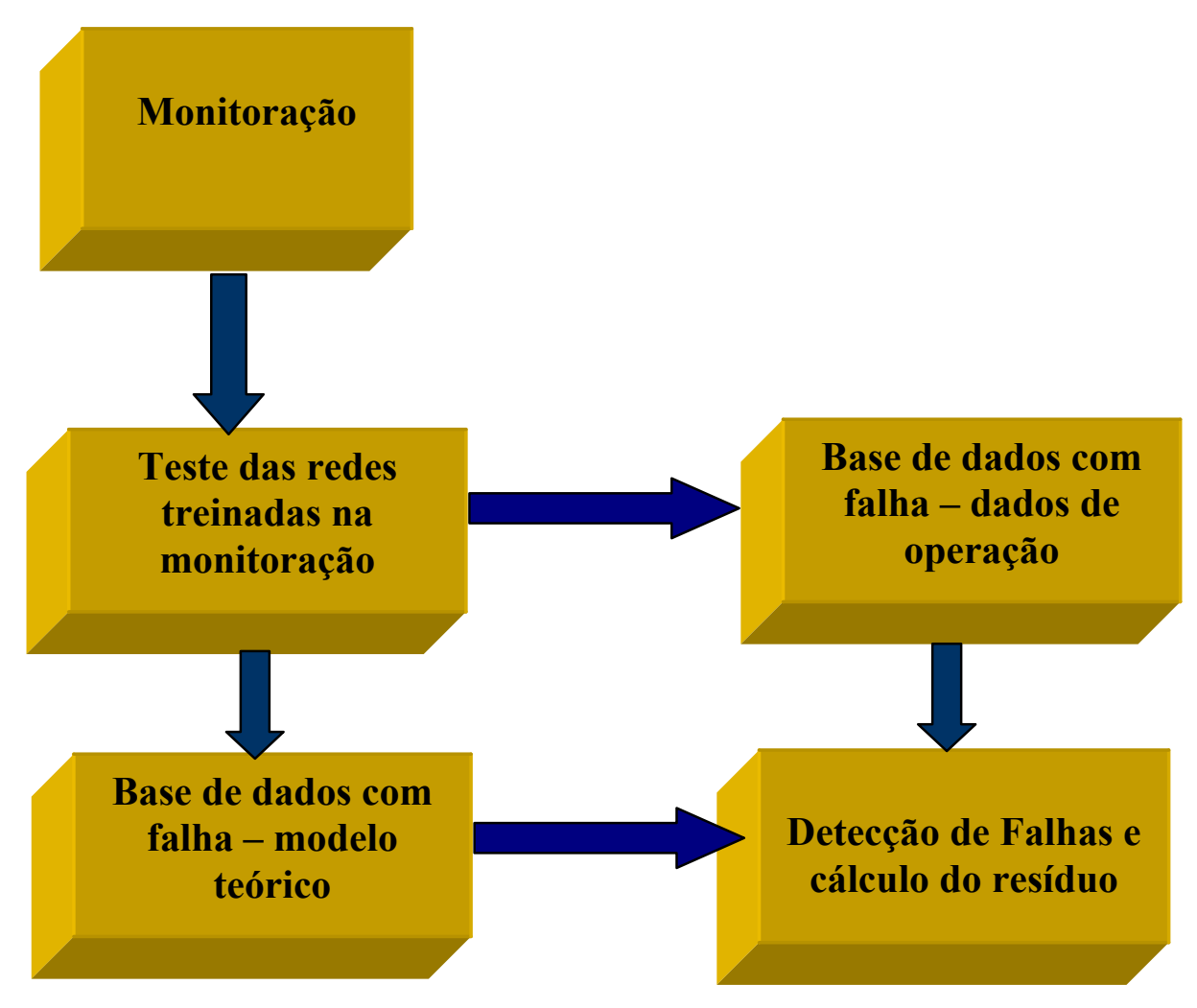

Figura 17. Segunda etapa desenvolvida: Detecção de Falhas

Após a etapa de detecção de falha, decidiu-se elaborar um sistema fuzzy para realizar o diagnóstico de falhas, para tornar os resultados mais abrangentes porque a Lógica Nebulosa proporciona uma ferramenta sistemática para tomada de decisão do diagnóstico. O Sistema Fuzzy foi implementado através de uma base de regras Se - Então, para identificar a ocorrência de falhas provocadas pela descalibração de termopares. A Figura 18 apresenta um diagrama esquemático da implementação do Diagnóstico de falhas. 


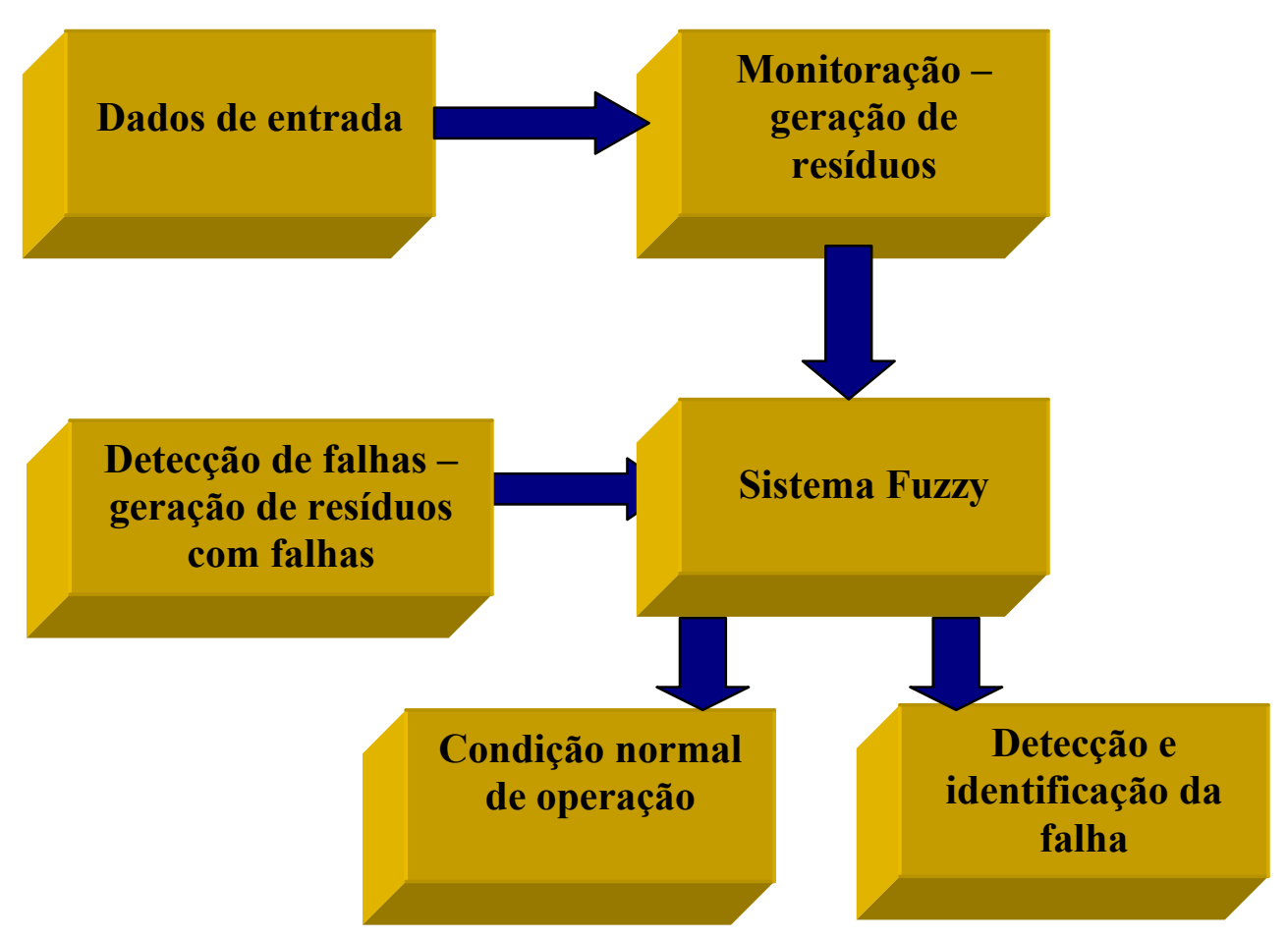

Figura 18. Diagnóstico de falhas

Nos próximos tópicos serão abordadas em detalhes todas as etapas de implementação do Sistema de Monitoração e Detecção de Falhas.

\subsection{Base de dados para treinamento das Redes Neurais}

Conforme já mencionado, este trabalho tem como objetivo o desenvolvimento de uma metodologia de monitoração e detecção de falhas usando RNA's e Lógica Nebulosa. Para a monitoração das variáveis, foram utilizadas duas bases de dados: uma gerada pelo modelo teórico do reator, descrito anteriormente; e outra contendo dados de operação do reator (SAD). Na Tabela 12, segue uma descrição detalhada das variáveis utilizadas neste trabalho.

Tabela 12. Descrição das variáveis utilizadas no trabalho

\begin{tabular}{|l|l|}
\hline Variáveis & Descrição \\
\hline N2 & \% de potência (canal de segurança 1 ) $[\%]$ \\
\hline F1M3 & Vazão do primário $[g p m]$ \\
\hline F3M3 & Vazão do secundário (trocador B) $[g p m]$ \\
\hline R1M3 & Ponte de sustentação do núcleo, lado esquerdo $[\mathrm{mR} / \mathrm{h}]$ \\
\hline T3 & temperatura sobre o núcleo do reator $\left[{ }^{\circ} \mathrm{C}\right]$ \\
\hline
\end{tabular}




\begin{tabular}{|l|l|}
\hline Variáveis & Descrição \\
\hline T4 & temperatura na entrada do tanque de decaimento $\left[{ }^{\circ} \mathrm{C}\right]$ \\
\hline T7 & temperatura na saída do primário (trocador $\mathrm{A}$ ) $\left[{ }^{\circ} \mathrm{C}\right]$ \\
\hline T8 & temperatura na entrada do secundário (trocador $\mathrm{A}$ ) $\left[{ }^{\circ} \mathrm{C}\right]$ \\
\hline T9 & temperatura na saída do secundário (trocador $\mathrm{A})\left[{ }^{\circ} \mathrm{C}\right]$ \\
\hline T10 & temperatura na saída do primário (trocador $\mathrm{B})\left[{ }^{\circ} \mathrm{C}\right]$ \\
\hline T11 & temperatura na entrada do secundário (trocador $\mathrm{B})\left[{ }^{\circ} \mathrm{C}\right]$ \\
\hline T12 & temperatura na saída do secundário (trocador $\mathrm{B})\left[{ }^{\circ} \mathrm{C}\right]$ \\
\hline
\end{tabular}

\subsection{Desenvolvimento das Redes Neurais}

Foram desenvolvidas redes do tipo MLP com três (3) camadas, usando a ferramenta de Redes Neurais do Matlab, onde os parâmetros de entrada e saída variam de acordo com a variável monitorada. Esta arquitetura foi escolhida por ser um modelo mais simples. As redes do tipo MLP, treinadas pelo algoritmo de retropropagação, apresentaram bons resultados para a tarefa de monitoração proposta neste trabalho. Além disso, foram testadas redes do tipo RBF (Radial Basis Function), sendo que este tipo de arquitetura não apresentou resultados satisfatórios para esta aplicação.

\subsection{Arquitetura das redes MLP desenvolvidas neste trabalho}

A rede MLP desenvolvida neste trabalho é composta por: uma camada de entrada, uma oculta e uma de saída.

$\mathrm{Na}$ monitoração com dados gerados pelo modelo teórico, o número de neurônios na camada de entrada é sete (7), pois corresponde ao vetor de entrada que foi apresentado à rede. Este vetor é composto pelas seguintes variáveis: F1M3, F3M3, N2, T3, T4, T7, T8, T9. A escolha das variáveis de entrada e saída dependerá da variável monitorada. Por exemplo, se o objetivo é a monitoração da potência (N2), as variáveis de entrada serão: F1M3, F3M3, T3, T4, T7, T8 e T9; e a variável de saída será N2. O mesmo procedimento é usado para a monitoração das outras variáveis.

$\mathrm{Na}$ monitoração com dados de operação do reator, o número de neurônios na camada de entrada também é sete, porém a rede será alimentada pelos seguintes valores: F1M3, F3M3, N2, T3, T4, T10, T11 e T12, sendo utilizado o mesmo procedimento ao da Monitoração com dados gerados pelo modelo teórico. 
As variáveis de temperatura são diferentes apenas na sua nomenclatura, pois no modelo teórico temos apenas um trocador de calor, ao contrário do reator que pode utilizar dois trocadores de calor (A ou B). Na semana de operação utilizada neste trabalho, o reator estava utilizando o trocador de calor (B).

$\mathrm{Na}$ camada de entrada foi utilizada a função linear (identidade). A função tangente hiperbólica foi utilizada, porém as redes não apresentaram bons resultados.

Para a camada oculta das redes desenvolvidas, foram estudados e testados 10 casos com diferentes números de neurônios. O estudo foi iniciado com um número pequeno de neurônios na camada oculta, observando se a rede apresentou bons resultados e se o erro obtido está dentro de um valor adequado para a aplicação. O mesmo procedimento é realizado, aumentando-se gradualmente o número de neurônios na camada oculta, até que o erro não apresente um aumento significativo. O objetivo deste estudo é determinar um número adequado de neurônios para a tarefa de monitoração. Na camada oculta foi utilizada a função tangente hiperbólica.

A camada de saída das redes é composta apenas por um neurônio, que representa a variável monitorada.

Na camada de saída foi utilizada a função linear, por apresentar um erro menor do que as outras funções de ativação e também por apresentar bons resultados para a implementação do Sistema de Monitoração e Detecção de Falhas.

\subsection{Monitoração}

\subsubsection{Treinamento da Rede com dados do modelo teórico do reator}

O modelo teórico foi utilizado para realizar cálculos com a precisão desejada e para comparar os erros da metodologia. Esse estudo inicial foi de extrema importância, pois o modelo teórico não sofre influências de ruídos, e o único erro associado ao modelo é o de arredondamento da máquina.

Através deste modelo, as redes foram treinadas com valores pré-selecionados, gerados pelo modelo teórico do reator. Com base neste modelo, foram gerados dados variando-se a Potência (N2) de 0 a 100\%, no intervalo de 5 em 5\%, sendo que para cada condição de potência gerada, foram criados 20 exemplos, totalizando 420 exemplos. Foram adicionados ruídos de $0,4 \%$ na variável T3 e 1\% na variável F1M3, por serem flutuações 
observadas durante a operação do reator IEA-R1. Esta base de dados foi normalizada no intervalo de -1 a 1 , de acordo com a equação (18):

$$
p n=2 \cdot(p-\min p) \div(\max p-\min p)
$$

Onde:

$p$ : entradas da rede

minp: menor valor de $\mathrm{p}$

maxp: maior valor de $\mathrm{p}$

$p n$ : valor normalizado das entradas da rede de $[-1,1]$

Foram estabelecidos dois parâmetros para interromper o treinamento das Redes Neurais. O primeiro parâmetro foi o MSE (Erro Médio Quadrático), cujo valor foi de $10^{-4}$; e o segundo parâmetro foi o número máximo de épocas, cujo valor foi 1000. Inicialmente, o MSE era de 0,01 , porém todas as redes atendiam a este critério e no intuito de reduzir ainda mais o valor do MSE, decidiu-se adotar o valor citado acima.

No treinamento das redes, foi utilizado o método de "Parada Antecipada" (Early Stopping). Este método sugere uma divisão da base de dados em três subconjuntos: treinamento $(50 \%)$, validação $(25 \%)$ e teste $(25 \%)$. O conjunto de treinamento é usado para calcular o gradiente e atualizar os pesos e bias da rede; o de validação é usado para monitorar o erro durante o processo de treinamento; e o de teste é usado para comparar diferentes modelos.

Como parâmetro para comparação do desempenho de cada rede foi utilizada a Função de Energia do Erro, descrita pela equação (11). A rede que apresentar a menor Energia do Erro (En), será escolhida para a aplicação.

Através deste estudo exaustivo, pode-se concluir o tipo de arquitetura, o número aproximado de neurônios na camada oculta e o algoritmo de treinamento, usados neste trabalho. Pode-se estudar também a colinearidade entre as variáveis de processo. Os resultados obtidos serão comentados no capítulo 6. 


\subsubsection{Treinamento da Rede com dados de operação do reator}

O treinamento das redes com dados de operação do reator tem como objetivo, realizar um estudo comparativo aos resultados obtidos com o modelo teórico do reator. Nos dados gerados pelo modelo teórico, foi simulado o ruído "comportado" das variáveis estudadas, o que não ocorria com os dados de operação do reator.

Os dados utilizados neste trabalho referem-se a uma semana de operação típica do reator IEA-R1. Como tínhamos informações operacionais a cada 30 segundos, decidiuse utilizar apenas 610 padrões/exemplos. Para tanto, foi elaborado um programa que fazia a leitura da base de dados no intervalo de 8 em 8 segundos, e guardava esta informação para utilizá-la posteriormente, no treinamento da rede. Esta base de dados também foi normalizada no intervalo de -1 a 1 , de acordo com a equação (18).

Foi utilizado o método de "Parada Antecipada", no treinamento das redes; e para interromper o treinamento, um MSE de $10^{-2}$ e um número máximo de épocas igual a 1000. Este MSE foi adotado, pois com o valor de $10^{-4}$, usado no treinamento com dados do modelo teórico, as redes não estavam convergindo, devido às flutuações observados ao longo do período de operação do reator IEA-R1. Desta forma, o MSE foi diminuído, até chegar no valor de $10^{-2}$, onde as redes passaram a convergir.

O critério de comparação do melhor modelo é o mesmo descrito pela equação (11). Os resultados obtidos com dados de operação serão apresentados nos próximos tópicos.

\subsection{Deteç̧ão de falhas}

Após o término da etapa de monitoração, iniciou-se a etapa de Detecção e Diagnóstico de Falhas, com o propósito de verificar o comportamento das redes treinadas sem falha, quando submetidas a testes com uma base de dados "com falha". A detecção e o Diagnóstico de Falhas são abordados separadamente, apenas para facilitar a compreensão desta etapa de Detecção e Diagnóstico.

$\mathrm{Na}$ detecção, as redes treinadas para a monitoração foram testadas, primeiramente com: dados ("com falha") gerados pelo modelo teórico e dados ("com falha”) referentes a uma semana típica de operação do reator, para verificar a descalibração dos termopares.

Os resultados obtidos serão comentados em detalhes no capítulo 7. 


\subsection{Diagnóstico de falhas}

Após a etapa de detecção de falha, foi elaborado um sistema fuzzy para realizar o diagnóstico de falhas. O sistema fuzzy foi implementado através de uma base de regras "Se - Então", para identificar a ocorrência de falhas ocasionadas pela descalibração dos termopares. O Sistema Fuzzy foi implementado utilizando a toolbox do Matlab.

No capítulo 8 será descrito em detalhes o sistema fuzzy desenvolvido e os resultados obtidos no diagnóstico de falhas. 


\section{RESULTADOS OBTIDOS NA MONITORAÇÃO}

\subsection{Base de dados do Modelo teórico}

\subsubsection{Potência}

Para a monitoração da Potência (N2), foram treinadas 10 RNA's variando-se o número de neurônios na camada oculta de 1 a 10. A camada de entrada foi alimentada pelas seguintes variáveis: T3, T4, T7, T8, T9, F1M3 e F3M3. O melhor modelo será aquele que apresentar a menor Energia do Erro (En), descrito pela equação (11). A rede que apresentou a menor Energia do Erro (En), foi a rede com 10 neurônios na camada oculta, cujo valor foi de $1,81934 \cdot 10^{-5}$ (ver Tabela 13).

Para comparar os valores estimados pelas RNA's com o valor calculado pelo modelo teórico, foi definida a variável "resíduo", que pode ser calculada através da equação (19). A Figura 19 mostra o resíduo calculado após o treinamento desta rede.

$$
r e s=\sum_{j=1}^{m}\left|y_{d j}(n)-y_{j}(n)\right|
$$

Onde:

res: resíduo da rede

$y_{d j}(n)$ : saída estimada pela RNA (desejada)

$y_{j}(n)$ : saída calculada pelo modelo teórico 


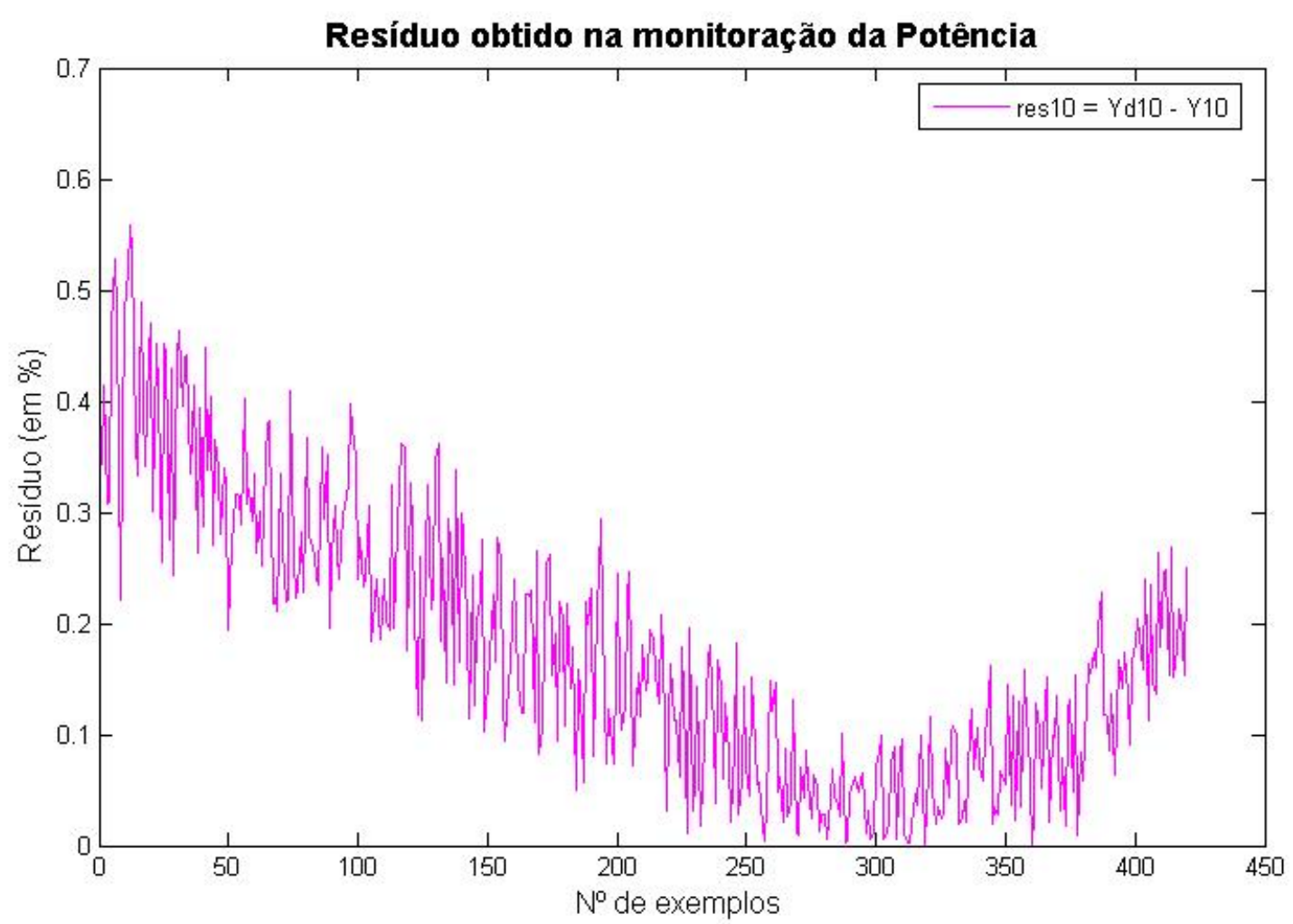

Figura 19. Resíduo da rede com 10 neurônios na camada oculta

Como pode ser visto na Figura 19, foram obtidos excelentes resultados no treinamento de uma RNA para a monitoração da Potência Nuclear, onde o resíduo obtido foi menor do que $0,55 \%$ da potência nominal do reator.

\subsubsection{Monitoração das temperaturas}

- Monitoração de T3

Para a monitoração de T3, foram treinadas 10 RNA's. A camada de entrada foi alimentada pelas seguintes variáveis: T4, T7, T8, T9, F1M3, F3M3 e N2. A rede que apresentou o menor Energia do Erro (En) foi a rede com 8 neurônios na camada oculta. A Energia do Erro (En) desta rede foi $1.59947 \cdot 10^{-5}$. A Figura 20 mostra o resíduo desta rede, calculado através da equação (19). 


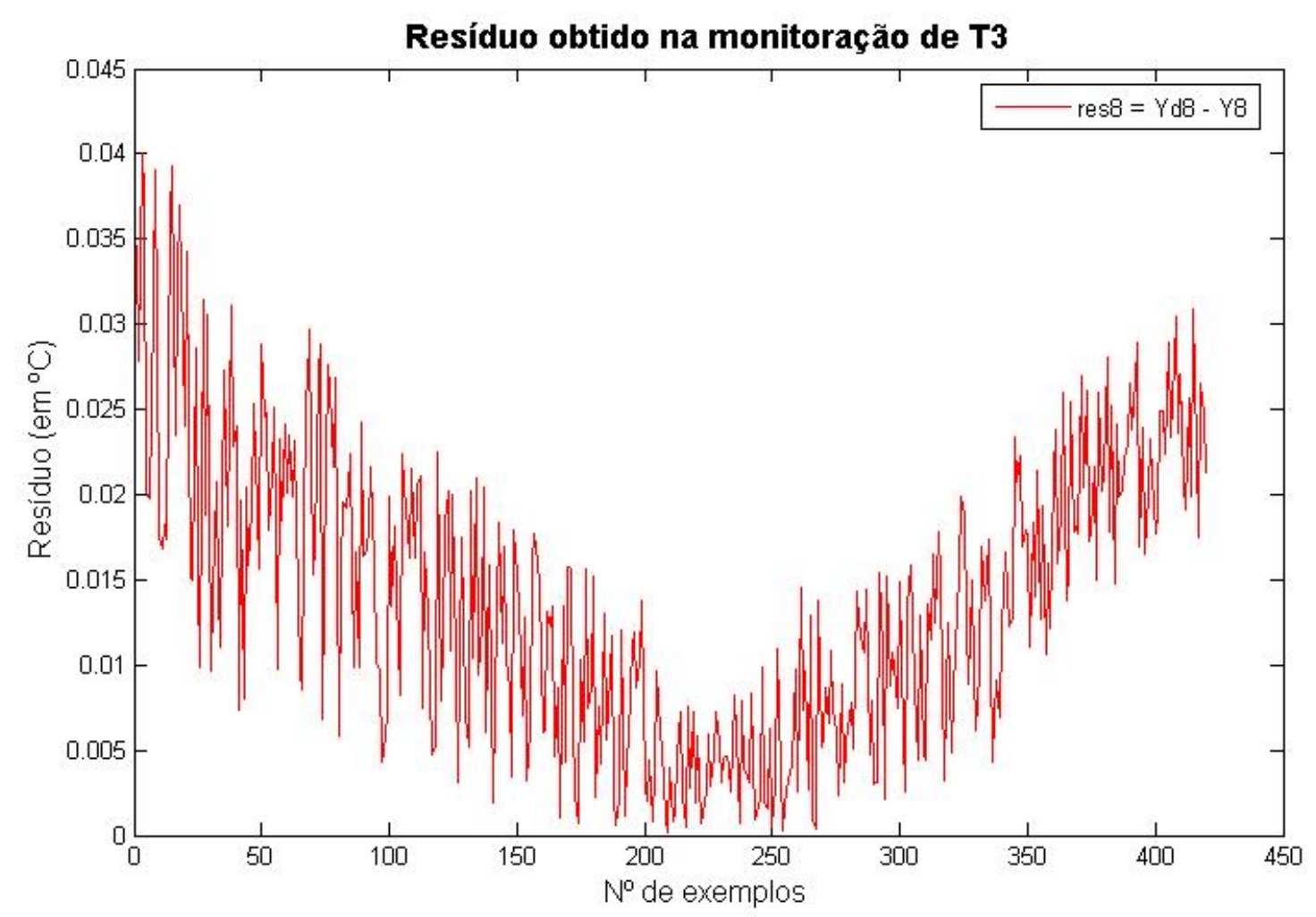

Figura 20. Resíduo da rede com 8 neurônios na camada oculta

Como pode ser visto na figura, foram obtidos excelentes resultados no treinamento de uma RNA para a monitoração da variável T3, descrita anteriormente. Além disso, os resíduos obtidos são menores que $0,04^{\circ} \mathrm{C}$, como pode ser visto na Figura 20.

- Monitoração de T4

Para a monitoração da variável T4, foram treinadas 10 RNA's. A camada de entrada foi alimentada pelas variáveis: T3, T7, T8, T9, F1M3, F3M3 e N2. A rede que apresentou a menor Energia do Erro (En) foi a rede com 10 neurônios na camada oculta. O valor da Energia do Erro (En) foi $6.98342 \cdot 10^{-6}$. A Figura 21 mostra o resíduo desta rede, calculado através da equação (19). 


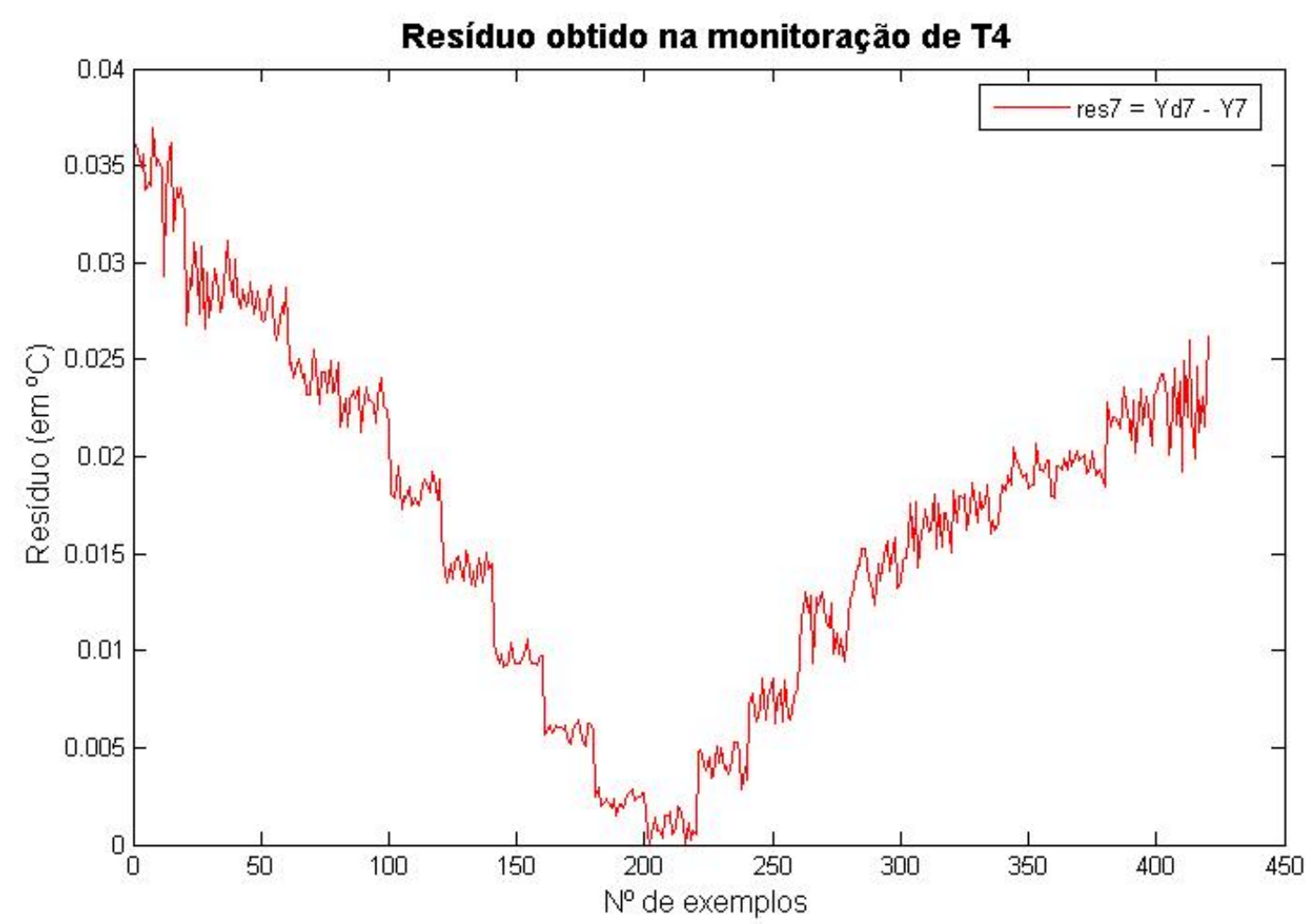

Figura 21. Resíduo da rede com 7 neurônios

Como pode ser visto na figura, foram obtidos excelentes resultados no treinamento de uma RNA para a monitoração da variável T4, descrita anteriormente. Além disso, os resíduos obtidos são menores que $0,04^{\circ} \mathrm{C}$ ), como pode ser visto na Figura 21.

-Monitoração de T7

Para a monitoração de T7, foram treinadas 10 RNA's. A camada de entrada foi alimentada pelas variáveis: T3, T4, T8, T9, F1M3, F3M3 e N2. A rede que apresentou a menor Energia do Erro (En), foi a rede com 6 neurônios na camada oculta. A Energia do Erro (En) desta rede foi de $1.19031 \cdot 10^{-5}$. A Figura 22 mostra o resíduo desta rede, calculado através da equação (19). 


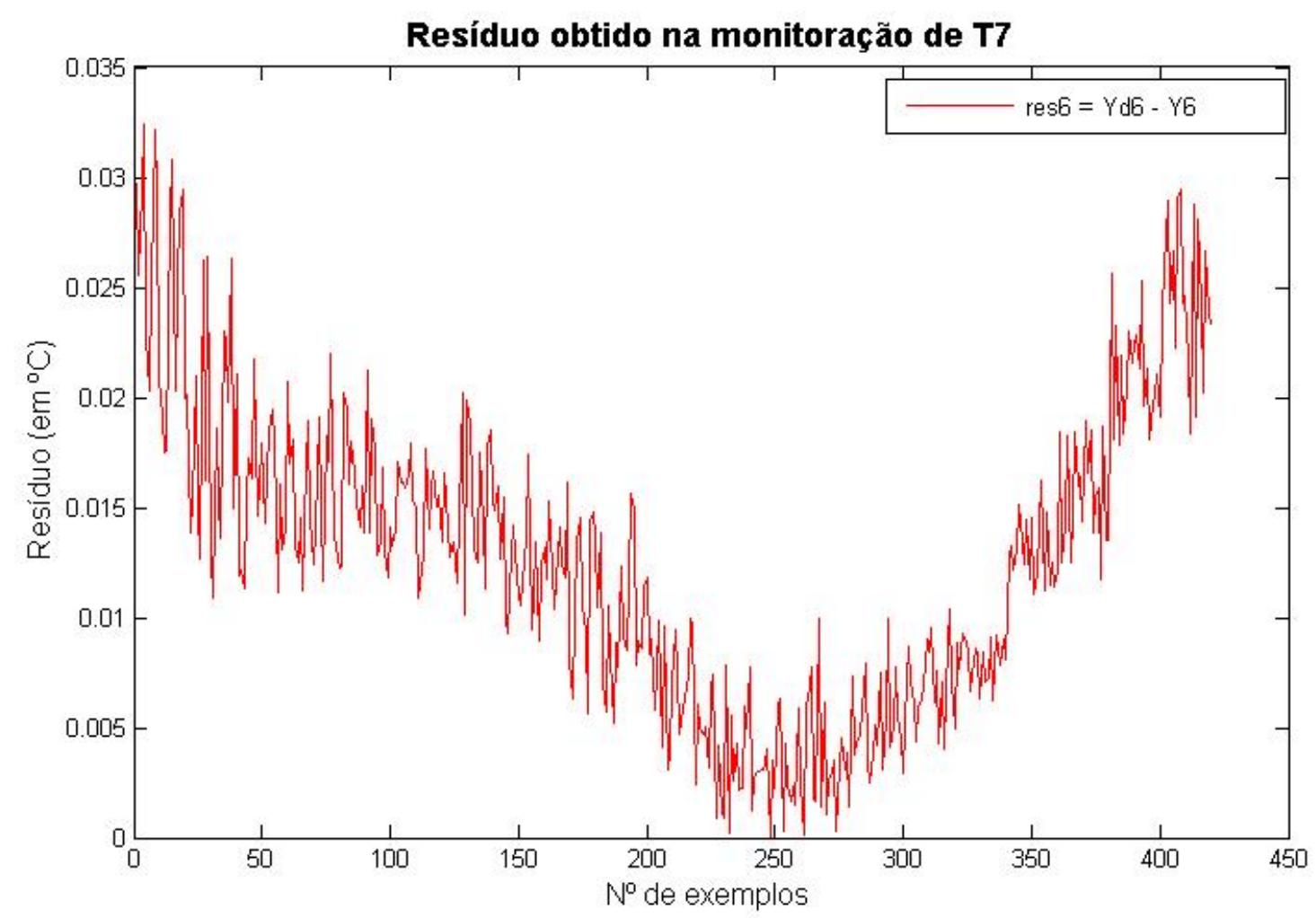

Figura 22. Resíduo da rede com 6 neurônios

Foram obtidos excelentes resultados no treinamento de uma RNA para a monitoração da variável T7, descrita anteriormente. Além disso, os resíduos obtidos são menores que $0,035^{\circ} \mathrm{C}$ ), como pode ser visto na Figura 22 .

- Monitoração de T8

Para a monitoração de T8, foram treinadas e testadas 10 RNA's. A camada de entrada foi alimentada pelas variáveis: T3, T4, F1M3, F3M3, T7, T9 e N2. A rede que apresentou a menor Energia do Erro (En) foi a rede com 10 neurônios na camada oculta. O valor da Energia do Erro (En) foi $1.8947 \cdot 10^{-5}$. A Figura 23 mostra o resíduo desta rede, calculado através da equação (19). 


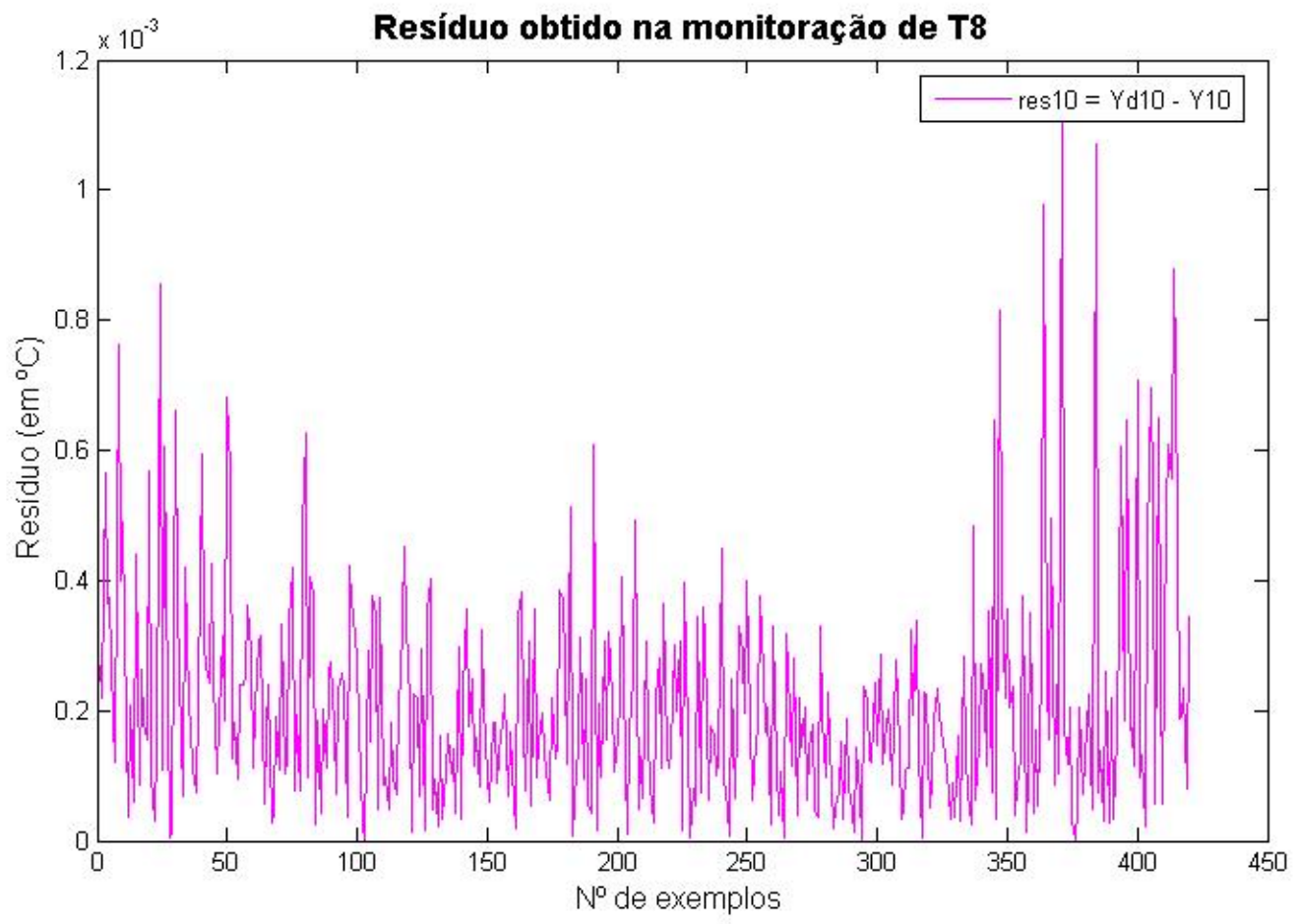

Figura 23. Resíduo da rede com 10 neurônios

A Figura 24 mostra as saídas calculadas pela rede (Y) e as desejadas (Yd), da rede com 10 neurônios na camada oculta.

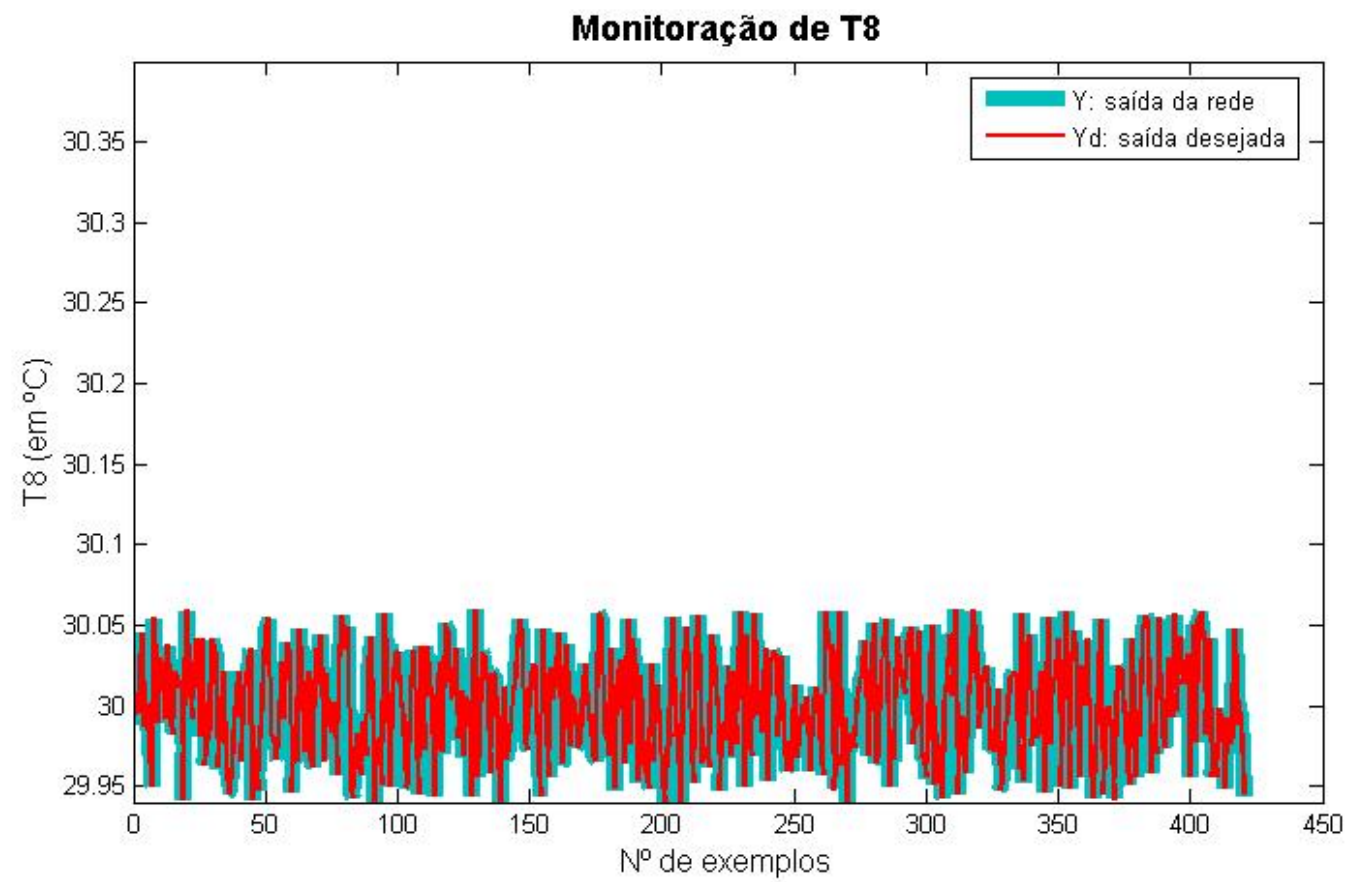

Figura 24. Saída desejada comparada com a saída obtida pela RNA 
Como pode ser visto na Figura 24, a variável T8 é praticamente constante, observando-se apenas pequenas flutuações na mesma. Isso se deve ao fato desta variável não sofrer influência quando há uma variação da potência na base de dados gerada pelo modelo teórico. Foram obtidos excelentes resultados e os resíduos obtidos são menores que $0,0012{ }^{\circ} \mathrm{C}$, como pode ser visto na Figura 23 .

- Monitoração de T9

Para monitorar a variável T9, foram utilizadas as seguintes variáveis de entrada: T3, T4, T7, T8, T9, F1M3, F3M3 e N2. A rede que apresentou a menor Energia do Erro (En) foi a rede com 9 neurônios na camada oculta. O valor da Energia do Erro (En) foi $2.07715 \cdot 10^{-6}$. A Figura 25 apresenta o resíduo desta rede, calculado através da equação (19).

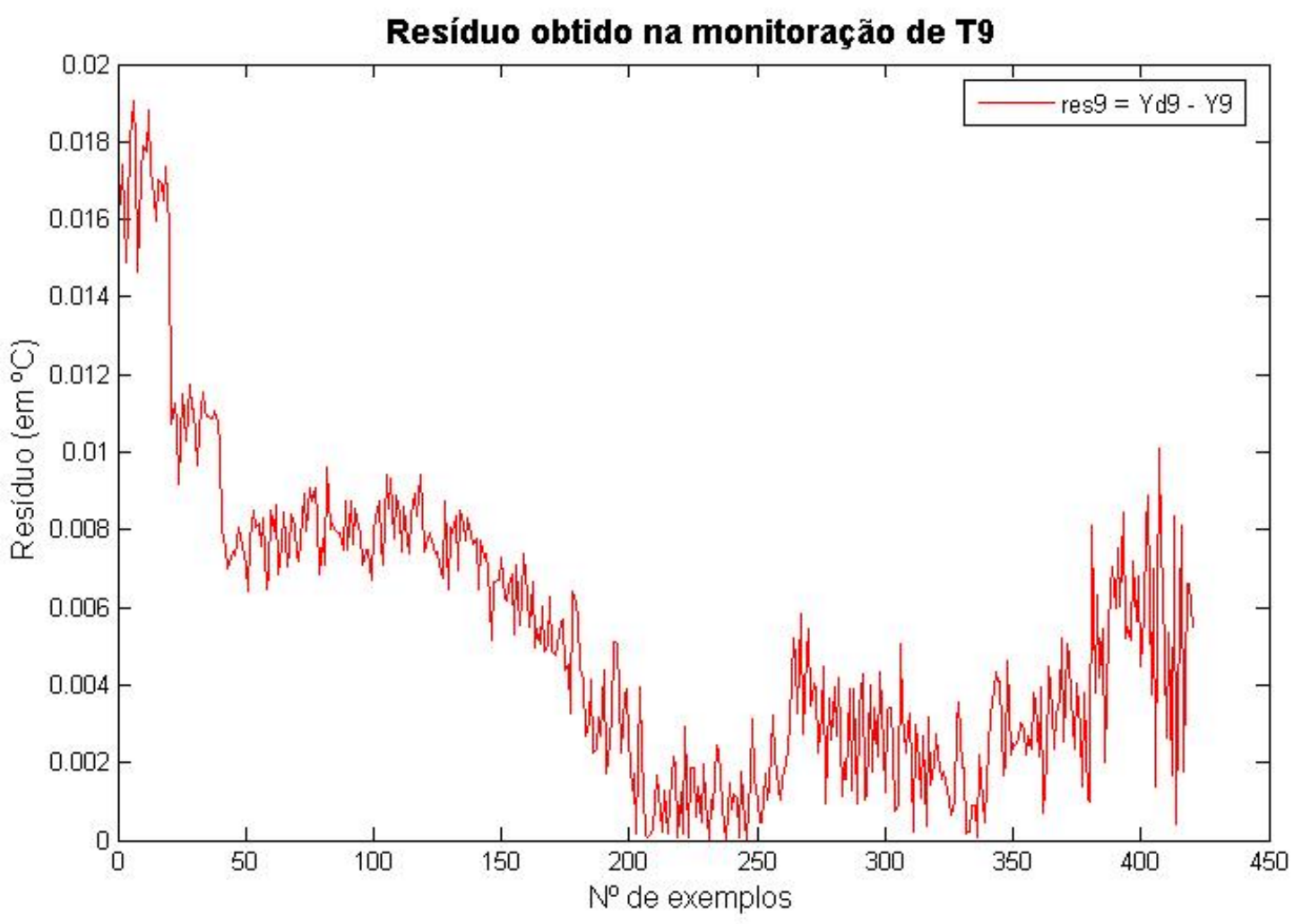

Figura 25. Resíduo da rede com 9 neurônios

Foram obtidos excelentes resultados no treinamento de uma RNA para a monitoração da variável T9, descrita anteriormente. Além disso, os resíduos obtidos são menores que $0,02{ }^{\circ} \mathrm{C}$, como pode ser visto na Figura 25 . 


\subsubsection{Análise dos resultados do Modelo Teórico}

Na Tabela 13 são mostrados os resultados obtidos durante o treinamento das Redes Neurais Artificiais para a monitoração das variáveis descritas anteriormente.

Tabela 13. Resultados obtidos durante o treinamento das RNA's

\begin{tabular}{|c|c|c|}
\hline Variáveis & $\mathbf{N}^{0}$ de neurônios & Energia do Erro (En) \\
\hline \multirow{10}{*}{ N2 } & 1 & $8,44494 \cdot 10^{-5}$ \\
\hline & 2 & $7,48608 \cdot 10^{-5}$ \\
\hline & 3 & $1,67561 \cdot 10^{-5}$ \\
\hline & 4 & $4,18841 \cdot 10^{-5}$ \\
\hline & 5 & $9,88622 \cdot 10^{-5}$ \\
\hline & 6 & $7,31984 \cdot 10^{-5}$ \\
\hline & 7 & $7,14665 \cdot 10^{-5}$ \\
\hline & 8 & $9,5468 \cdot 10^{-5}$ \\
\hline & 9 & $9,01996 \cdot 10^{-5}$ \\
\hline & 10 & $1,81934 \cdot 10^{-5}$ \\
\hline \multirow{10}{*}{$\mathrm{T} 3$} & 1 & $8,8378 \cdot 10^{-5}$ \\
\hline & 2 & $8,8295 \cdot 10^{-5}$ \\
\hline & 3 & $8,8609 \cdot 10^{-5}$ \\
\hline & 4 & $7,01844 \cdot 10^{-5}$ \\
\hline & 5 & $8,28297 \cdot 10^{-5}$ \\
\hline & 6 & $5,02826 \cdot 10^{-5}$ \\
\hline & 7 & $8,26823 \cdot 10^{-5}$ \\
\hline & 8 & $1,59947 \cdot 10^{-5}$ \\
\hline & 9 & $4,77755 \cdot 10^{-5}$ \\
\hline & 10 & $7,7899 \cdot 10^{-5}$ \\
\hline \multirow{10}{*}{$\mathrm{T} 4$} & 1 & $8,47311 \cdot 10^{-5}$ \\
\hline & 2 & $9,5941 \cdot 10^{-5}$ \\
\hline & 3 & $9,45613 \cdot 10^{-5}$ \\
\hline & 4 & $1,13202 \cdot 10^{-5}$ \\
\hline & 5 & $5,90726 \cdot 10^{-5}$ \\
\hline & 6 & $6.03562 \cdot 10^{-5}$ \\
\hline & 7 & $1.08411 \cdot 10^{-5}$ \\
\hline & 8 & $1.90662 \cdot 10^{-5}$ \\
\hline & 9 & $3,9158 \cdot 10^{-5}$ \\
\hline & 10 & $6,98342 \cdot 10^{-6}$ \\
\hline \multirow{7}{*}{$\mathrm{T} 7$} & 1 & $8,95812 \cdot 10^{-5}$ \\
\hline & 2 & $9,18025 \cdot 10^{-5}$ \\
\hline & 3 & $8,40264 \cdot 10^{-5}$ \\
\hline & 4 & $2,28493 \cdot 10^{-5}$ \\
\hline & 5 & $8,41331 \cdot 10^{-5}$ \\
\hline & 6 & $1,19031 \cdot 10^{-5}$ \\
\hline & 7 & $1,79687 \cdot 10^{-5}$ \\
\hline
\end{tabular}




\begin{tabular}{|c|c|c|}
\hline Variáveis & $\mathbf{N}^{0}$ de neurônios & Energia do Erro (En) \\
\hline \multirow{3}{*}{$\mathrm{T} 7$} & 8 & $4,83962 \cdot 10^{-5}$ \\
\hline & 9 & $4,80404 \cdot 10^{-5}$ \\
\hline & 10 & $7,21102 \cdot 10^{-5}$ \\
\hline \multirow{10}{*}{$\mathrm{T} 8$} & 1 & $7,26882 \cdot 10^{-5}$ \\
\hline & 2 & $2,38244 \cdot 10^{-5}$ \\
\hline & 3 & $2,5374 \cdot 10^{-5}$ \\
\hline & 4 & $9,66861 \cdot 10^{-5}$ \\
\hline & 5 & $8,78082 \cdot 10^{-5}$ \\
\hline & 6 & $9,3253 \cdot 10^{-5}$ \\
\hline & 7 & $3,99132 \cdot 10^{-5}$ \\
\hline & 8 & $6,87056 \cdot 10^{-5}$ \\
\hline & 9 & $8,36769 \cdot 10^{-5}$ \\
\hline & 10 & $1,8947 \cdot 10^{-5}$ \\
\hline \multirow{10}{*}{ T9 } & 1 & $9,90004 \cdot 10^{-5}$ \\
\hline & 2 & $8,70302 \cdot 10^{-5}$ \\
\hline & 3 & $8,75422 \cdot 10^{-5}$ \\
\hline & 4 & $1,59751 \cdot 10^{-5}$ \\
\hline & 5 & $9,72773 \cdot 10^{-5}$ \\
\hline & 6 & $4,16469 \cdot 10^{-5}$ \\
\hline & 7 & $6,8979 \cdot 10^{-5}$ \\
\hline & 8 & $7,29494 \cdot 10^{-5}$ \\
\hline & 9 & $2,07715 \cdot 10^{-6}$ \\
\hline & 10 & $1,08752 \cdot 10^{-5}$ \\
\hline
\end{tabular}

Os valores destacados em negritos foram os melhores resultados obtidos no treinamento das Redes Neurais Artificiais para a monitoração das variáveis do processo. Além disso, pode-se verificar através da análise da Tabela 13, que:

* A menor Energia do Erro (En) obtida foi na monitoração da variável T4 e T9 (da ordem de $10^{-6} \mathrm{C}$ );

* Para as demais variáveis: N2, T3, T7 e T8, as Energias do Erro (En) obtidas foram da ordem de $10^{-5}$.

Os resultados obtidos durante o treinamento das Redes Neurais Artificiais na monitoração das variáveis do processo, utilizando uma base de dados gerados pelo modelo teórico do reator, mostram a viabilidade de aplicação das mesmas no desenvolvimento de uma metodologia de Monitoração e Detecção de Falhas em Sensores. Além disso, através da análise dos resultados obtidos, pode-se verificar que as RNA's apresentaram um excelente desempenho, quando foram treinadas com dados do modelo teórico. No próximo tópico, serão apresentados os resultados obtidos no treinamento das redes com dados 
referentes a uma semana típica de operação do reator, e será feita uma comparação aos resultados obtidos com o modelo teórico.

\subsection{Resultados obtidos com dados de operação do reator}

\subsubsection{Monitoração da potência}

Para a monitoração da variável N2, foram utilizadas as seguintes variáveis de entrada: T3, T4, F1M3, F3M3, T10, T11, T12. A rede que apresentou a menor Energia do erro (En) foi a rede com 5 neurônios na camada oculta. O valor da Energia do Erro (En) foi $7,94451 \cdot 10^{-3}$ (ver tabela 14). A Figura 26 apresenta o resíduo desta rede, calculado através da equação (19).

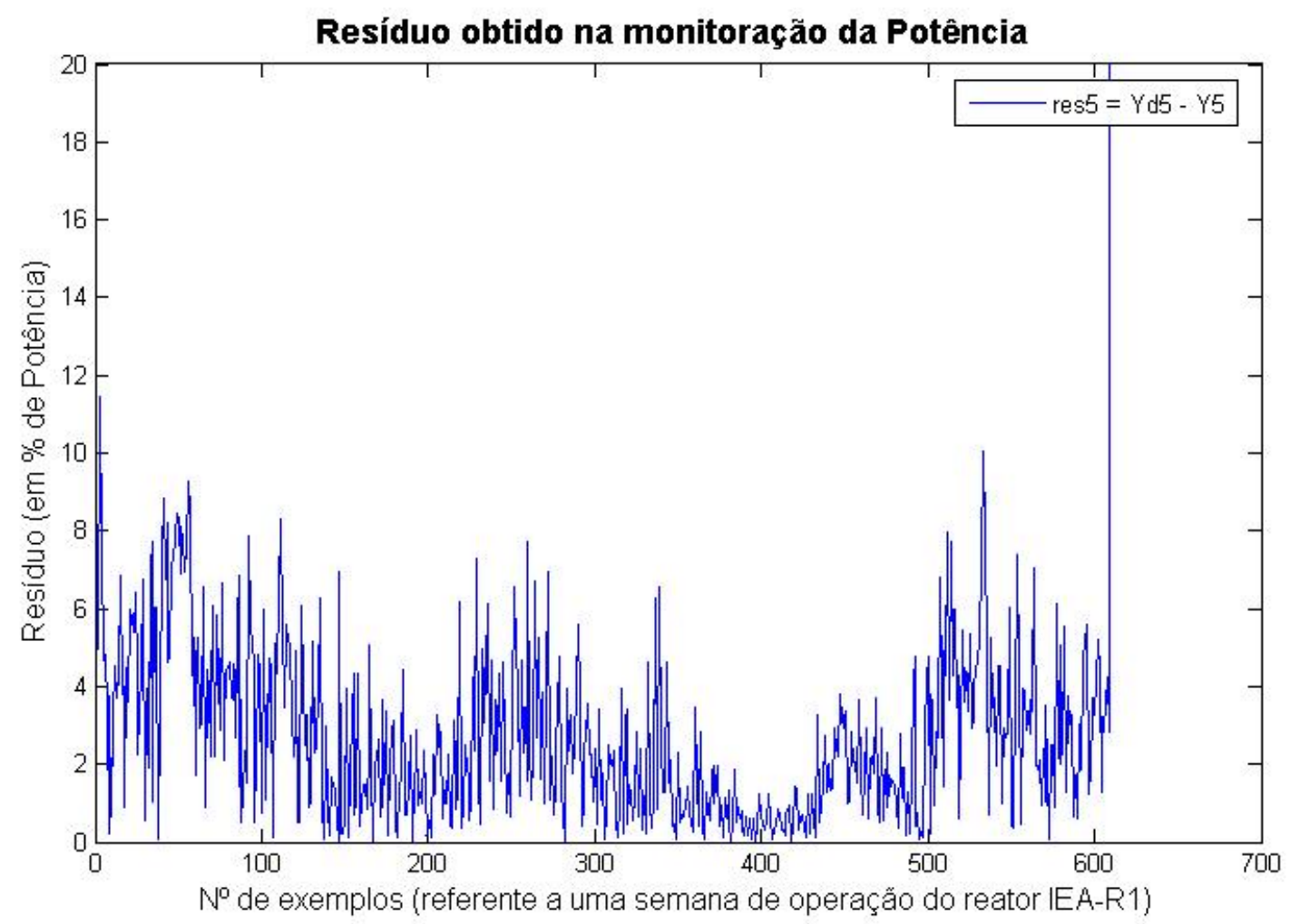

Figura 26. Resíduo da rede com 5 neurônios

A Figura 27 mostra as saídas da rede neural (Y) e as desejadas (Yd), da rede com 5 neurônios na camada oculta. 


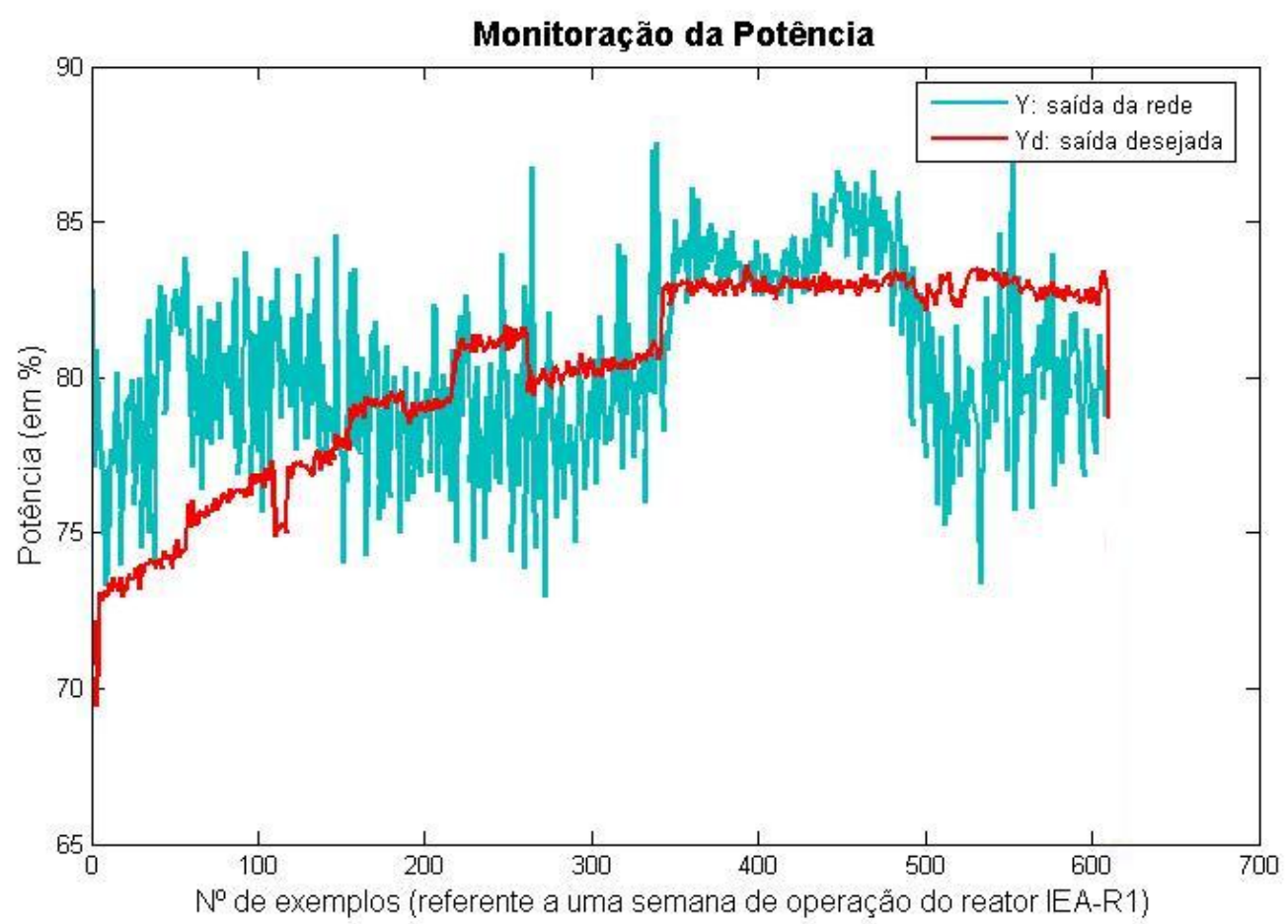

Figura 27. Saída desejada comparada à saída da rede com 5 neurônios na camada oculta

Como pode ser visto na Figura 26, os resíduos obtidos na monitoração da potência nuclear com dados de operação foram maiores do que os resíduos obtidos com os dados gerados pelo modelo teórico. Isto é explicado porque no modelo teórico a potência é dada como um valor fixo para cada condição de operação, enquanto que nos dados de operação a potência é medida por um detector de radiação nuclear.

\subsubsection{Monitoração das temperaturas}

- Monitoração de T3

Para a monitoração da variável T3, foram utilizadas as seguintes variáveis de entrada: T4, T10, T11, T12, F1M3, F3M3 e N2. A rede que apresentou a menor Energia do Erro (En) foi a rede com 9 neurônios na camada oculta. O valor da Energia do Erro (En) médio foi $9,21064 \cdot 10^{-3}$. A Figura 28 mostra o resíduo desta rede, calculado através da equação (19).

A figura 29 mostra as saídas da rede (Y) e as desejadas (Yd), da rede com 9 neurônios na camada oculta. 


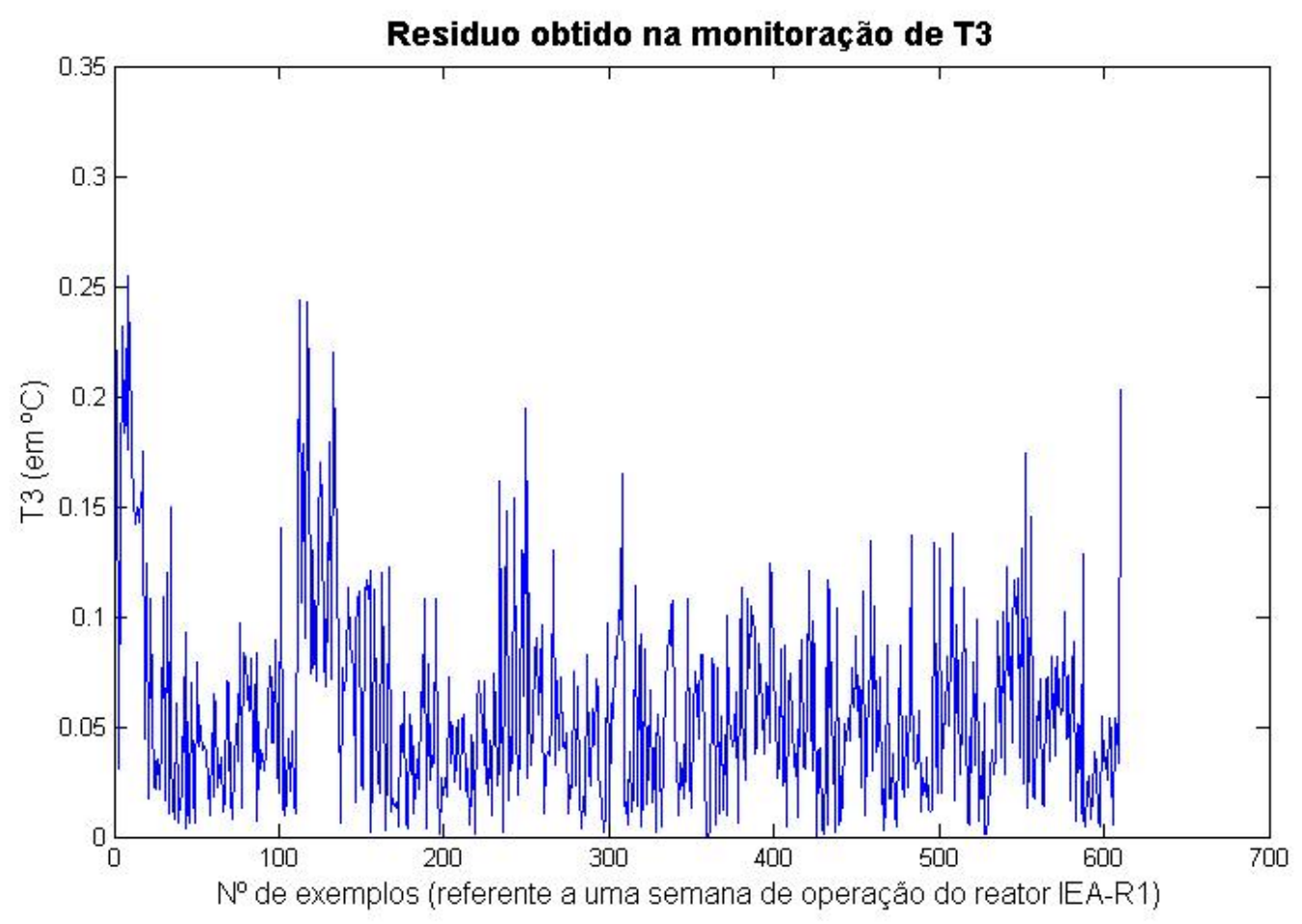

Figura 28. Resíduo da rede com 9 neurônios

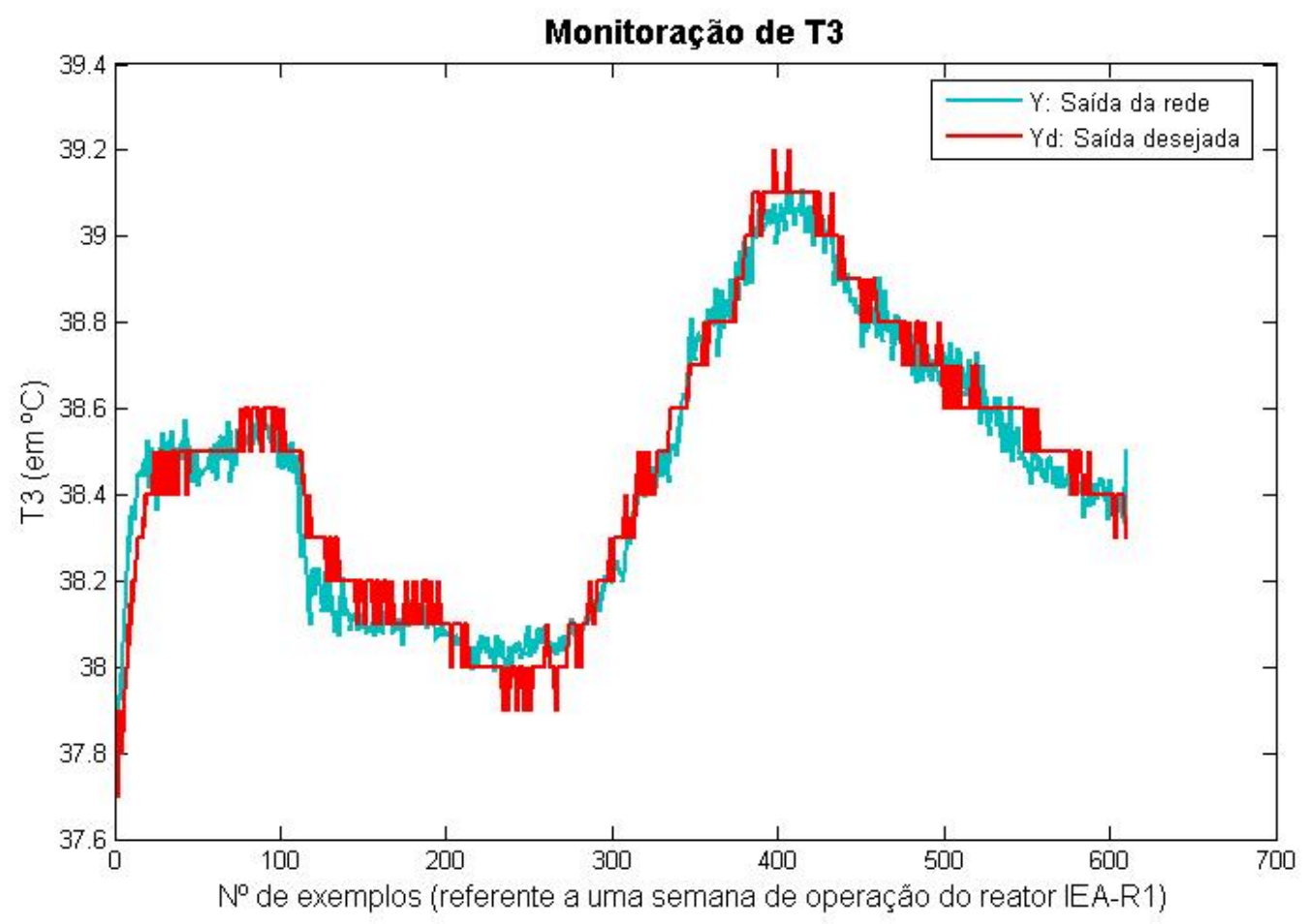

Figura 29. Saída desejada comparada à saída da rede com 9 neurônios na camada oculta

Como pode ser visto na Figura 29, foram obtidos excelentes resultados no treinamento de uma RNA para a monitoração da variável T3, descrita anteriormente. Os resíduos obtidos foram menores que $0,25^{\circ} \mathrm{C}$, como pode ser visto na Figura 28 . 
Para a monitoração da variável T4, foram utilizadas as seguintes variáveis de entrada: T3, T10, T11, T12, F1M3, F3M3 e N2. A rede que apresentou a menor Energia do Erro (En) foi a rede com 5 neurônios na camada oculta. O valor da Energia do Erro (En) foi $7,26921 \cdot 10^{-3}$. A Figura 30 mostra o resíduo desta rede, calculado através da equação (19).

A Figura 31 mostra as saídas da rede (Y) e as desejadas (Yd), da rede com 5 neurônios na camada oculta.

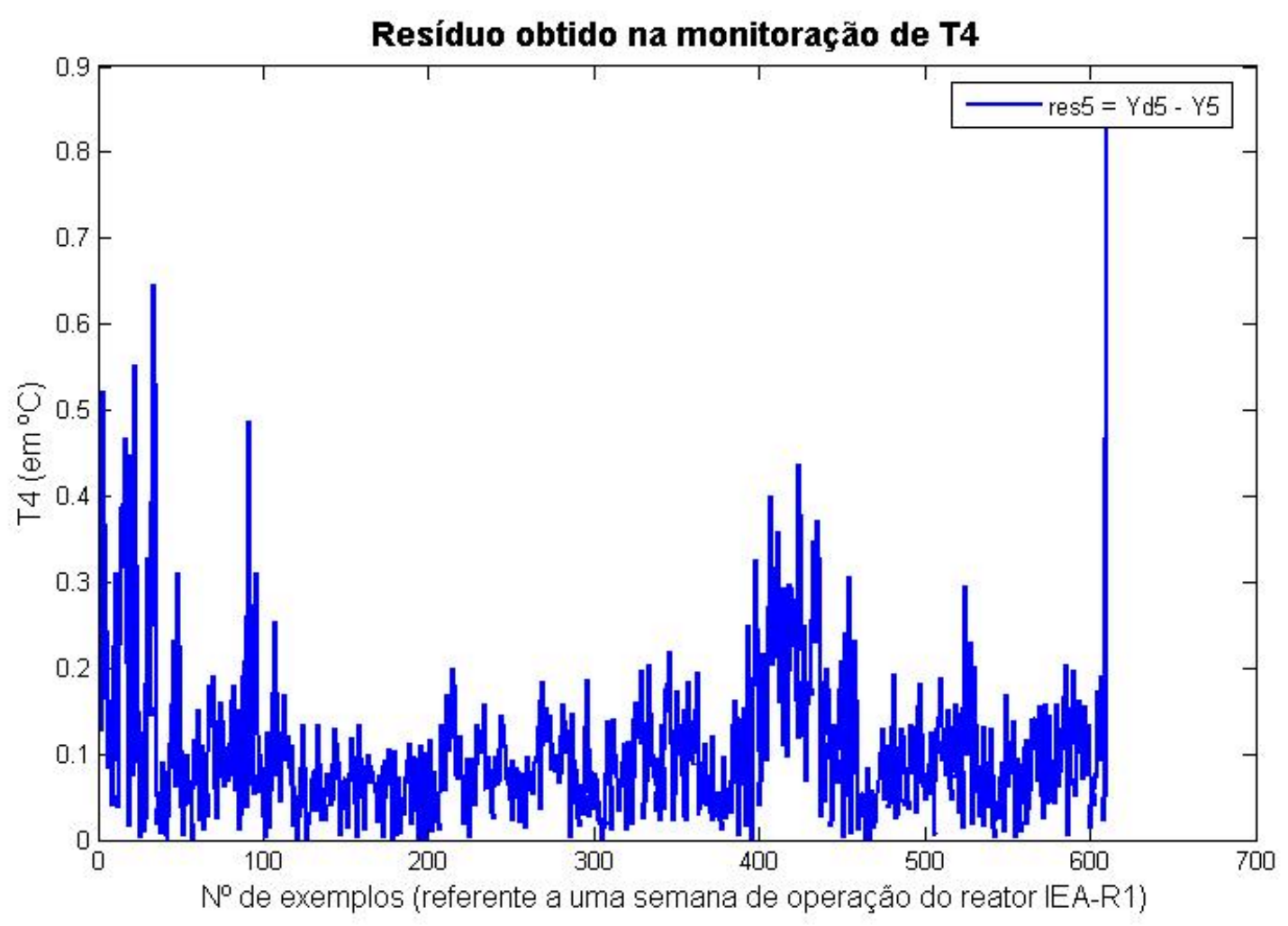

Figura 30. Resíduo da rede com 5 neurônios 


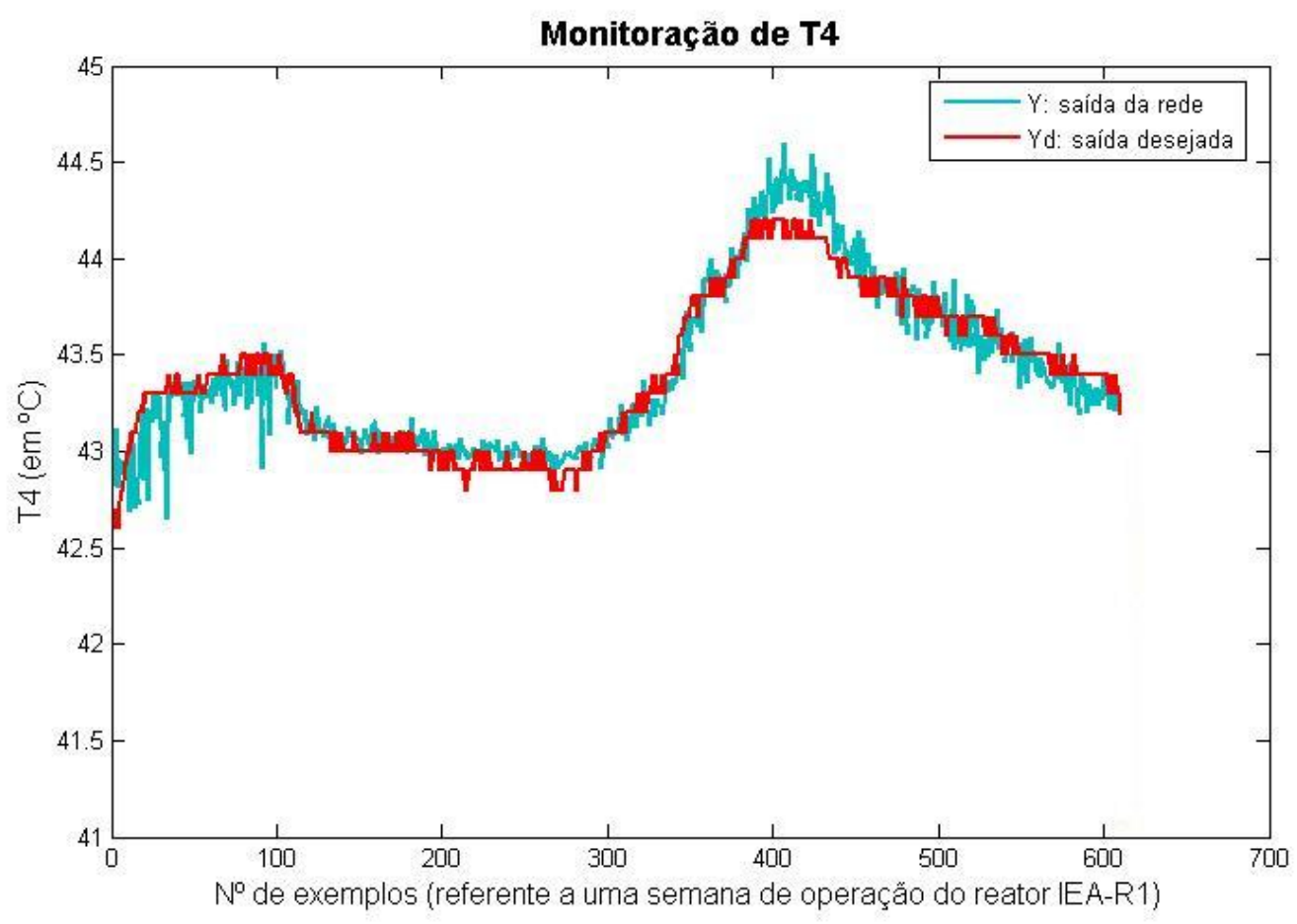

Figura 31. Saída desejada comparada à saída da rede com 5 neurônios na camada oculta

Como pode ser visto na figura, foram obtidos excelentes resultados no treinamento de uma RNA para a monitoração da variável T4, descrita anteriormente. Os resíduos obtidos foram menores que $0,65^{\circ} \mathrm{C}$, como pode ser visto na figura 31 .

- Monitoração de T10

Para a monitoração desta variável, foram utilizadas as seguintes variáveis de entrada: T3, T4, T11, T12, F1M3, F3M3 e N2. A rede que apresentou a menor Energia do Erro (En) foi a rede com 9 neurônios na camada oculta. O valor da Energia do Erro (En) foi $9,46129 \cdot 10^{-3}$. A Figura 32 mostra o resíduo desta rede, calculado através da equação (19).

A figura 33 mostra as saídas da rede (Y) e as desejadas (Yd), da rede com 9 neurônios na camada oculta. 


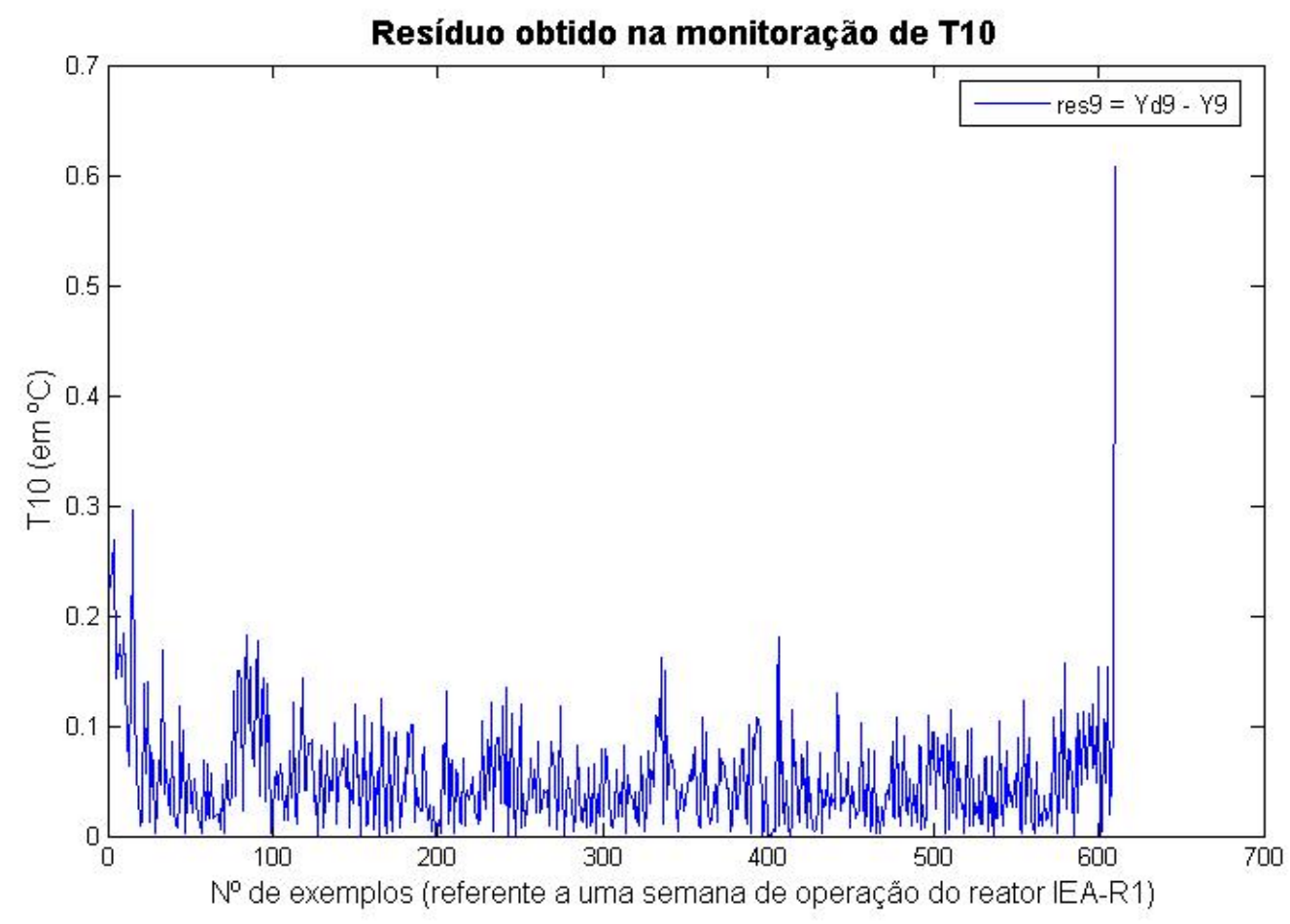

Figura 32. Resíduo da rede com 9 neurônios

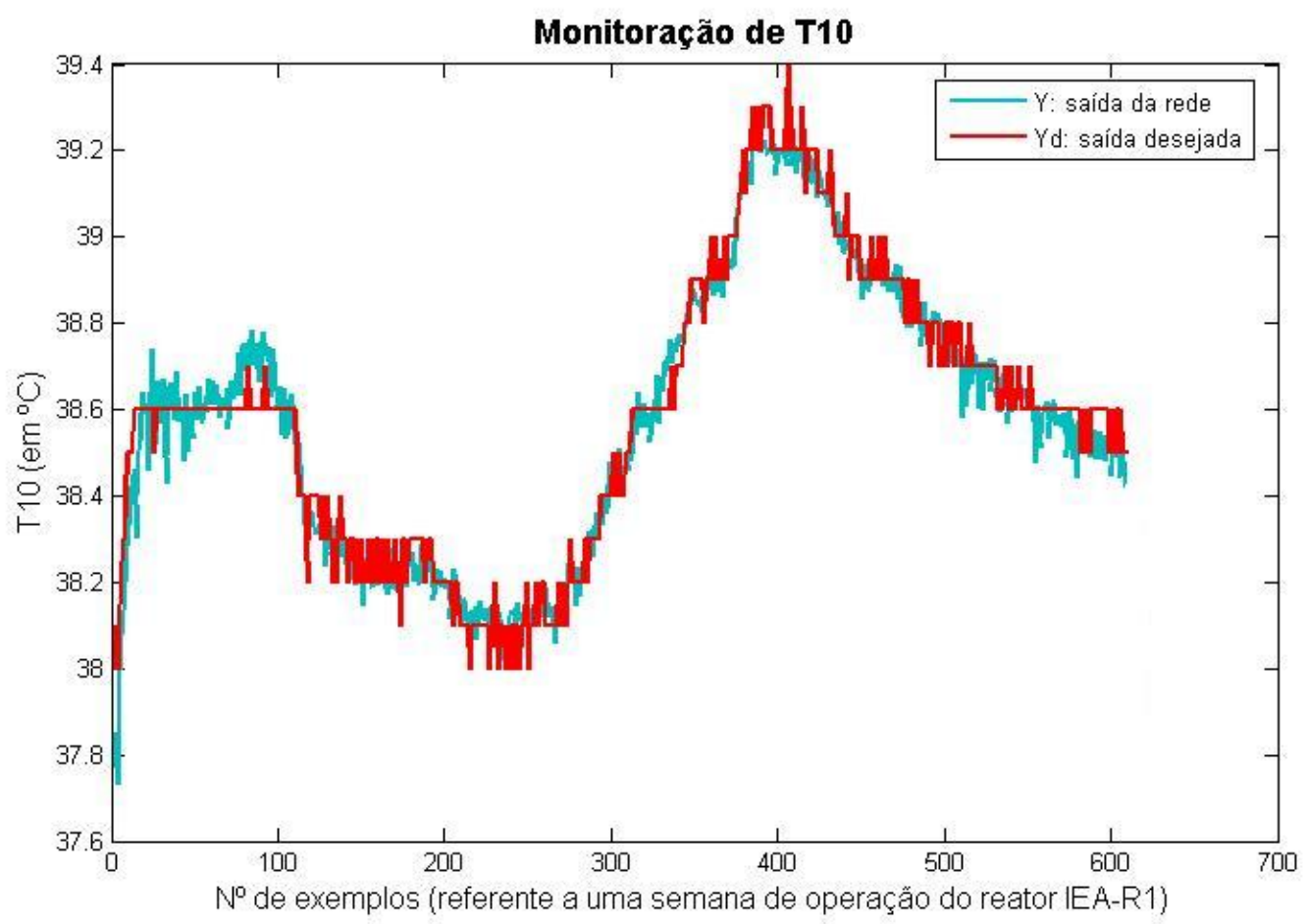

Figura 33. Saída desejada comparada à saída da rede com 9 neurônios na camada oculta

Como pode ser visto na figura, foram obtidos resultados satisfatórios no treinamento de uma RNA para a monitoração da variável T10, descrita anteriormente. Os resíduos obtidos foram menores que $0,3{ }^{\circ} \mathrm{C}$, como pode ser visto na figura 32 . 
- Monitoração de T11

Para a monitoração desta variável, foram utilizadas as seguintes variáveis de entrada: T3, T4, T10, T12, F1M3, F3M3 e N2. A rede que apresentou a menor Energia do Erro (En) foi a rede com 9 neurônios na camada oculta. $\mathrm{O}$ valor da Energia do Erro foi $9,65393 \cdot 10^{-3}$. A Figura 34 mostra o resíduo desta rede, calculado através da equação (19).

A Figura 35 mostra as saídas da rede (Y) e as desejadas (Yd), da rede com 9 neurônios na camada oculta.

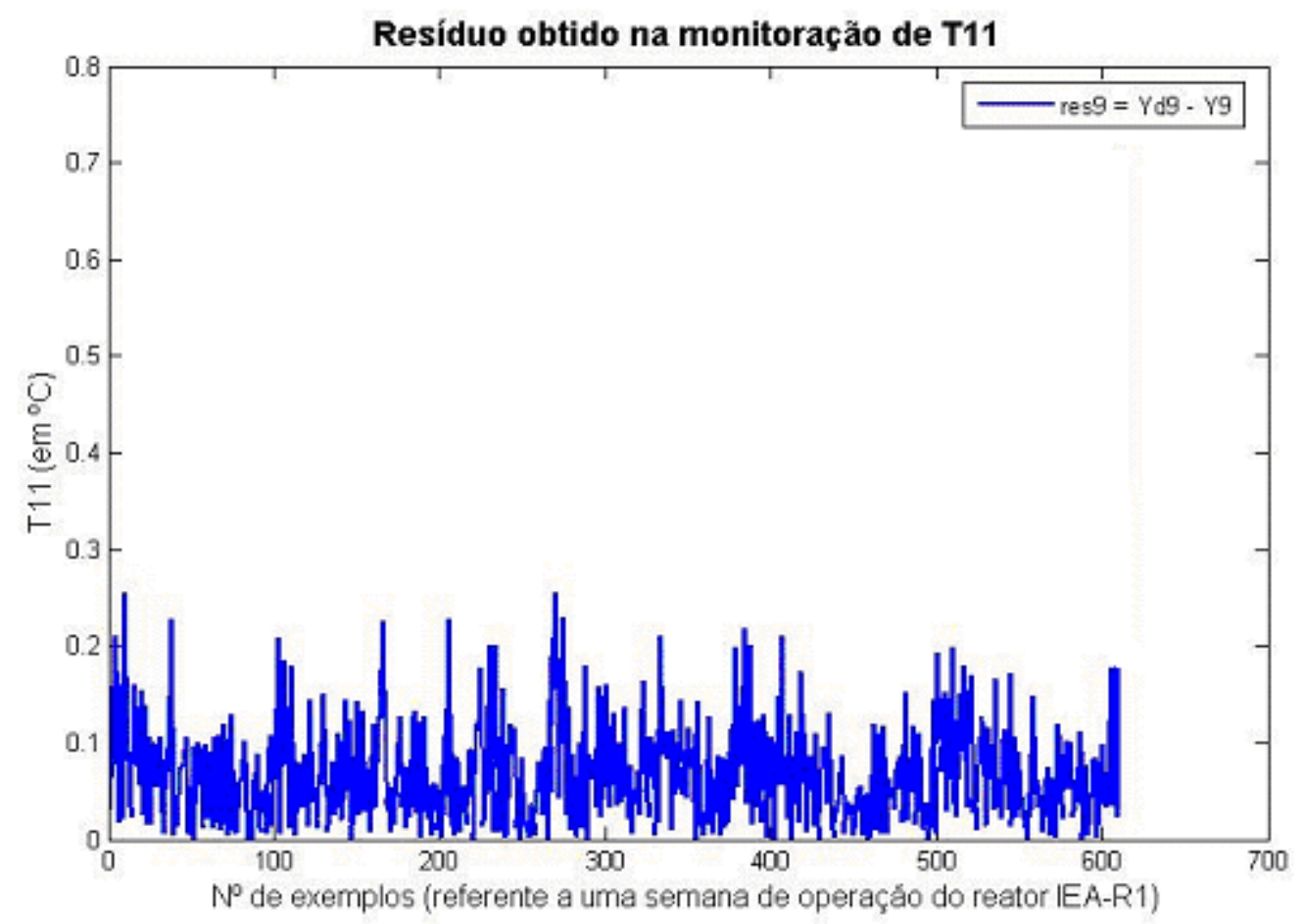

Figura 34. Resíduo da rede com 9 neurônios 


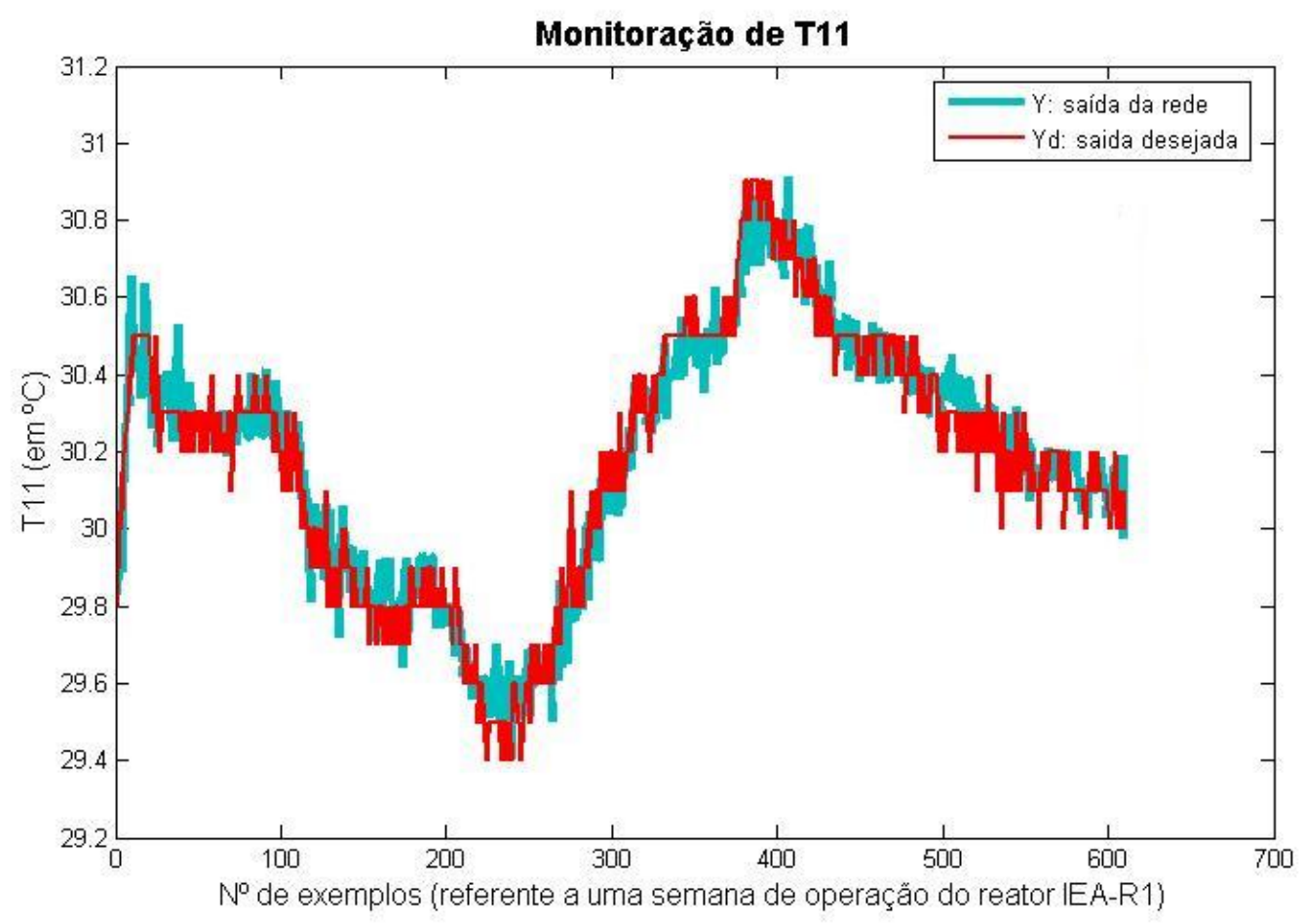

Figura 35. Saída desejada comparada à saída da rede com 9 neurônios na camada oculta

Como pode ser visto na Figura 35, foram obtidos excelentes resultados no treinamento de uma RNA para a monitoração da variável T11, descrita anteriormente. Os resíduos obtidos foram menores que $0,3{ }^{\circ} \mathrm{C}$, como pode ser visto na Figura 34 .

- Monitoração de T12

Para a monitoração desta variável, foram utilizadas as seguintes variáveis: T3, T4, T10, T11, F1M3, F3M3 e N2. A rede que apresentou a menor Energia do Erro (En) foi a rede com quatro (4) neurônios na camada oculta. O valor da Energia do Erro (En) foi $8,82605 \cdot 10^{-3}$. A Figura 36 apresenta o resíduo desta rede, calculado através da equação (19).

A Figura 37 mostra as saídas da rede (Y) e as desejadas (Yd), da rede com 4 neurônios na camada oculta. 


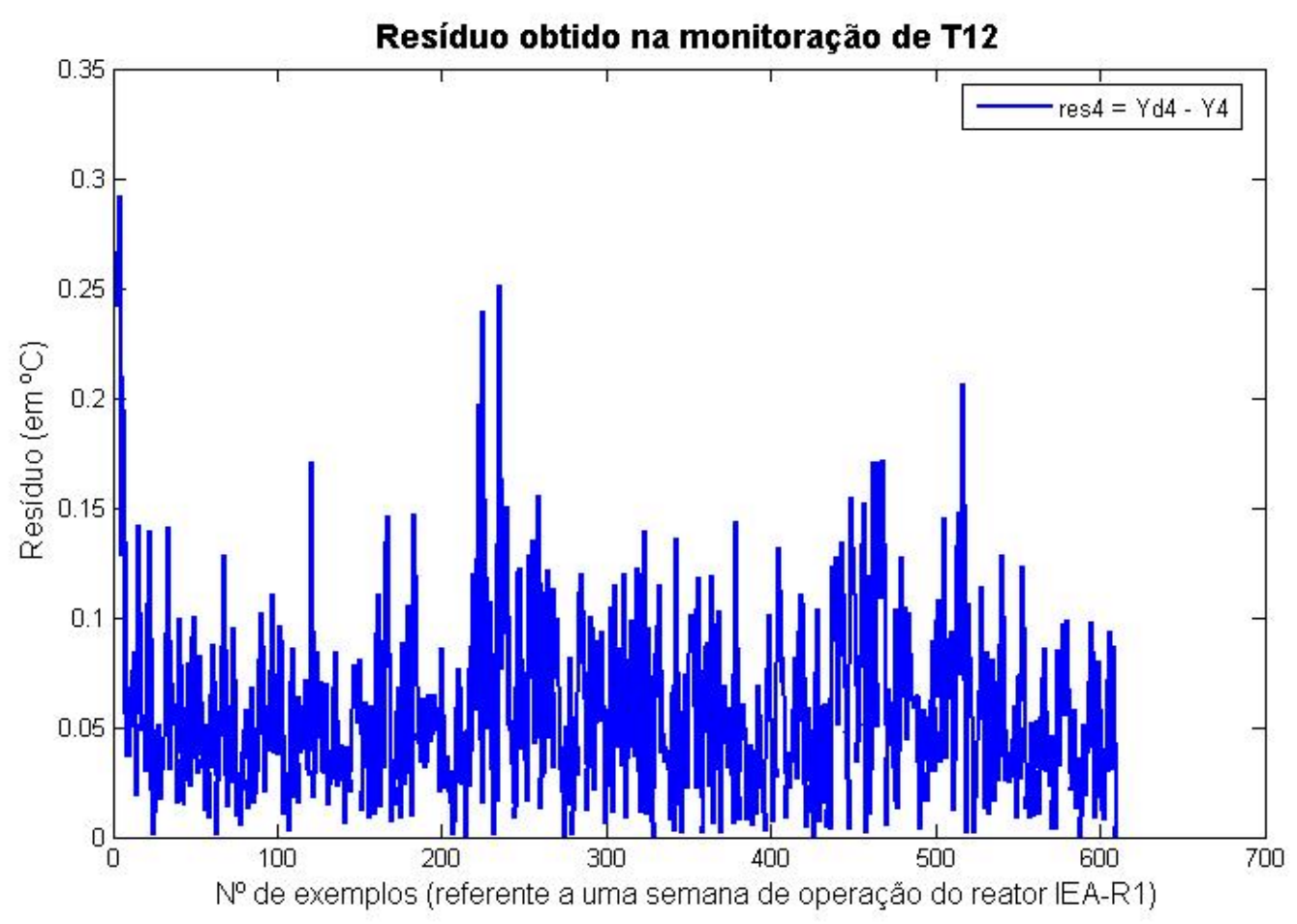

Figura 36. Resíduo da rede com 4 neurônios

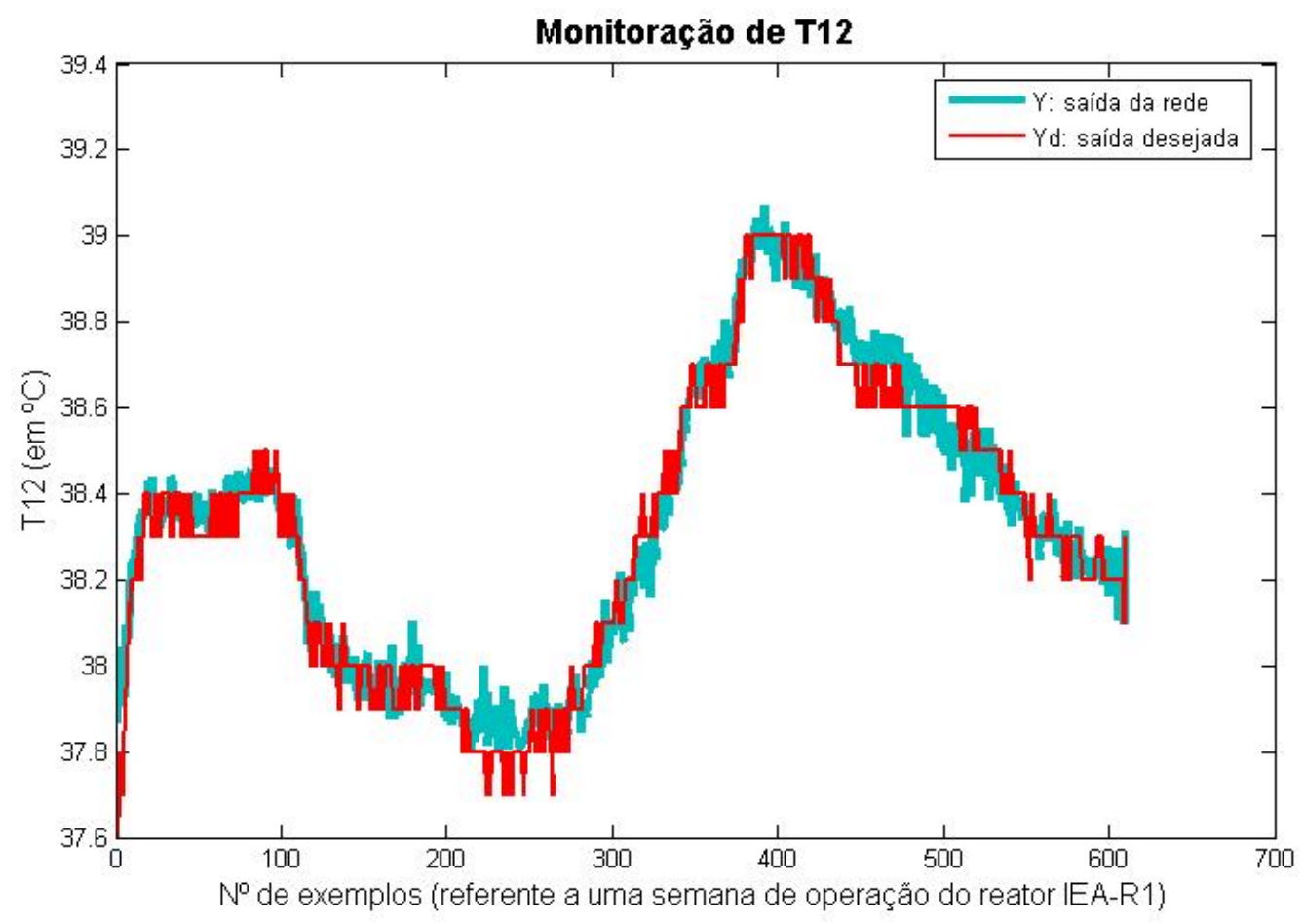

Figura 37. Saída desejada comparada à saída da rede com 4 neurônios na camada oculta

Como pode ser visto na Figura 37, foram obtidos excelentes resultados no treinamento de uma RNA para a monitoração da variável T12, descrita anteriormente. Os resíduos obtidos foram menores que $0,15^{\circ} \mathrm{C}$, como pode ser visto na Figura 36 . 


\subsubsection{Monitoração da Taxa de Dose}

Após o estudo realizado com as variáveis de potência, temperatura e vazão, decidiu-se incluir a variável taxa de dose, pois a obtenção do seu valor é complexa, visto que deve considerar todos os caminhos percorridos desde sua emissão no núcleo do reator, passando pelas estruturas dos elementos combustíveis, piscina, saguão do reator, etc, até atingir os detectores de radiação. No caso das variáveis de processo, as equações de transferência de calor são conhecidas e relativamente simples de ser obtidas.

Para a monitoração desta variável, foram utilizadas as seguintes variáveis: T3, T4, T10, T11, T12 F1M3, F3M3 e N2. A monitoração da taxa de dose foi realizada após o estabelecimento de um modelo de monitoração, onde se decidiu acrescentar uma variável de dose para estudar o comportamento deste modelo e realizar o treinamento de uma RNA para verificar a Energia do Erro (En) obtida. A rede que apresentou a menor Energia do Erro (En) foi a rede com 4 neurônios na camada oculta. O valor da Energia do Erro (En) foi $8,76471 \cdot 10^{-2}$. A Figura 38 apresenta o resíduo desta rede, calculado através da equação (19). A Figura 39 mostra as saídas da rede (Y) e as desejadas (Yd), da rede com 4 neurônios na camada oculta.

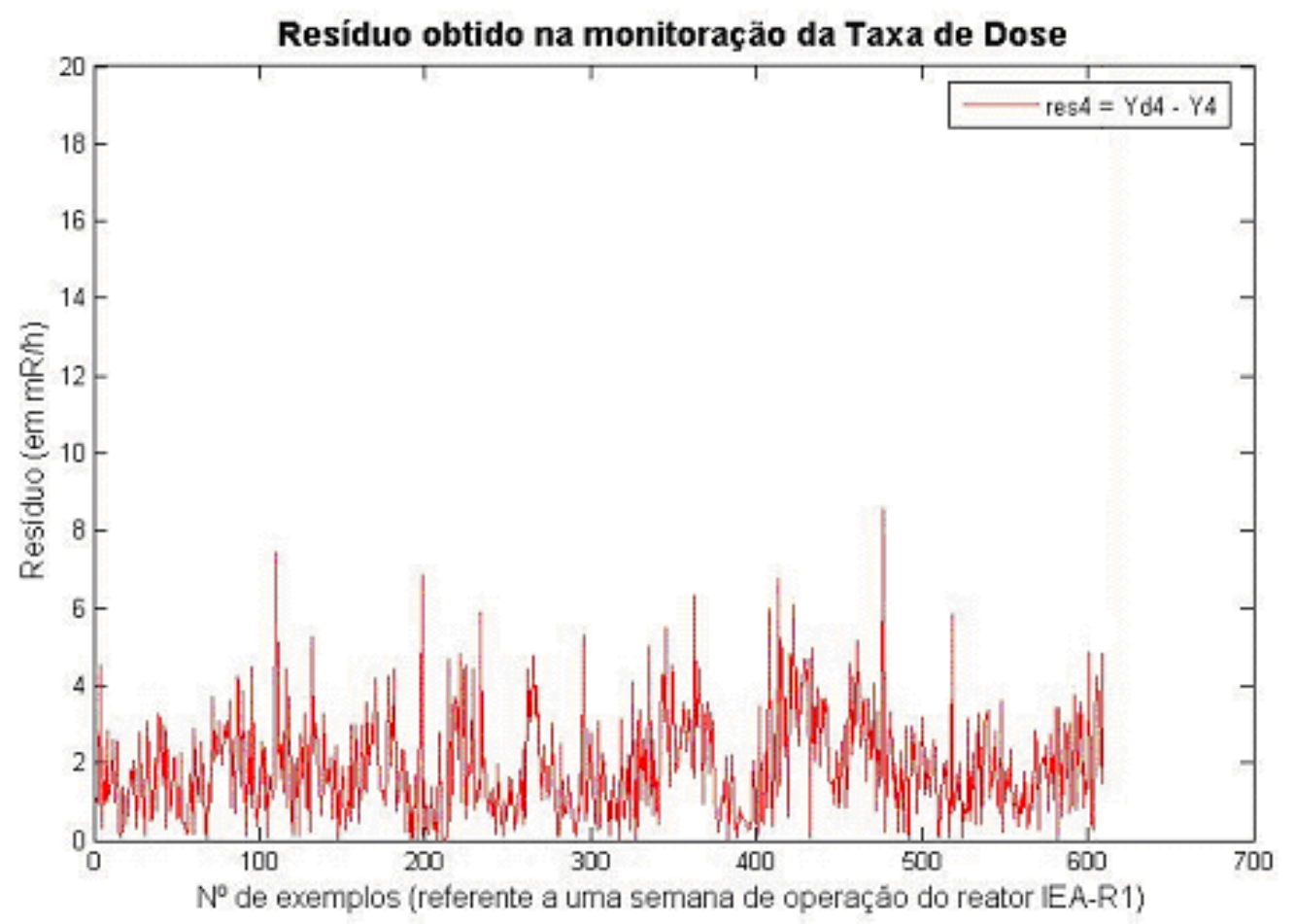

Figura 38. Resíduo da rede com 4 neurônios 


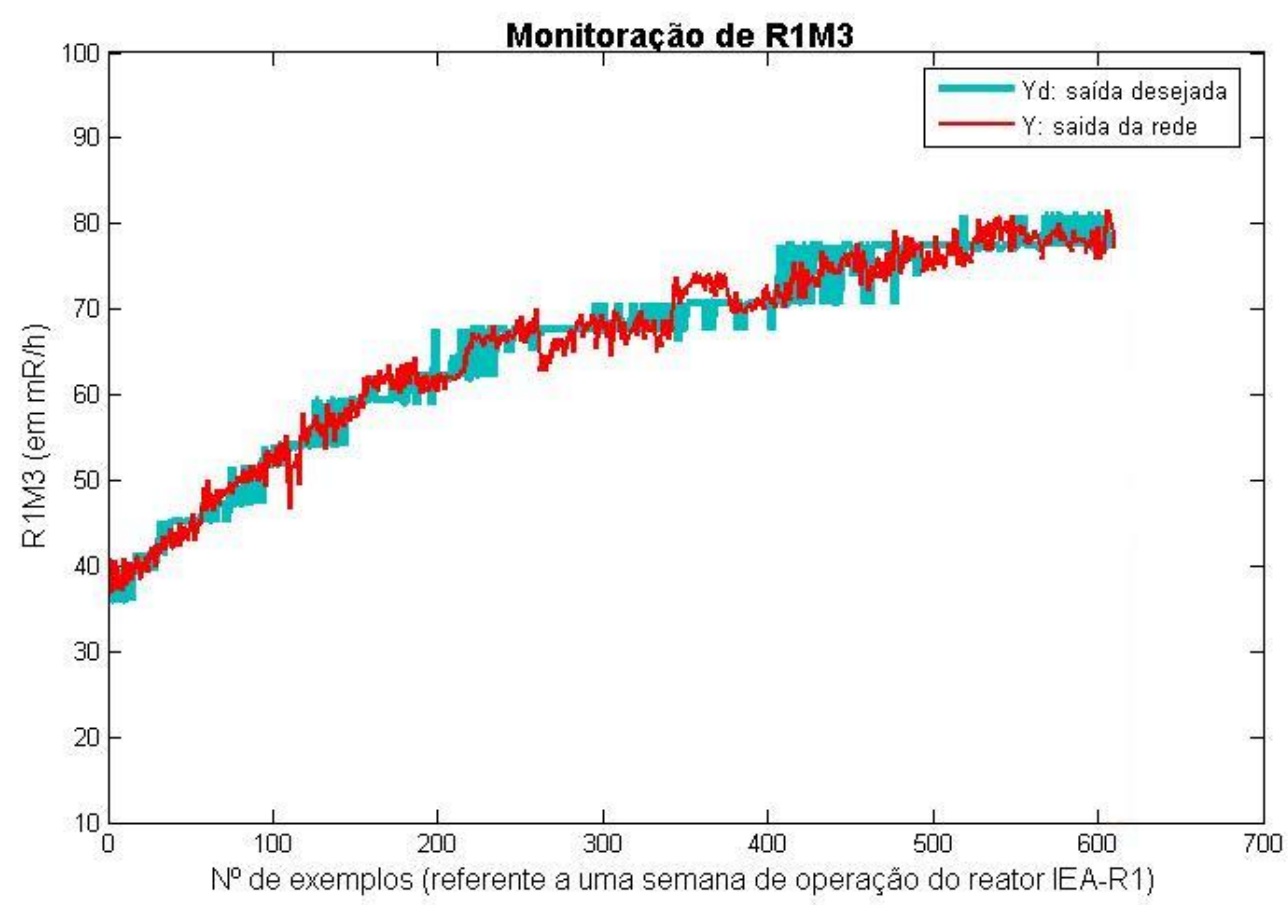

Figura 39. Saída desejada comparada à saída da rede com 4 neurônios na camada oculta

Como pode ser visto na Figura 39, foram obtidos bons resultados no treinamento de uma RNA para a monitoração da variável R1M3, descrita anteriormente. Os resíduos obtidos são da ordem de aproximadamente $4 \mathrm{mR} / \mathrm{h}$ como pode ser visto na Figura 38. Além disso, os resultados obtidos mostram a necessidade de estudar a relação da variável R1M3 com as outras variáveis do SAD, para melhorar o desempenho da RNA para a monitoração desta variável.

\subsubsection{Análise dos resultados com dados de operação do reator}

A Tabela 14 apresenta todos os resultados obtidos durante o treinamento das Redes Neurais Artificiais para a monitoração das variáveis descritas anteriormente.

Tabela 14. Resultados obtidos durante o treinamento das RNA's

\begin{tabular}{|c|c|c|}
\hline Variáveis & $\mathbf{N}^{0}$ de neurônios & Energia do erro (Em) \\
\hline \multirow{6}{*}{ N2 } & 1 & $8,13134 \cdot 10^{-3}$ \\
\hline & 2 & $8,42146 \cdot 10^{-3}$ \\
\hline & 3 & $9,46523 \cdot 10^{-3}$ \\
\hline & 4 & $9,59264 \cdot 10^{-3}$ \\
\hline & 5 & $8,02234 \cdot 10^{-3}$ \\
\hline & 6 & $8,85603 \cdot 10^{-3}$ \\
\hline
\end{tabular}




\begin{tabular}{|c|c|c|}
\hline Variáveis & $\mathrm{N}^{0}$ de neurônios & Energia do erro (Em) \\
\hline \multirow{4}{*}{$\mathrm{N} 2$} & 7 & $8,84974 \cdot 10^{-3}$ \\
\hline & 8 & $8,97393 \cdot 10^{-3}$ \\
\hline & 9 & $9,98449 \cdot 10^{-3}$ \\
\hline & 10 & $9,55392 \cdot 10^{-3}$ \\
\hline \multirow{10}{*}{$\mathrm{T} 3$} & 1 & $9,91515 \cdot 10^{-3}$ \\
\hline & 2 & $9,98657 \cdot 10^{-3}$ \\
\hline & 3 & $9,93382 \cdot 10^{-3}$ \\
\hline & 4 & $9,23656 \cdot 10^{-3}$ \\
\hline & 5 & $9,47529 \cdot 10^{-3}$ \\
\hline & 6 & $9,60226 \cdot 10^{-3}$ \\
\hline & 7 & $9,99466 \cdot 10^{-3}$ \\
\hline & 8 & $9,66867 \cdot 10^{-3}$ \\
\hline & 9 & $9,21064 \cdot 10^{-3}$ \\
\hline & 10 & $9,994 \cdot 10^{-3}$ \\
\hline \multirow{10}{*}{ T4 } & 1 & $9,95272 \cdot 10^{-3}$ \\
\hline & 2 & $9,92185 \cdot 10^{-3}$ \\
\hline & 3 & $7,94949 \cdot 10^{-3}$ \\
\hline & 4 & $8,12816 \cdot 10^{-3}$ \\
\hline & 5 & $7,26921 \cdot 10^{-3}$ \\
\hline & 6 & $9,35324 \cdot 10^{-3}$ \\
\hline & 7 & $9,45752 \cdot 10^{-3}$ \\
\hline & 8 & $9,40197 \cdot 10^{-3}$ \\
\hline & 9 & $9,66428 \cdot 10^{-3}$ \\
\hline & 10 & $9,32883 \cdot 10^{-3}$ \\
\hline \multirow{10}{*}{$\mathrm{T} 10$} & 1 & $9,97569 \cdot 10^{-3}$ \\
\hline & 2 & $9,96781 \cdot 10^{-3}$ \\
\hline & 3 & $9,98853 \cdot 10^{-3}$ \\
\hline & 4 & $9,80417 \cdot 10^{-3}$ \\
\hline & 5 & $9,80624 \cdot 10^{-3}$ \\
\hline & 6 & $9,71745 \cdot 10^{-3}$ \\
\hline & 7 & $9,63227 \cdot 10^{-3}$ \\
\hline & 8 & $9,68202 \cdot 10^{-3}$ \\
\hline & 9 & $9,46129 \cdot 10^{-3}$ \\
\hline & 10 & $9,91418 \cdot 10^{-3}$ \\
\hline \multirow{6}{*}{ T11 } & 5 & $9,97198 \cdot 10^{-3}$ \\
\hline & 6 & $9,99382 \cdot 10^{-3}$ \\
\hline & 7 & $9,72394 \cdot 10^{-3}$ \\
\hline & 8 & $9,77966 \cdot 10^{-3}$ \\
\hline & 9 & $9,65393 \cdot 10^{-3}$ \\
\hline & 10 & $9,99679 \cdot 10^{-3}$ \\
\hline \multirow{6}{*}{ T12 } & 1 & $9,51213 \cdot 10^{-3}$ \\
\hline & 2 & $9,84741 \cdot 10^{-3}$ \\
\hline & 3 & $9,88841 \cdot 10^{-3}$ \\
\hline & 4 & $8,82605 \cdot 10^{-3}$ \\
\hline & 5 & $9,187 \cdot 10^{-3}$ \\
\hline & 6 & $9,61793 \cdot 10^{-3}$ \\
\hline
\end{tabular}




\begin{tabular}{|c|c|c|}
\hline Variáveis & $\mathbf{N}^{0}$ de neurônios & Energia do erro (Em) \\
\hline \multirow{4}{*}{ T12 } & 7 & $9,66175 \cdot 10^{-3}$ \\
\hline & 8 & $9,22278 \cdot 10^{-3}$ \\
\hline & 9 & $9,14475 \cdot 10^{-3}$ \\
\hline & 10 & $8,87503 \cdot 10^{-3}$ \\
\hline \multirow{7}{*}{ R1M3 } & 4 & $8,76471 \cdot 10^{-3}$ \\
\hline & 5 & $9,31383 \cdot 10^{-3}$ \\
\hline & 6 & $9,86085 \cdot 10^{-3}$ \\
\hline & 7 & $9,97801 \cdot 10^{-3}$ \\
\hline & 8 & $9,25268 \cdot 10^{-3}$ \\
\hline & 9 & $9,7651 \cdot 10^{-3}$ \\
\hline & 10 & $9,0297 \cdot 10^{-3}$ \\
\hline
\end{tabular}

Através da análise da Tabela 14, pode-se verificar que:

A menor energia do erro foi obtida foi na monitoração da variável T4 (igual a 7.26921e-003);

$\checkmark$ Para as demais variáveis (T3, T7, T10, T11, T12 e N2), os valores são da ordem de $10 \mathrm{e}-03$.

Os resultados obtidos com dados de operação do reator foram excelentes e mostram a importância da aplicação de RNA's na monitoração de falhas em sensores, servindo como um sistema de apoio aos operadores das usinas nucleares. 


\section{DETECÇÃO DE FALHAS}

Após a definição de um modelo para a monitoração das variáveis de processo do reator IEA-R1, as redes que apresentaram os melhores resultados foram testadas com uma base de dados contendo falhas inseridas artificialmente, para simular a descalibração dos termopares, sendo esta detecção implementada usando Redes Neurais Artificiais. Para tanto, foram utilizadas duas bases de dados: uma base de dados com falha gerada pelo modelo teórico e outra contendo dados de operação.

As falhas foram geradas com base nos valores limites de erros, sugeridas pelos fabricantes dos termopares, encontradas em [43]. Esta referência mostra que existem valores limites de erro para termopares padrão e para termopares especiais. No caso do reator IEA-R1, foram considerados os valores limites de erro para termopares especiais, que é $\pm 0,5^{\circ} C$.

Como os valores limites de erro de calibração é $\pm 0,5^{\circ} C$, definiu-se falha como uma diferença de $\pm 1^{\circ} \mathrm{C}$ entre o valor lido e o valor estimado pelas Redes Neurais Artificiais, cujos resíduos foram sempre menores que $\pm 1^{\circ} C$ permitindo tal comparação.

Nos próximos tópicos serão mostrados os resultados obtidos na detecção de Falha nos termopares responsáveis pela leitura das variáveis, T3 e T4, descritas anteriormente.

\subsection{Modelo teórico}

\subsubsection{Detecção de Falha em T3}

A detecção de falha na variável T3 foi realizada da seguinte maneira: foram inseridas falhas artificiais de $+1{ }^{\circ} \mathrm{C}$ e de $-1^{\circ} \mathrm{C}$ no valor calculado (modelo teórico) pelo termopar responsável pela leitura desta variável.

Na Figura 40, pode-se verificar que foi testado um caso onde a falha é de $+1^{\circ} \mathrm{C}$ em T3, onde foi utilizada a rede que apresentou o melhor desempenho no modelo de monitoração desta variável, como pode ser visto no item 6.1.2, que foi uma rede do tipo MLP com 8 neurônios na camada escondida. 
Nesta etapa de detecção, as RNA's foram apenas testadas com uma base de dados contendo falhas, para verificar a capacidade de generalização das redes treinadas na etapa de monitoração.

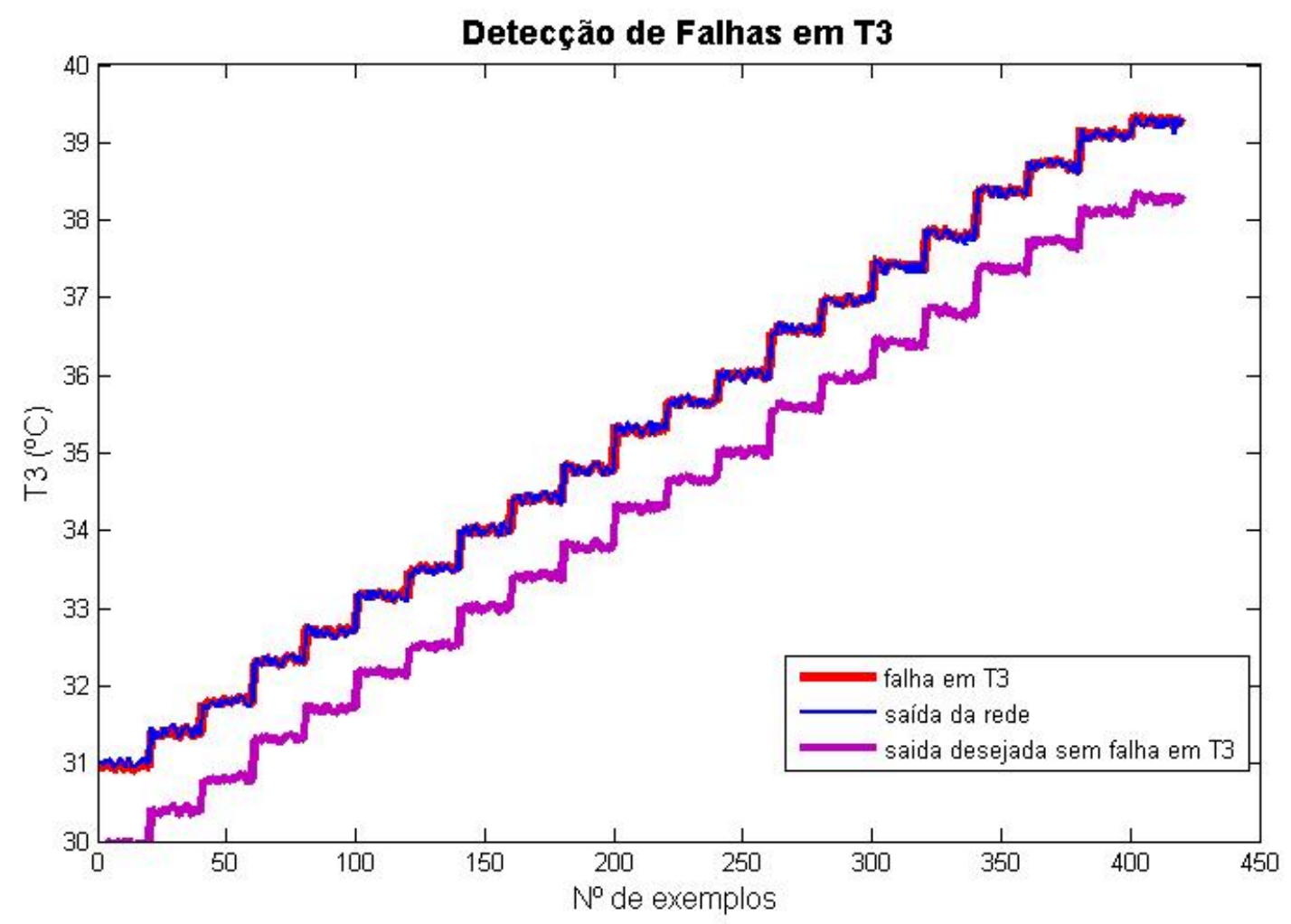

Figura 40. Detecção de falha em T3 - Falha de $+1^{\circ} \mathrm{C}$ em T3

Através da análise da Figura 40, verifica-se que a rede treinada para a monitoração de $\mathrm{T} 3$, quando testada com uma base de dados contendo falha de $+1{ }^{\circ} \mathrm{C}$ no valor lido, é capaz de identificar este desvio, mostrando desta maneira a capacidade de generalização das redes treinadas na monitoração da mesma variável.

Para indicar a presença ou ausência de falha, serão utilizadas as diferenças entre o valor lido e o valor estimado pelas Redes Neurais, sendo que esta diferença recebe o nome de resíduo, calculado através da equação (19). O resíduo será usado na elaboração do Sistema de Diagnóstico de Falhas, que será discutido em detalhes, no capítulo 8.

A Figura 41 apresenta o resíduo obtido na detecção de falha em T3. 


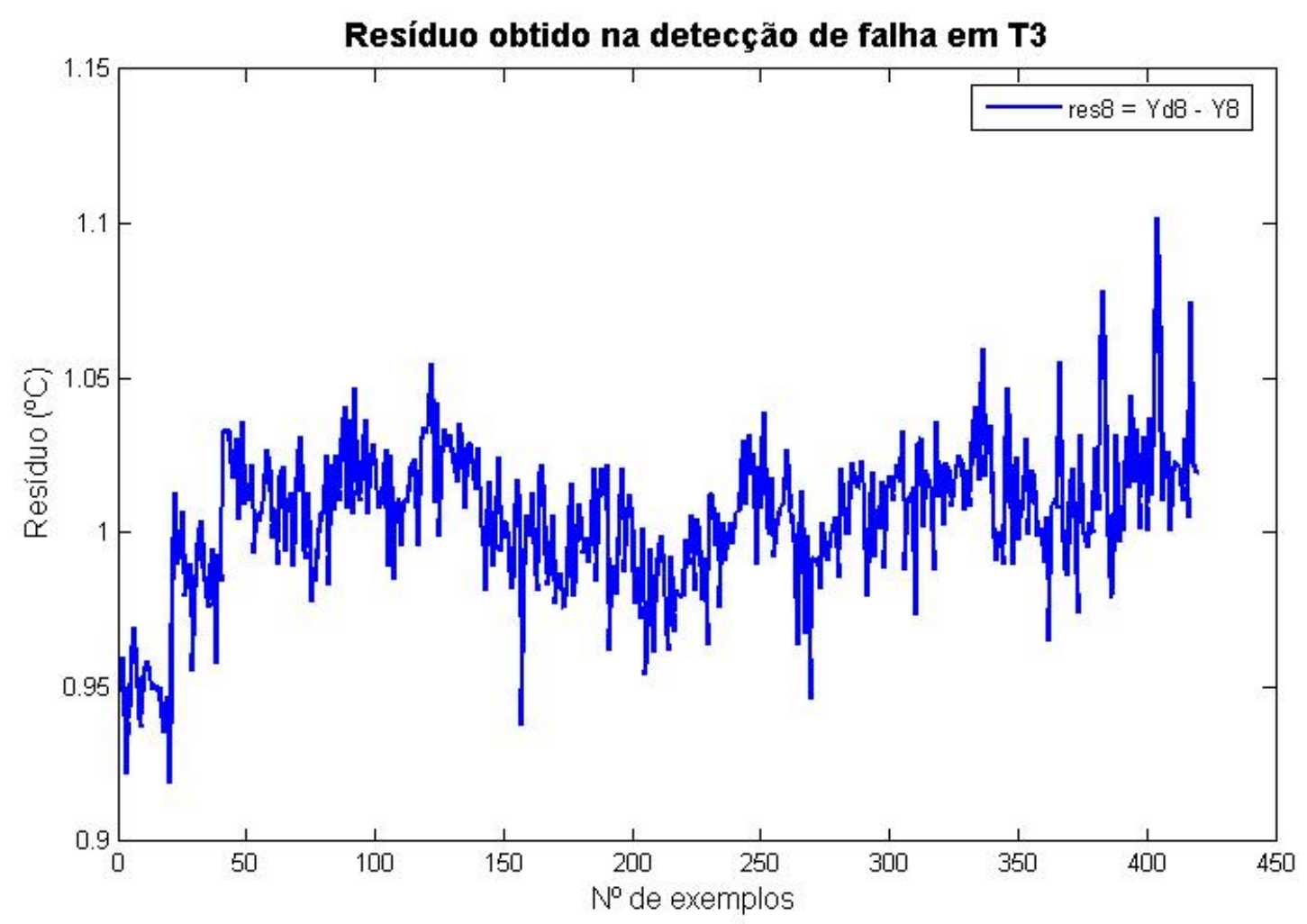

Figura 41. Resíduo obtido na detecção de falha em T3

Comparando a Figura 41 com a Figura 20 do item 6.1.2, pode-se verificar que o resíduo obtido na etapa de detecção é maior do que o resíduo obtido na monitoração, indicando a ocorrência de falha neste termopar, pois o resíduo é maior do que o valor limite de calibração para este termopar que é igual a $\pm 0,5^{\circ} \mathrm{C}$.

$\mathrm{Na}$ Figura 42, verifica-se que foi simulada uma falha de $-1^{\circ} \mathrm{C}$ na variável $\mathrm{T} 3$, para simular a descalibração do termopar quando o mesmo realizar uma leitura de $-1^{\circ} \mathrm{C}$ abaixo do seu valor real de operação.

A Figura 43 mostra o resíduo obtido na detecção de falha em T3, onde se verifica que os resíduos obtidos na etapa de detecção foram maiores do que os obtidos na monitoração, mostrando a ocorrência de uma falha de descalibração, uma vez que os resíduos obtidos são maiores do que os valores limites de calibração. 


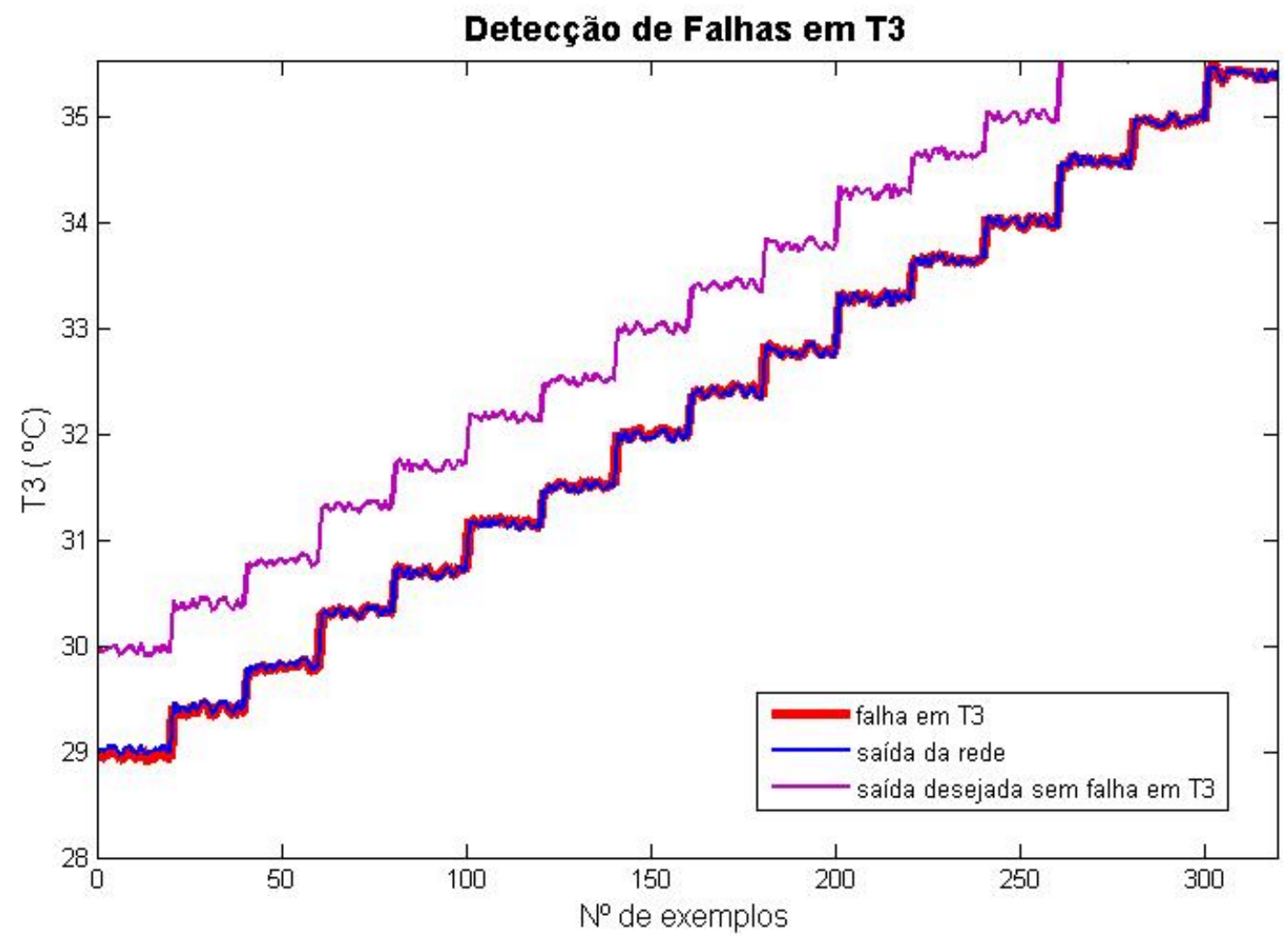

Figura 41. Detecção de falhas em T3 - Falha de $-1^{\circ} \mathrm{C}$ em T3

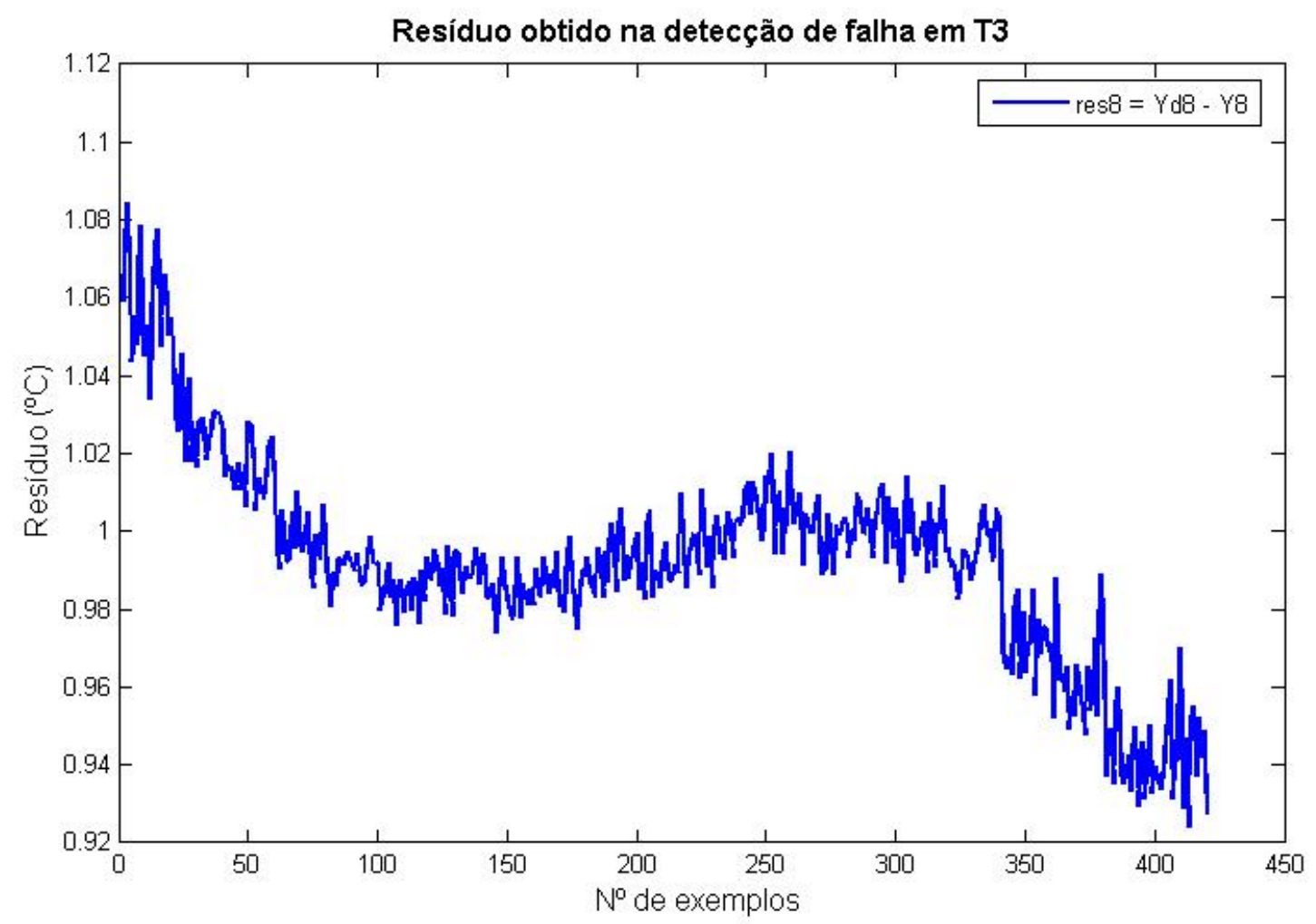

Figura 42. Resíduo obtido na detecção de falha em T3 


\subsubsection{Detecção de Falha em T4}

A detecção na variável T4 foi realizada do mesmo modo que foi feito para T3: foram inseridas falhas artificiais de $+1^{\circ} \mathrm{C}$ e de $-1^{\circ} \mathrm{C}$ no valor lido pelo termopar responsável pela leitura desta variável.

$\mathrm{Na}$ Figura 43, pode-se verificar que foi simulada uma falha de $+1^{\circ} \mathrm{C}$ em T4, através do uso da mesma rede do modelo de monitoração desta variável, como pode ser visto no item 6.1.2, que foi uma rede do tipo MLP com 7 neurônios na camada escondida.

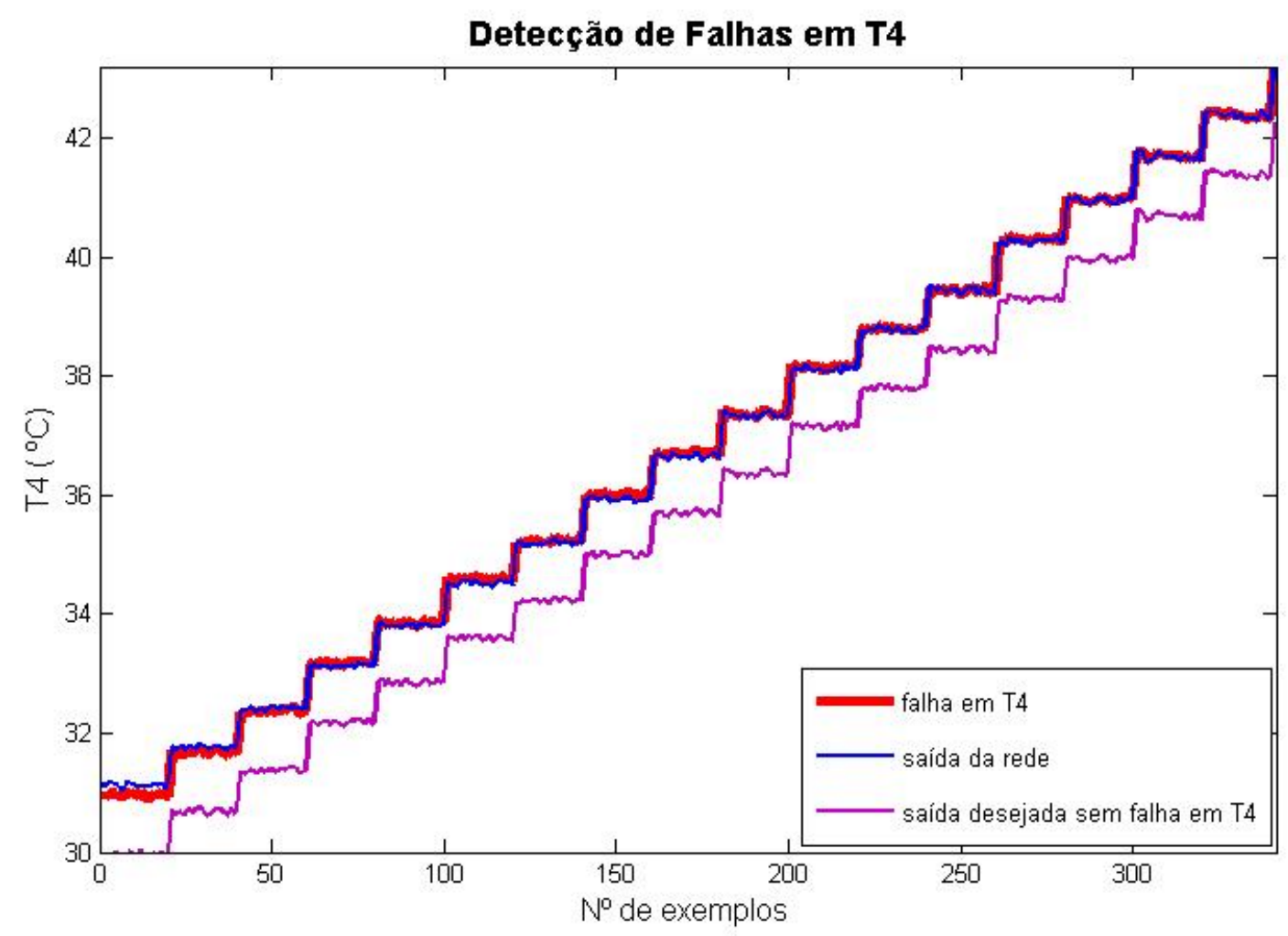

Figura 43. Detecção de Falha em T4 - Falha de $+1^{\circ} \mathrm{C}$ em T4

A Figura 44 mostra o resíduo obtido na detecção de falha em T4, que foi maior do que o resíduo obtido na monitoração desta variável, como pode ser visto na Figura 21. 


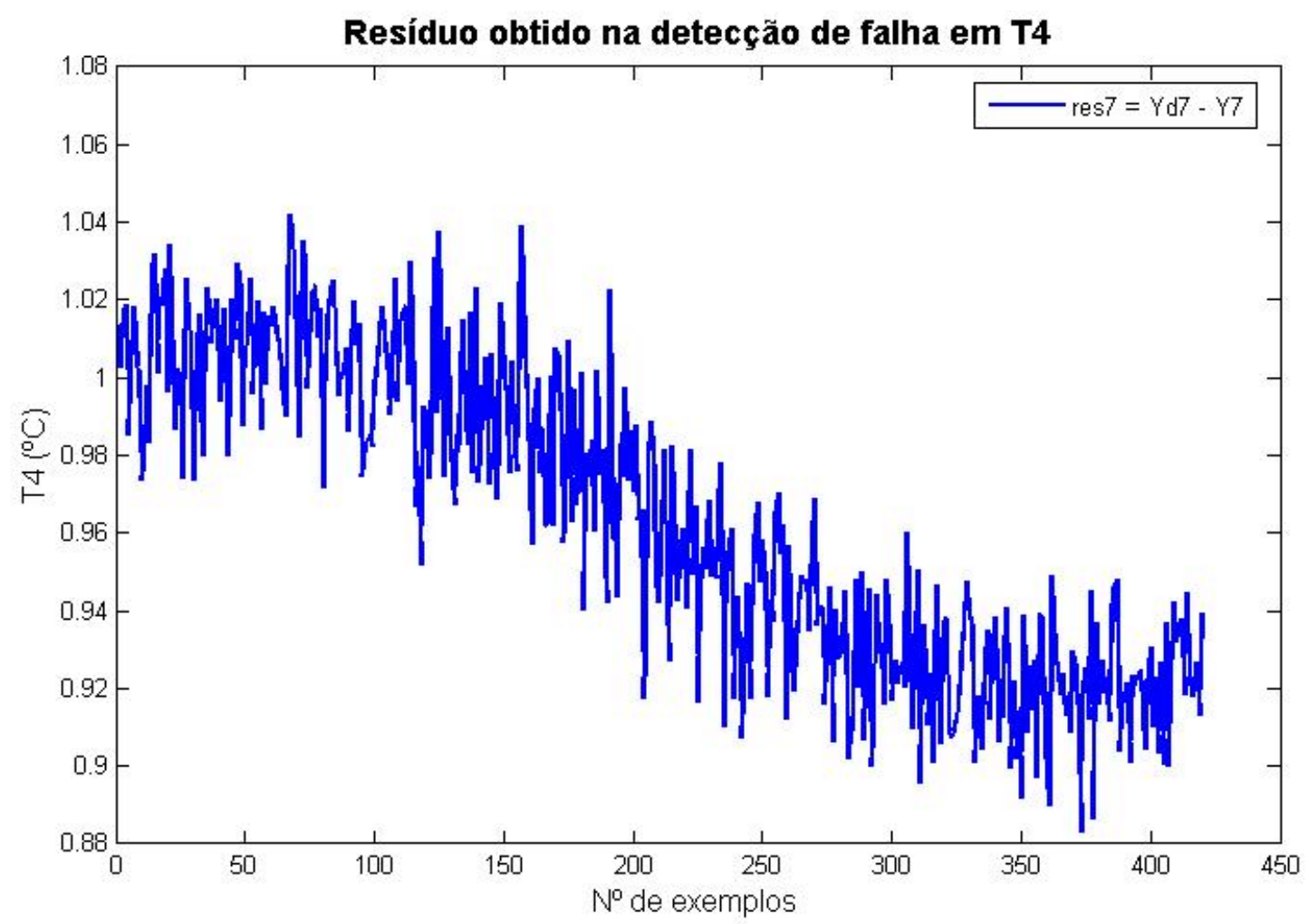

Figura 44. Resíduo obtido na detecção de falha em T4

$\mathrm{Na}$ Figura 45, verifica-se que foi simulada uma falha de $-1^{\circ} \mathrm{C}$ na variável $\mathrm{T} 4$ para simular a presença de falha, quando o valor lido pelo termopar estiver a $-1^{\circ} \mathrm{C}$ abaixo do valor limite de calibração do instrumento.

A Figura 46 mostra o resíduo obtido na detecção de falha em T4, onde os resultados obtidos na detecção são maiores do que os obtidos na monitoração, como pode ser visto na Figura 21, mostrando a presença de falha no termopar, pois o resíduo obtido é maior do que o valor limite de calibração deste instrumento. 


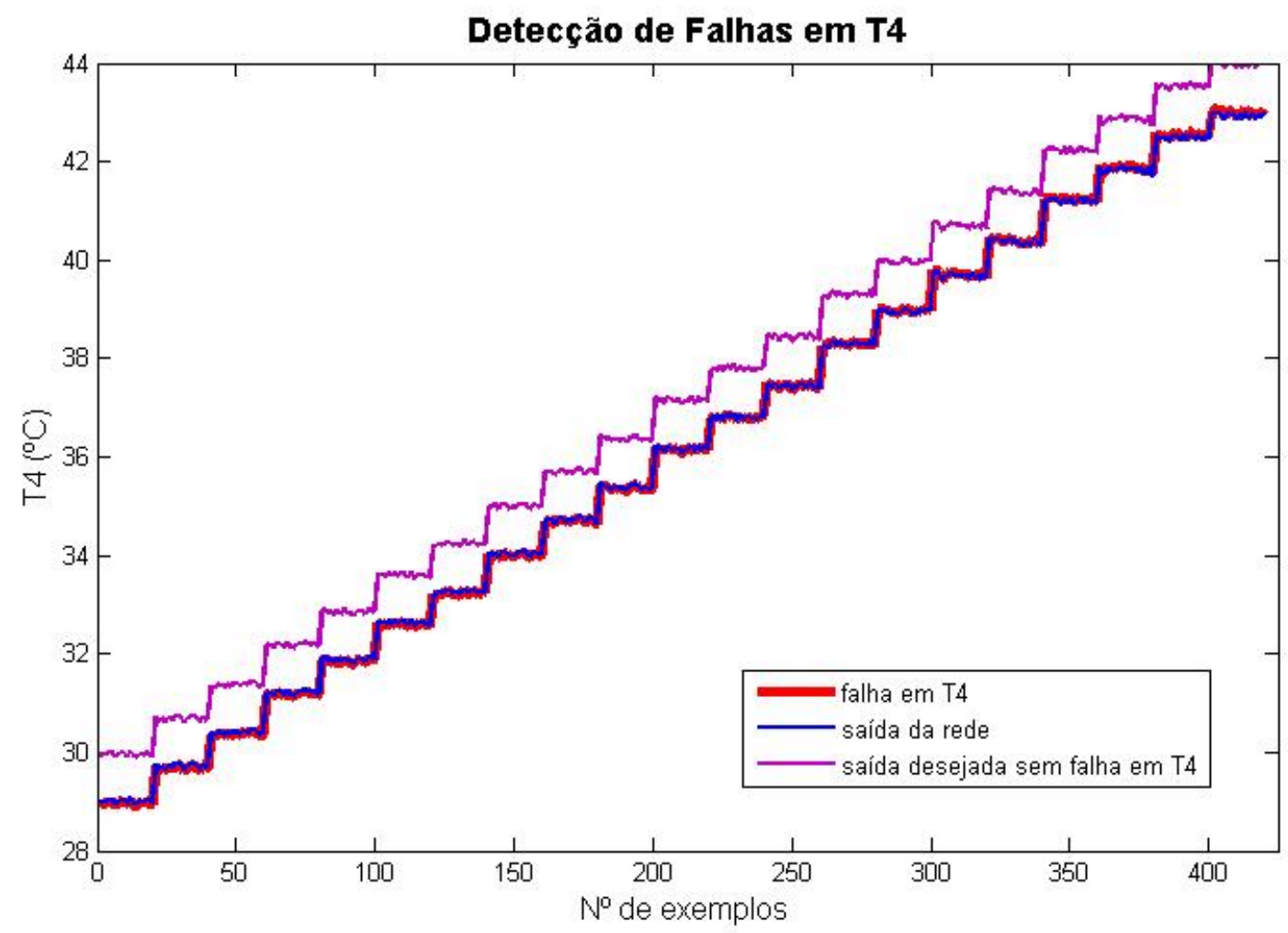

Figura 45. Detecção de falhas em T4 - Falha de $-1^{\circ} \mathrm{C}$ em T4

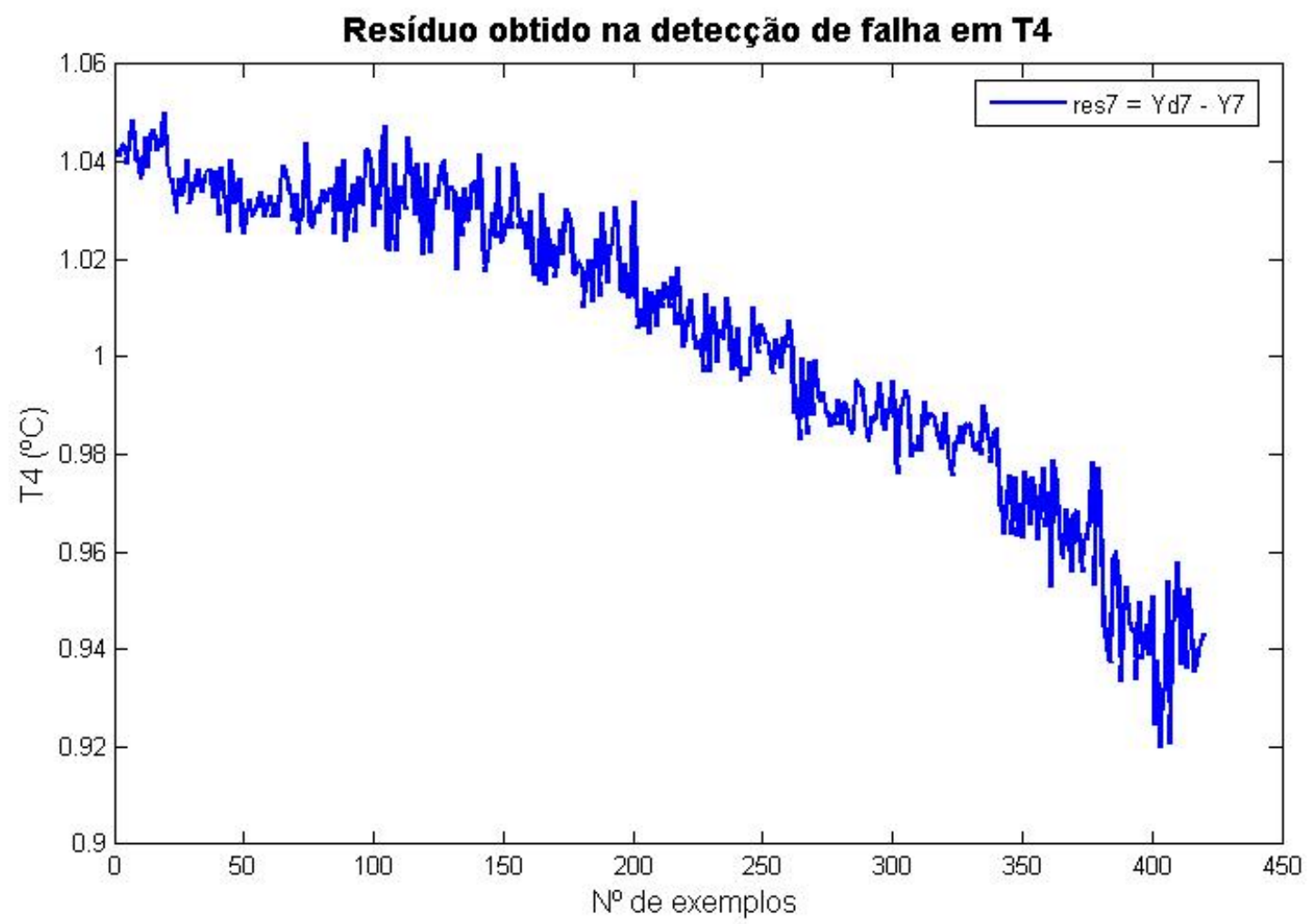

Figura 46. Resíduo obtido na detecção de falha em T4 
Os resultados obtidos usando dados de um modelo teórico mostram a viabilidade de aplicação das Redes Neurais Artificiais na detecção de falhas, pois as mesmas apresentam um excelente desempenho, quando testadas com uma base de dados contendo falhas, que não foi apresentada no treinamento da RNA.

\subsection{Dados de operação do reator IEA-R1}

\subsubsection{Detecção de Falhas em T3}

Após a detecção de falhas usando dados do modelo teórico, foram utilizados dados referentes a uma semana típica de operação do reator IEA-R1 para realizar estudos comparativos entre os resultados obtidos na detecção com dados de um modelo teórico, e os obtidos com dados de operação do reator.

Para realizar a detecção de falha na variável T3, primeiramente foram inseridas falhas artificiais de $+1{ }^{\circ} \mathrm{C}$ no valor lido pelo termopar responsável pela leitura desta variável, que pode ser visto na Figura 47.

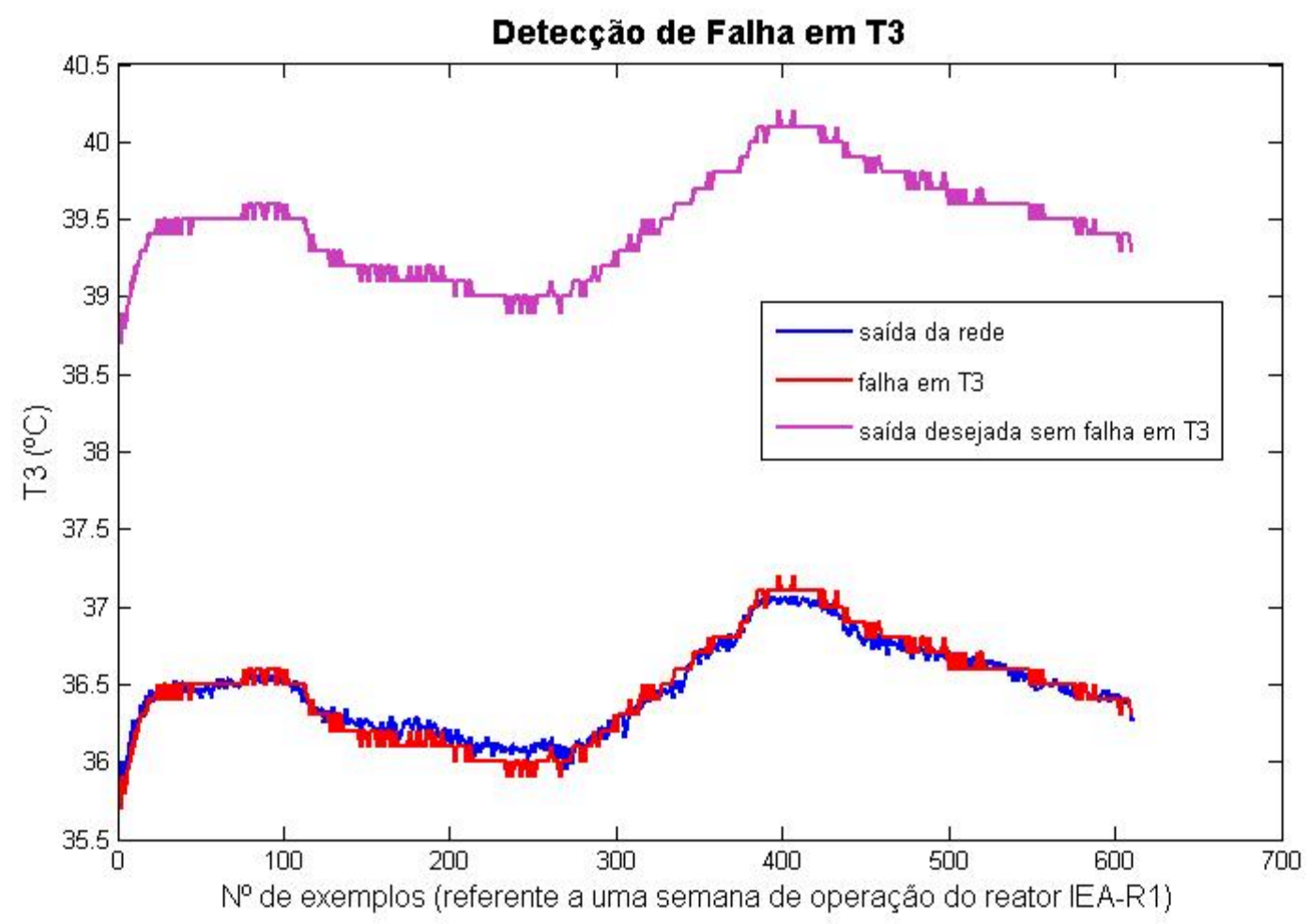

Figura 47. Detecção de falhas em T3 - Falha de $+1^{\circ} \mathrm{C}$ em T3 
A Figura 48 mostra o resíduo obtido na detecção de Falha em T3 que foi maior do que o resíduo obtido na monitoração da mesma variável, como pode ser visto na Figura 28 do item 6.2.2.

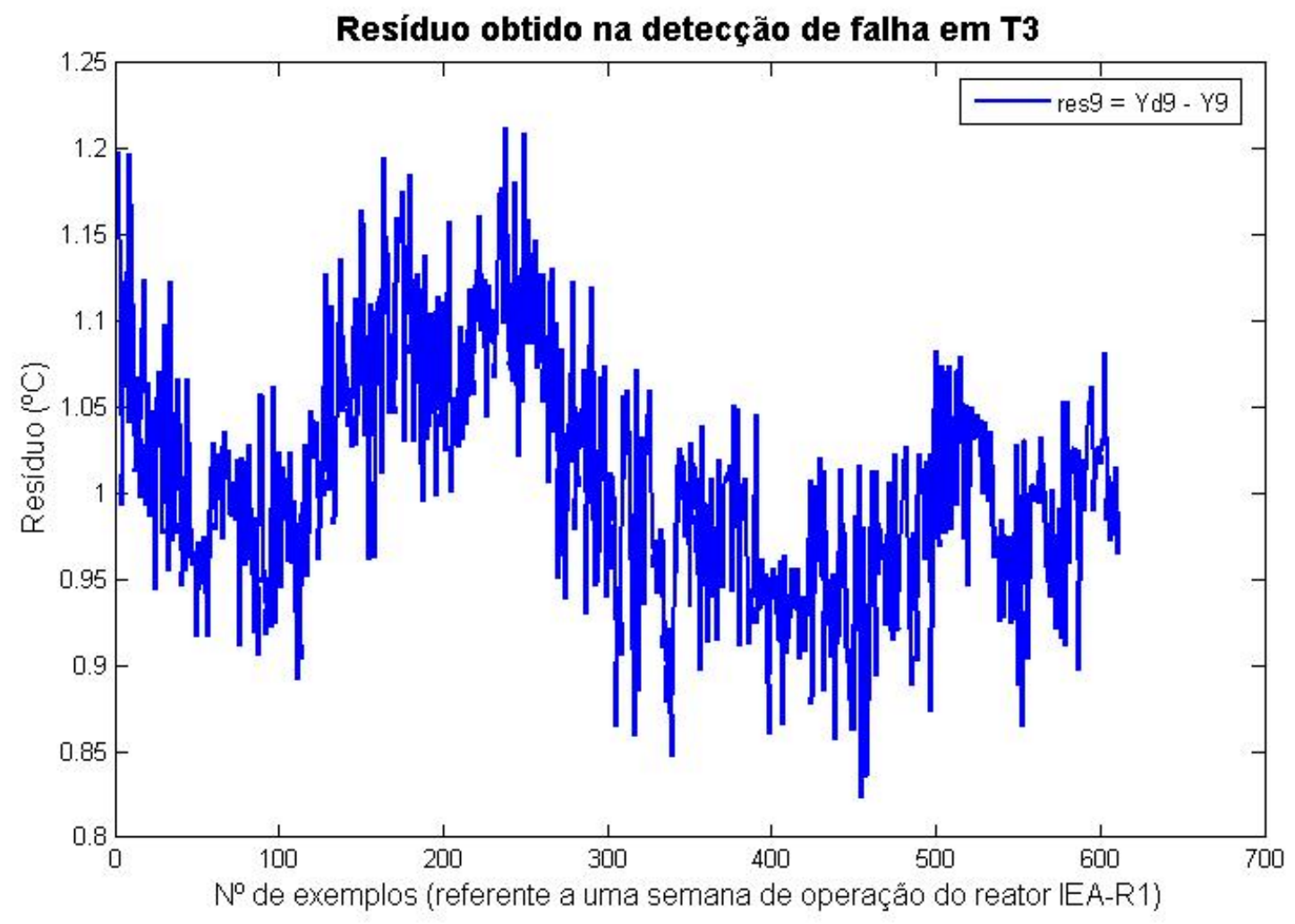

Figura 48. Resíduo obtido na detecção de falha em T3

A Figura 49 mostra a detecção de falha em T3, onde foi simulada uma falha de $-1^{\circ} \mathrm{C}$ na leitura do termopar responsável pela leitura de T3.

Na Figura 50 é mostrado o resíduo obtido na detecção de falha em T3, que foi maior que o obtido na monitoração da mesma variável, como pode ser visto na Figura 28. 


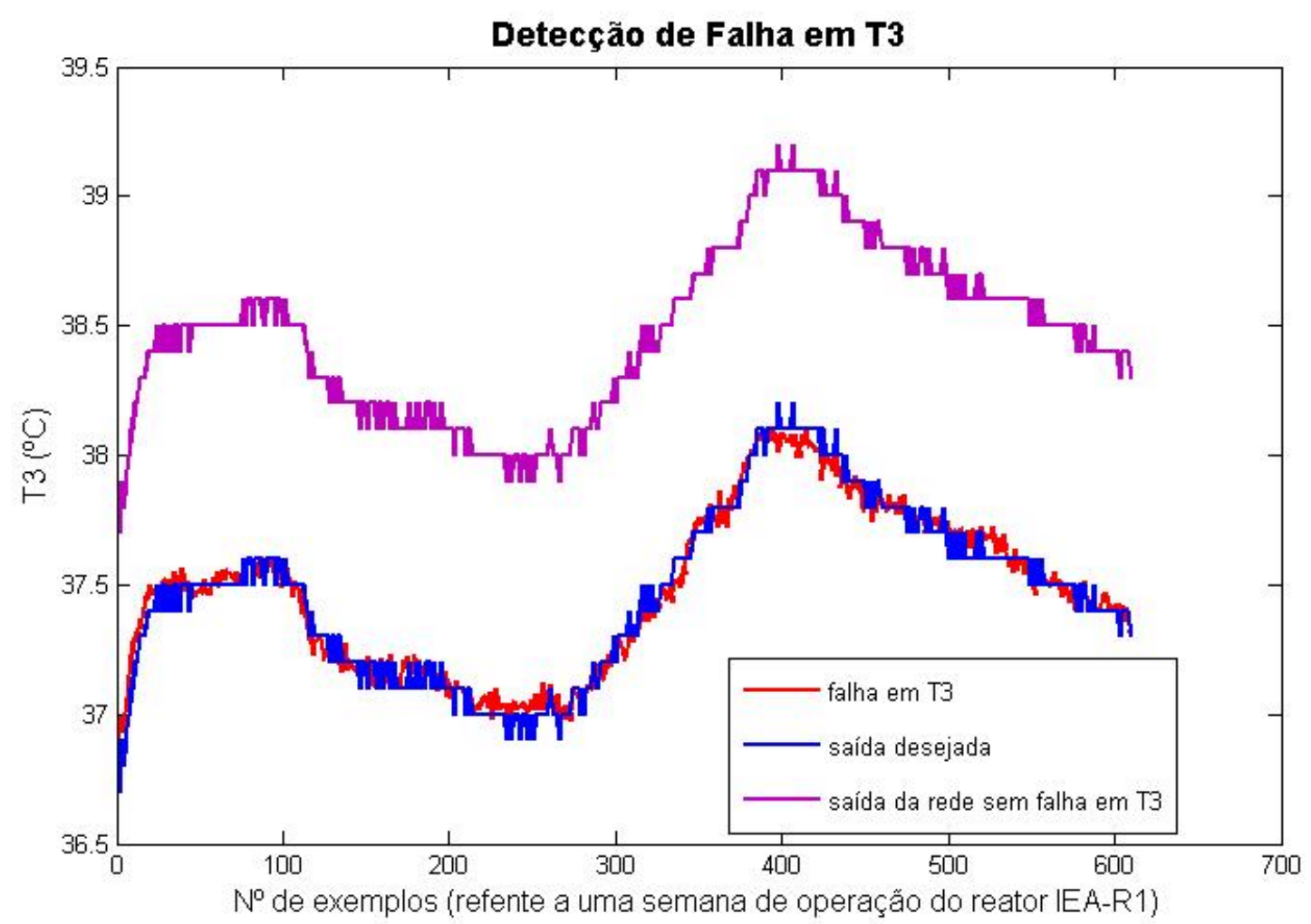

Figura 49. Detecção de falha em T3 - Falha de $-1^{\circ} \mathrm{C}$ em T3

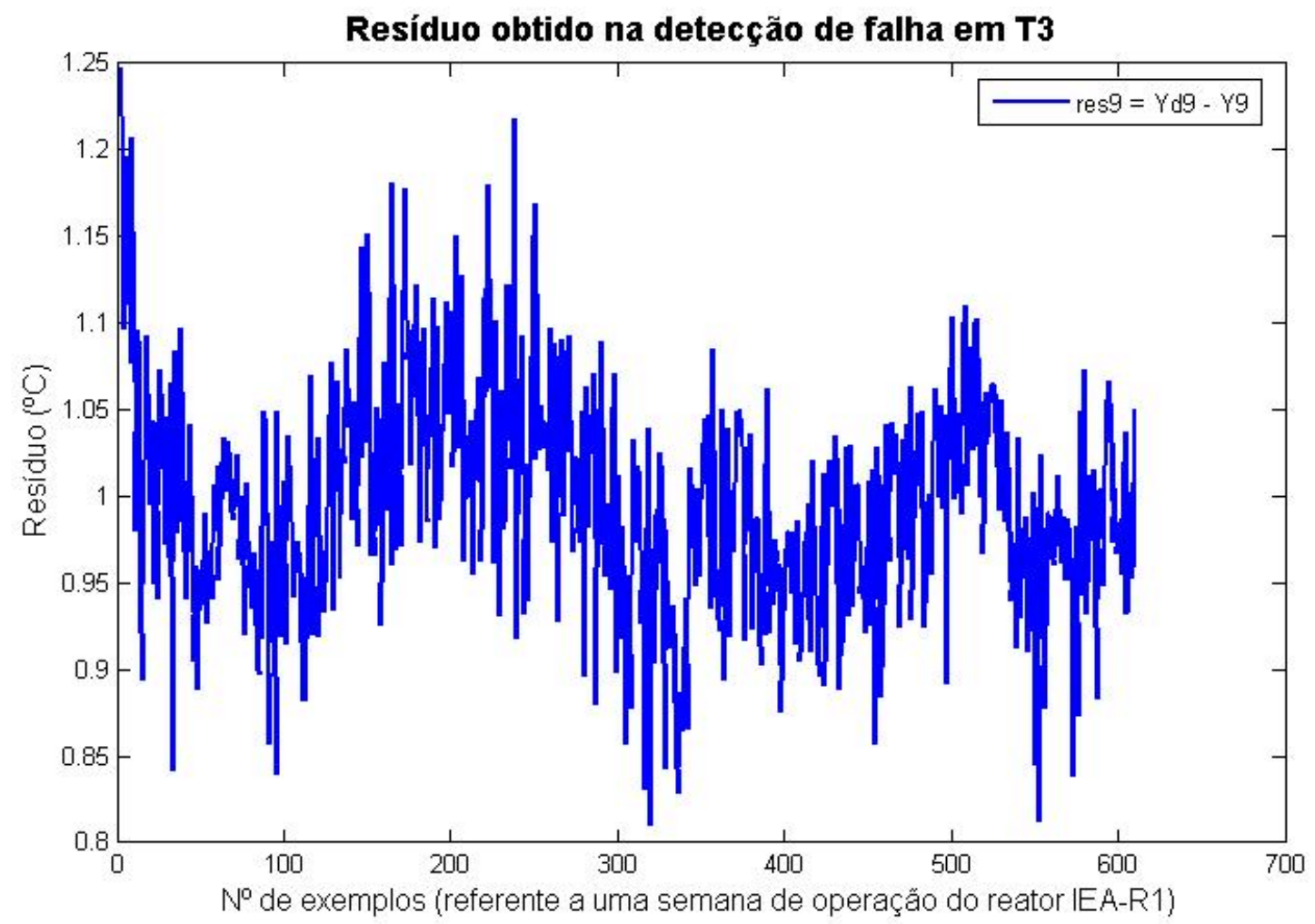

Figura 50. Resíduo obtido na detecção de falha em T3 


\subsubsection{Detecção de Falhas em T4}

A detecção da variável T4 foi realizada da seguinte maneira: foram inseridas falhas artificiais de $+1{ }^{\circ} \mathrm{C}$ e de $-1^{\circ} \mathrm{C}$ no valor lido pelo termopar responsável pela leitura desta variável.

Na Figura 51, pode-se verificar que foi inserida uma falha de $+1{ }^{\circ} \mathrm{C} \mathrm{em} \mathrm{T4}$, na rede escolhida para a monitoração desta variável, como pode ser visto no item 6.2.2, que foi uma rede do tipo MLP com 5 neurônios na camada escondida.

A Figura 52 mostra o resíduo obtido na detecção de falha em T4, que é maior do que o resíduo obtido na monitoração desta variável, como pode ser visto na Figura 30.

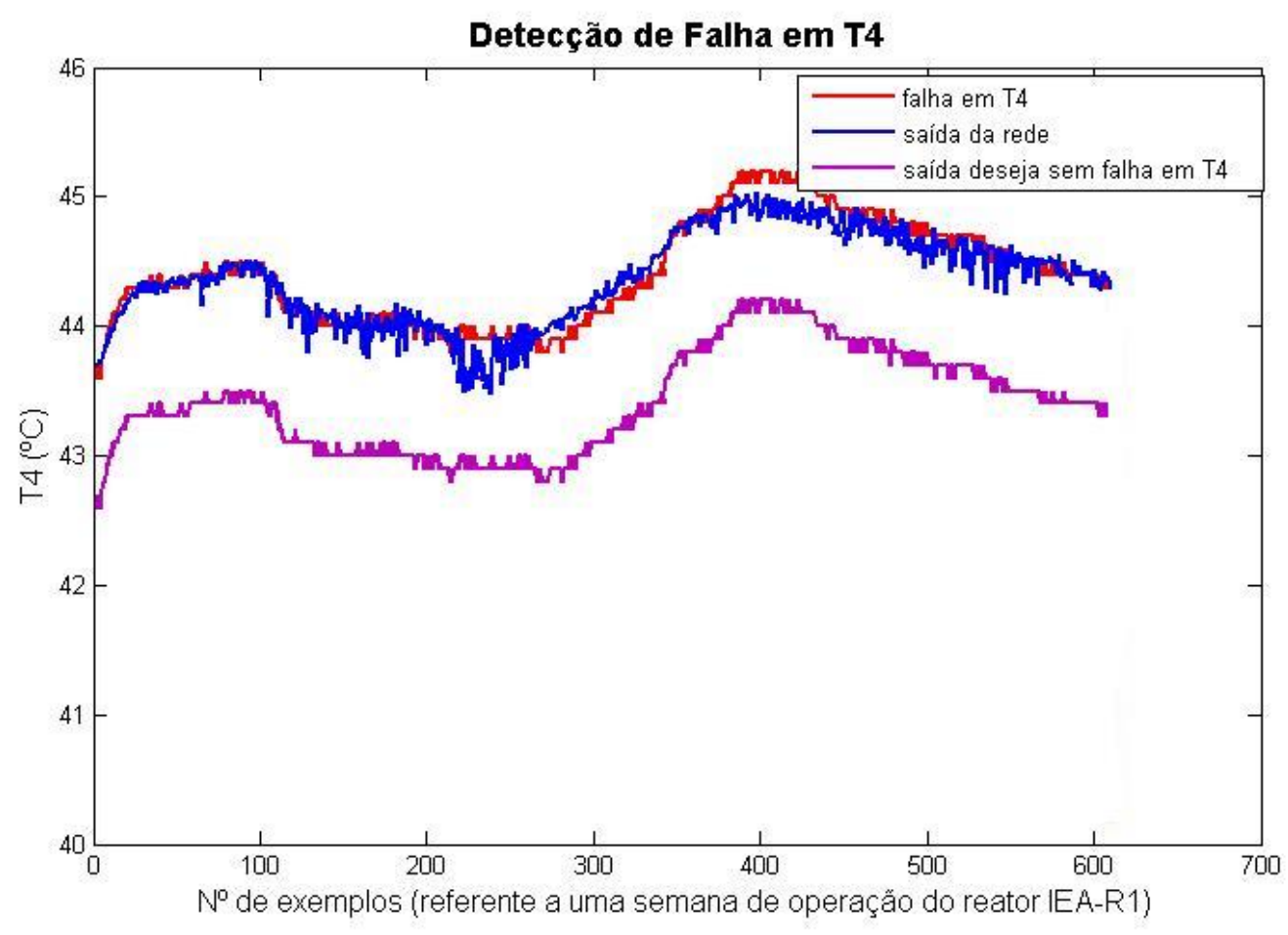

Figura 51. Detecção de falha em T4 - Falha de $+1^{\circ} \mathrm{C}$ em T4 


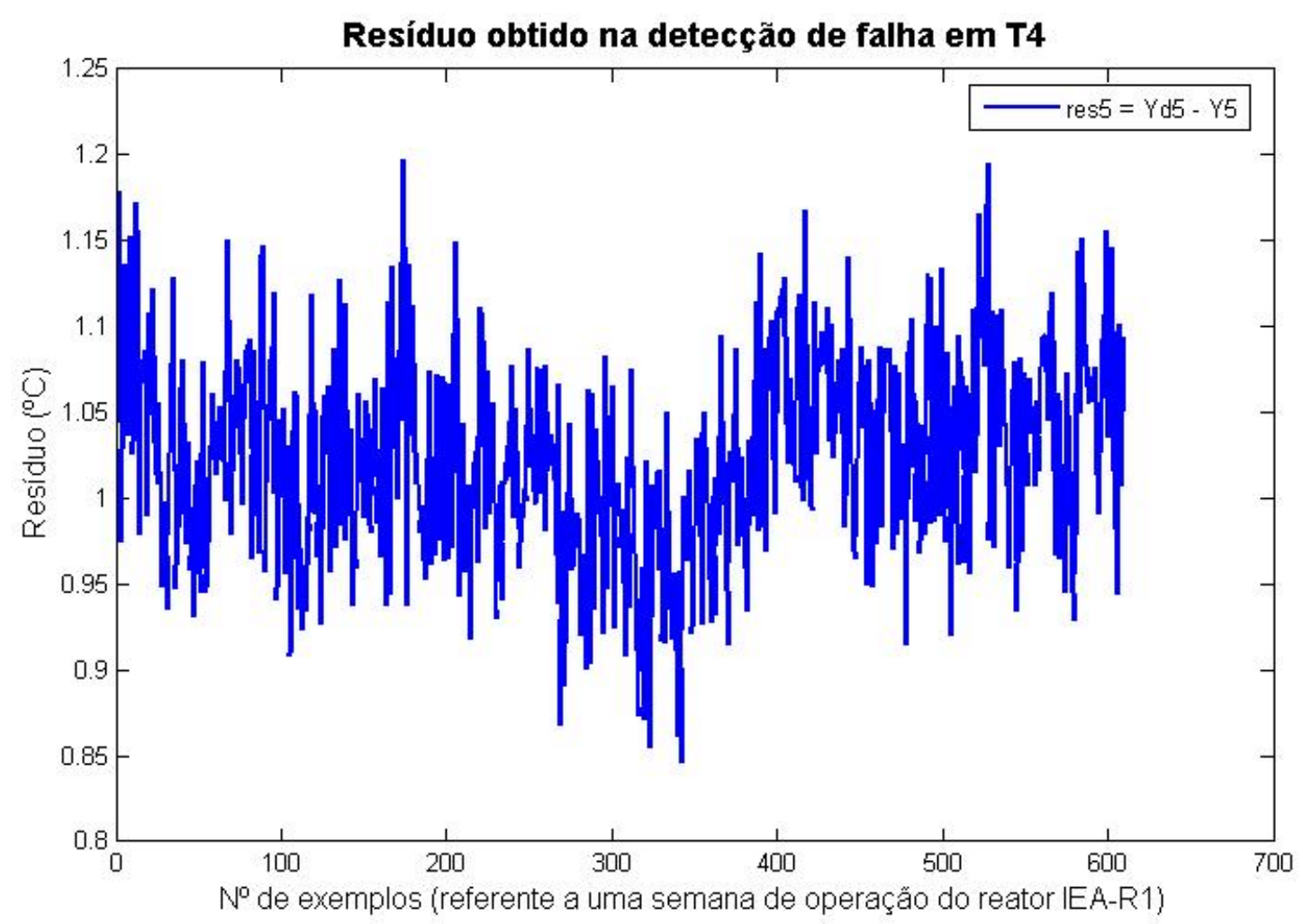

Figura 52. Resíduo obtido na detecção de falha em T4

Na Figura 53 foi simulada uma falha de $-1{ }^{\circ} \mathrm{C}$ abaixo do valor lido pelo termopar responsável pela medida da variável T4.

A Figura 54 mostra o resíduo obtido na detecção de falha em T4 que foi maior do que o obtido na monitoração da mesma variável, como pode ser visto na Figura 30. 


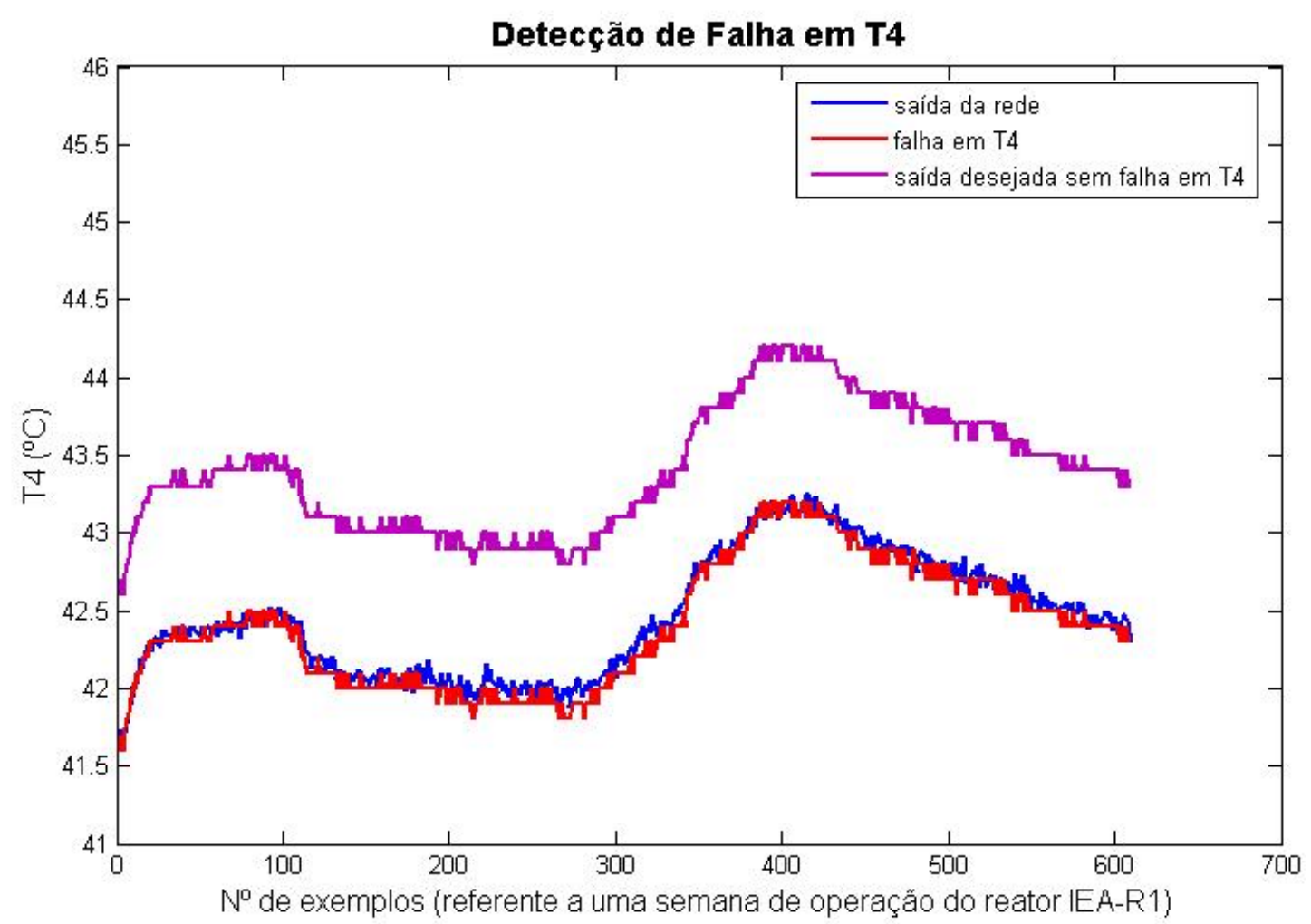

Figura 53. Detecção de falhas em T4 - Falha de $-1^{\circ} \mathrm{C}$ em T4

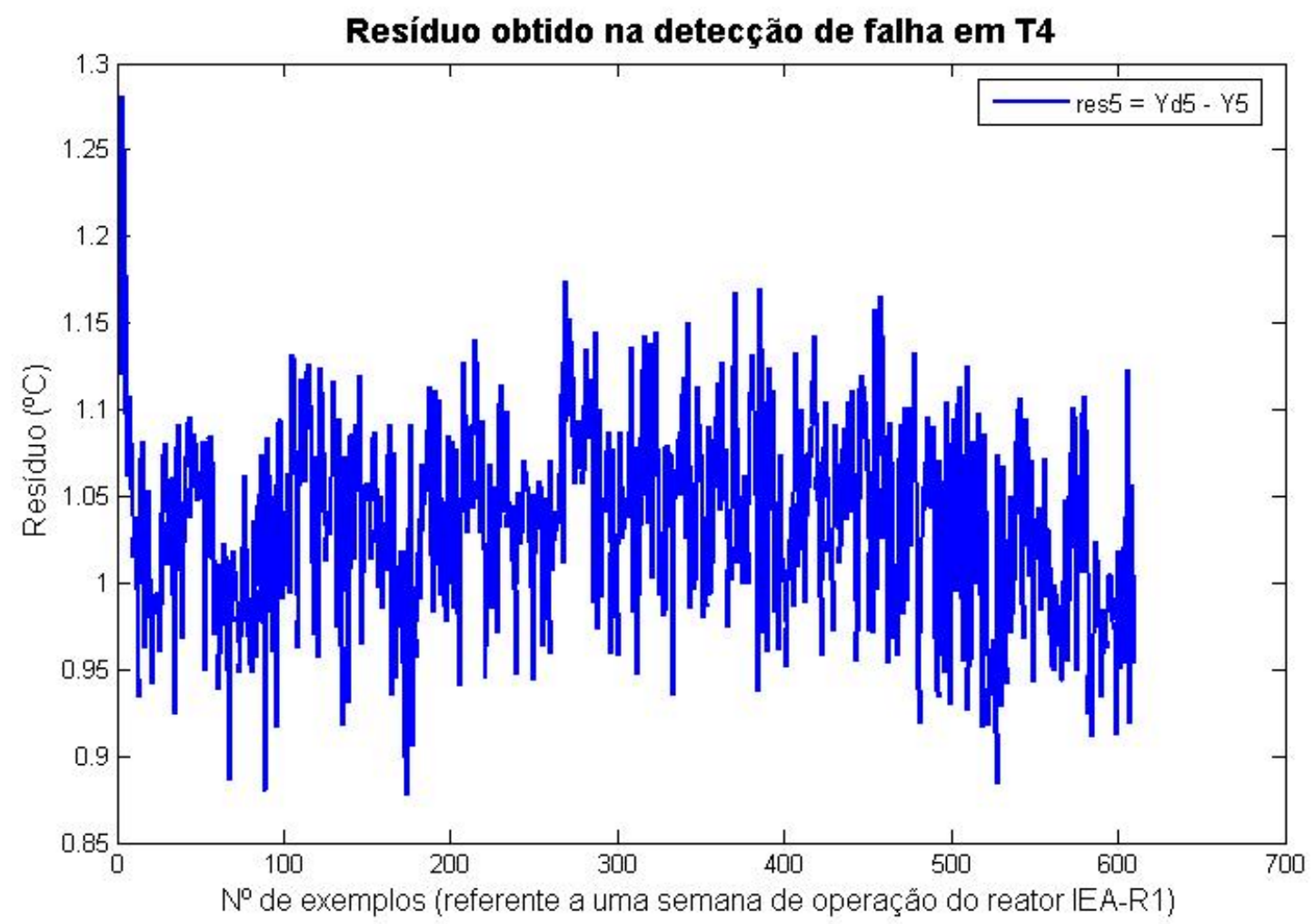

Figura 54. Resíduo obtido na detecção de falha em T4 
Os resultados obtidos usando dados referentes a uma semana típica de operação do reator, mostram a viabilidade de utilização das Redes Neurais Artificiais na detecção de falhas em sensores e atuadores do reator IEA-R1.

\subsection{Discussão e análise dos resultados obtidos}

A Tabela 15 apresenta um resumo dos resultados obtidos na etapa de detecção e monitoração de falhas.

Tabela 15. Resumo dos resultados obtidos na monitoração e detecção de falhas

\begin{tabular}{|c|c|c|c|}
\hline Monitoração & Variáveis & $\mathbf{N}^{0}$ de Neurônios & Energia do Erro (En) \\
\hline \multirow{2}{*}{ Modelo Teórico } & $\mathrm{T} 3$ & 8 & $1,59947 \cdot 10^{-5}$ \\
\hline & T4 & 10 & $6,98342 \cdot 10^{-6}$ \\
\hline \multirow{2}{*}{ Dados de Operação } & T3 & 9 & $9,21064 \cdot 10^{-3}$ \\
\hline & $\mathrm{T} 4$ & 5 & $7,26921 \cdot 10^{-3}$ \\
\hline Detecção de Falhas & Variáveis & $\mathbf{N}^{0}$ de Neurônios & Energia do Erro (En) \\
\hline \multirow{4}{*}{ Modelo Teórico } & T3 (falha de $+1 \%$ ) & 8 & $6,44891 \cdot 10^{-5}$ \\
\hline & T3 (falha de $-1 \%$ ) & 8 & $7,48689 \cdot 10^{-5}$ \\
\hline & T4 (falha de $+1 \%$ ) & 10 & $6,03138 \cdot 10^{-5}$ \\
\hline & T4 (falha de $-1 \%$ ) & 10 & $6,69459 \cdot 10^{-5}$ \\
\hline \multirow{4}{*}{ Dados de Operação } & T3 (falha de $+1 \%$ ) & 9 & $6,71722 \cdot 10^{-2}$ \\
\hline & T3 (falha de $-1 \%$ ) & 9 & $6,81395 \cdot 10^{-2}$ \\
\hline & T4 (falha de $+1 \%$ ) & 5 & $9,44376 \cdot 10^{-3}$ \\
\hline & T4 (falha de $-1 \%$ ) & 5 & $9,84578 \cdot 10^{-3}$ \\
\hline
\end{tabular}

Através da análise da Tabela 15, pode-se verificar que as funções de Energia do Erro (En) obtidas na detecção de falhas foram maiores do que as obtidas na monitoração das mesmas variáveis.

Além disso, os resultados obtidos na detecção de falhas foram excelentes, pois mostraram que as redes usadas na monitoração apresentaram um bom desempenho quando testadas com uma base de dados contendo dados com falha. 


\section{DIAGNÓSTICO DE FALHAS}

Neste capítulo pretendemos apenas apresentar um exemplo antecipando como seria um método de diagnóstico automático de falhas e para tal, foi desenvolvido um Sistema Fuzzy utilizando Lógica Nebulosa, implementado utilizando-se a toolbox do Matlab [44], que pode ser visto na Figura 55. O objetivo deste Sistema Fuzzy é identificar a ocorrência de falhas nos termopares do reator IEA-R1.

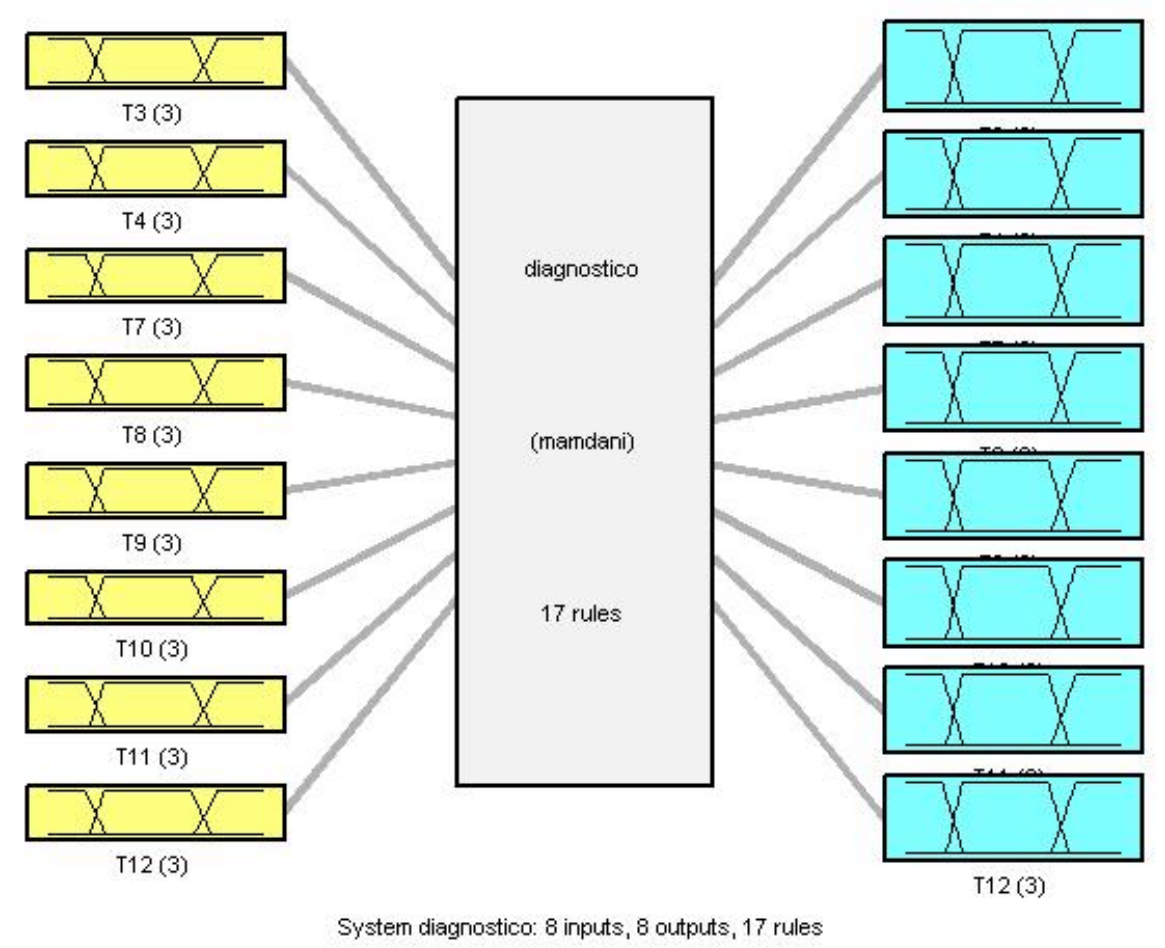

Figura 55. Sistema Fuzzy desenvolvido para o diagnóstico de Falhas

Como pode ser visto na referência [43], existem valores limites de erro de calibração para termopares especiais, que é de $\pm 0,5^{\circ} C$. Assim, definiu-se falha como uma diferença de $\pm 1^{\circ} \mathrm{C}$ entre o valor lido pelo termopar e o valor estimado pelas Redes Neurais Artificiais, sendo que esta diferença recebeu o nome de resíduo e é calculada através da equação (19). 
Desta forma, foram utilizados os resíduos das variáveis monitoradas como entrada do Sistema Fuzzy, sendo consideradas as seguintes variáveis: T3, T4, T7, T8, T9, T10, T11 e T12. Já as variáveis de saída são as possibilidades de falha em cada uma das variáveis de temperatura.

\subsection{Modelagem Fuzzy do Conhecimento Especialista}

O objetivo do Sistema Fuzzy desenvolvido é o de diagnosticar falhas de descalibração nos sensores de temperatura. O conhecimento especialista foi modelado da seguinte maneira:

a) Variáveis de entrada:

T3, T4, T7, T8, T9, T10 e T11.

b) Variáveis de saída:

T3, T4, T7, T8, T9, T10 e T11.

\subsection{Modelagem das Variáveis de Entrada}

A Figura 56 mostra a função de pertinência da variável de entrada T3. As variáveis lingüísticas escolhidas como etiquetas foram: Falha $-1{ }^{\circ} \mathrm{C}$, Normal e Falha $+1^{\circ} \mathrm{C}$. $\mathrm{O}$ universo de discurso de todas as variáveis de entrada varia de -1 a 1 , sendo que o termopar estará funcionando corretamente apenas se ele estiver compreendido entre o valor de $-0,5$ a $+0,5$, valor considerado normal por se tratar do limite máximo de erro de calibração dos termopares especiais.

Para as demais variáveis de entrada foram utilizadas as mesmas funções de pertinências, variáveis lingüísticas e etiquetas, compreendidas no universo de discurso que também varia de -1 a 1 .

Como as funções de pertinências das outras variáveis de entrada são iguais à função de pertinência de T3, optou-se por mostrar apenas a função de pertinência de T3. 


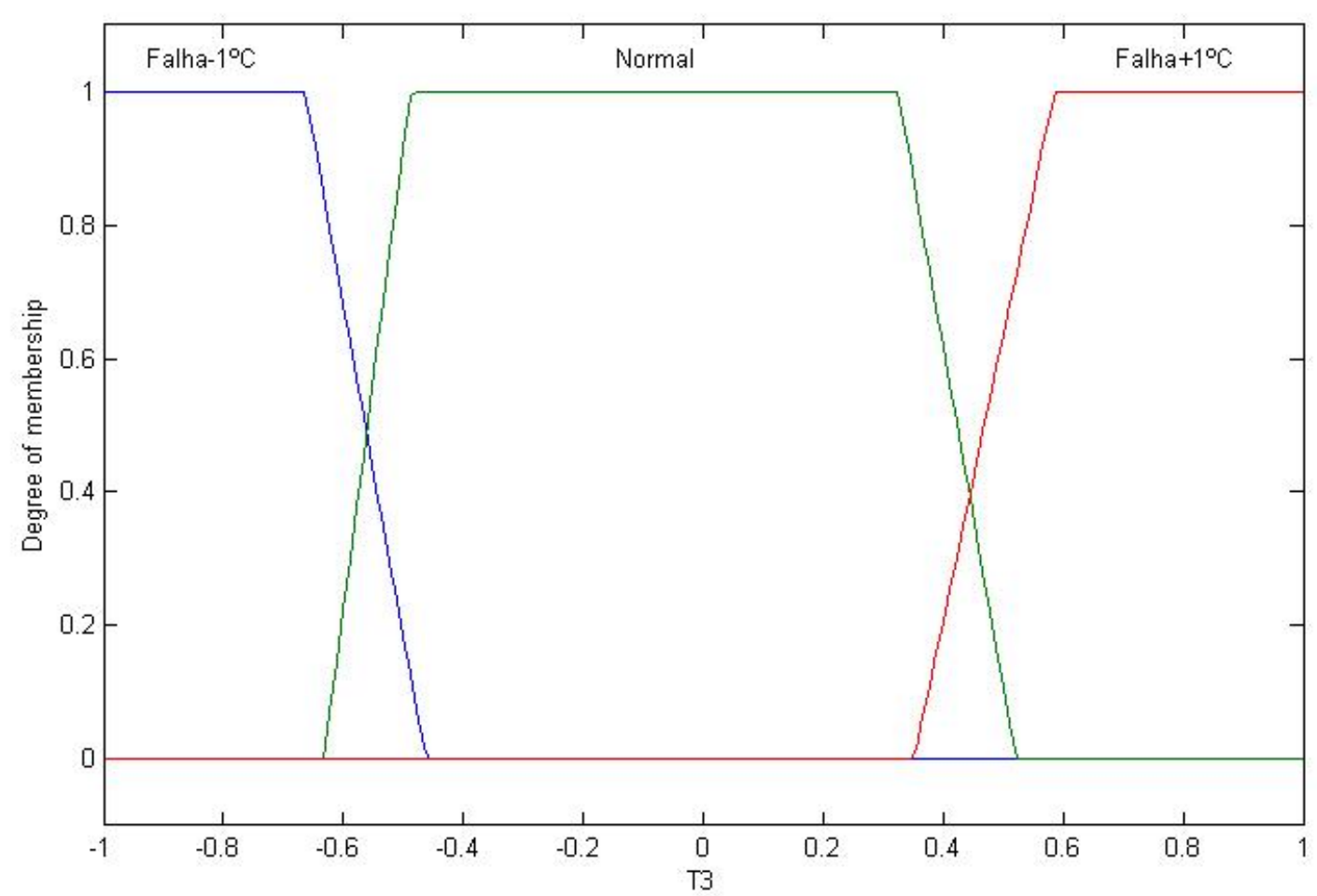

Figura 56. Função de Pertinência da variável de entrada T3

\subsection{Modelagem das Variáveis de Saída}

As funções de pertinência das variáveis de saída indicam a possibilidade de ocorrência de falha em cada um dos termopares. Na Figura 57 é mostrada a função de pertinência da variável de saída T3. As funções de pertinência das demais variáveis de saída são iguais. 


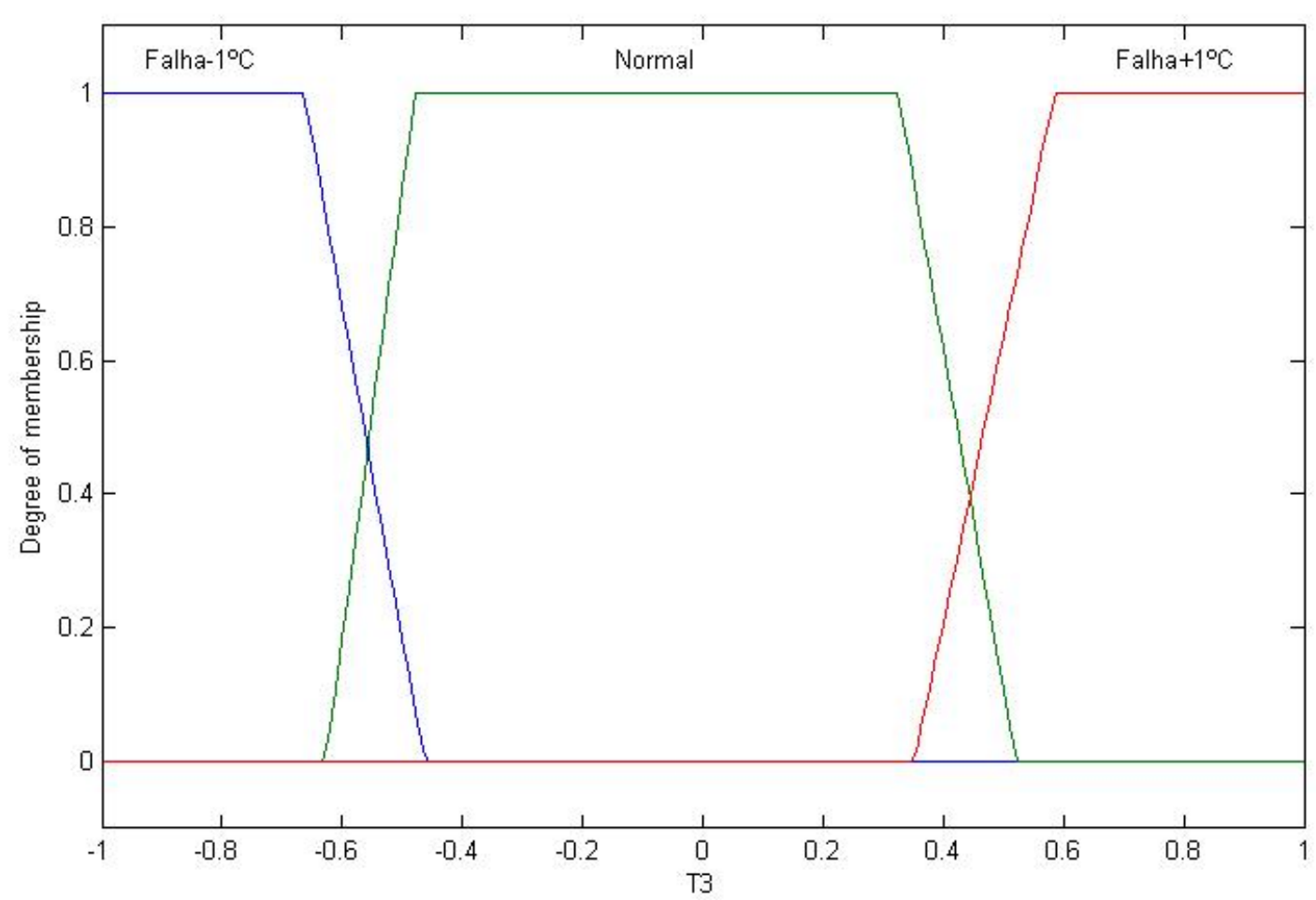

Figura 57. Função de pertinência da variável de saída T3

\subsection{A base de regras do Sistema Fuzzy}

Para implementação do Sistema Fuzzy, utilizou-se como base de conhecimento os resíduos obtidos na monitoração das variáveis de processo. Lembrando apenas que o resíduo é a diferença entre a saída desejada e a saída calculada pela RNA. Assim, os resíduos obtidos na monitoração dos sensores de temperatura foram utilizados na elaboração do Sistema Fuzzy.

Desta maneira, o conhecimento especialista foi modelado através de um conjunto de regras "If - Then (Se - Então)", baseado nos resíduos dos termopares. As regras criadas são mostradas a seguir:

1. If (T3 is Falha- $\left.1^{\circ} \mathrm{C}\right)$ and (T4 is Normal) and (T7 is Normal) and (T8 is Normal) and (T9 is Normal) and (T10 is Normal) and (T11 is Normal) and (T12 is Normal) then (T3 is Falha- $\left.1^{\circ} \mathrm{C}\right)(\mathrm{T} 4$ is Normal)(T7 is Normal)(T8 is Normal)(T9 is Normal)(T10 is Normal)(T11 is Normal)(T12 is Normal) (1) 
2. If (T3 is Falha $\left.+1^{\circ} \mathrm{C}\right)$ and (T4 is Normal) and (T7 is Normal) and (T8 is Normal) and (T9 is Normal) and (T10 is Normal) and (T11 is Normal) and (T12 is Normal) then (T3 is Falha $\left.+1^{\circ} \mathrm{C}\right)(\mathrm{T} 4$ is Normal)(T7 is Normal)(T8 is Normal)(T9 is Normal)(T10 is Normal)(T11 is Normal)(T12 is Normal) (1)

3. If (T3 is Normal) and (T4 is Falha- $\left.1^{\circ} \mathrm{C}\right)$ and (T7 is Normal) and (T8 is Normal) and (T9 is Normal) and (T10 is Normal) and (T11 is Normal) and (T12 is Normal) then (T3 is Normal)(T4 is Falha- $\left.1^{\circ} \mathrm{C}\right)(\mathrm{T} 7$ is Normal)(T8 is Normal)(T9 is Normal)(T10 is Normal)(T11 is Normal)(T12 is Normal) (1)

4. If (T3 is Normal) and (T4 is Falha $\left.+1^{\circ} \mathrm{C}\right)$ and (T7 is Normal) and (T8 is Normal) and (T9 is Normal) and (T10 is Normal) and (T11 is Normal) and (T12 is Normal) then (T3 is Normal)(T4 is Falha $\left.+1^{\circ} \mathrm{C}\right)(\mathrm{T} 7$ is Normal)(T8 is Normal)(T9 is Normal)(T10 is Normal)(T11 is Normal)(T12 is Normal) (1)

5. If (T3 is Normal) and (T4 is Normal) and ( $\mathrm{T} 7$ is Falha- $\left.1^{\circ} \mathrm{C}\right)$ and (T8 is Normal) and (T9 is Normal) and (T10 is Normal) and (T11 is Normal) and (T12 is Normal) then (T3 is Normal)(T4 is Normal)(T7 is Falha- $\left.1^{\circ} \mathrm{C}\right)(\mathrm{T} 8$ is Normal)(T9 is Normal)(T10 is Normal)(T11 is Normal)(T12 is Normal) (1)

6. If (T3 is Normal) and (T4 is Normal) and (T7 is Falha $\left.+1^{\circ} \mathrm{C}\right)$ and (T8 is Normal) and (T9 is Normal) and (T10 is Normal) and (T11 is Normal) and (T12 is Normal) then (T3 is Normal)(T4 is Normal)(T7 is Falha $\left.+1^{\circ} \mathrm{C}\right)(\mathrm{T} 8$ is Normal)(T9 is Normal)(T10 is Normal)(T11 is Normal)(T12 is Normal) (1)

7. If (T3 is Normal) and (T4 is Normal) and (T7 is Normal) and (T8 is Falha$1^{\circ} \mathrm{C}$ ) and (T9 is Normal) and (T10 is Normal) and (T11 is Normal) and (T12 is Normal) then (T3 is Normal)(T4 is Normal)(T7 is Normal)(T8 is Falha- $\left.1^{\circ} \mathrm{C}\right)(\mathrm{T} 9$ is Normal)(T10 is Normal)(T11 is Normal)(T12 is Normal) (1)

8. If (T3 is Normal) and (T4 is Normal) and (T7 is Normal) and (T8 is Falha $+1^{\circ} \mathrm{C}$ ) and (T9 is Normal) and (T10 is Normal) and (T11 is Normal) and (T12 is Normal) then (T3 is Normal)(T4 is Normal)(T7 is Normal)(T8 is Falha $\left.+1^{\circ} \mathrm{C}\right)(\mathrm{T} 9$ is Normal)(T10 is Normal)(T11 is Normal)(T12 is Normal) (1) 
9. If (T3 is Normal) and (T4 is Normal) and (T7 is Normal) and (T8 is Normal) and (T9 is Falha- $\left.{ }^{\circ} \mathrm{C}\right)$ and (T10 is Normal) and (T11 is Normal) and (T12 is Normal) then (T3 is Normal)(T4 is Normal)(T7 is Normal)(T8 is Normal)(T9 is Falha- $\left.{ }^{\circ} \mathrm{C}\right)(\mathrm{T} 10$ is Normal)(T11 is Normal)(T12 is Normal) (1)

10. If (T3 is Normal) and (T4 is Normal) and (T7 is Normal) and (T8 is Normal) and (T9 is Falha $\left.+1{ }^{\circ} \mathrm{C}\right)$ and (T10 is Normal) and (T11 is Normal) and (T12 is Normal) then (T3 is Normal)(T4 is Normal)(T7 is Normal)(T8 is Normal)(T9 is Falha $\left.+1^{\circ} \mathrm{C}\right)(\mathrm{T} 10$ is Normal)(T11 is Normal)(T12 is Normal) (1)

11. If (T3 is Normal) and (T4 is Normal) and (T7 is Normal) and (T8 is Normal) and (T9 is Normal) and (T10 is Falha- $\left.1^{\circ} \mathrm{C}\right)$ and (T11 is Normal) and (T12 is Normal) then (T3 is Normal)(T4 is Normal)(T7 is Normal)(T8 is Normal)(T9 is Normal)(T10 is Falha $\left.-1^{\circ} \mathrm{C}\right)(\mathrm{T} 11$ is Normal)(T12 is Normal) (1)

12. If (T3 is Normal) and (T4 is Normal) and (T7 is Normal) and (T8 is Normal) and (T9 is Normal) and (T10 is Falha $\left.+1^{\circ} \mathrm{C}\right)$ and (T11 is Normal) and (T12 is Normal) then (T3 is Normal)(T4 is Normal)(T7 is Normal)(T8 is Normal)(T9 is Normal)(T10 is Falha $\left.+1^{\circ} \mathrm{C}\right)(\mathrm{T} 11$ is Normal)(T12 is Normal) (1)

13. If (T3 is Normal) and (T4 is Normal) and (T7 is Normal) and (T8 is Normal) and (T9 is Normal) and (T10 is Normal) and (T11 is Falha- $1^{\circ} \mathrm{C}$ ) and (T12 is Normal) then (T3 is Normal)(T4 is Normal)(T7 is Normal)(T8 is Normal)(T9 is Normal)(T10 is Normal)(T11 is Falha- $\left.1^{\circ} \mathrm{C}\right)(\mathrm{T} 12$ is Normal) (1)

14. If (T3 is Normal) and (T4 is Normal) and (T7 is Normal) and (T8 is Normal) and (T9 is Normal) and (T10 is Normal) and (T11 is Falha $\left.+1^{\circ} \mathrm{C}\right)$ and (T12 is Normal) then (T3 is Normal)(T4 is Normal)(T7 is Normal)(T8 is Normal)(T9 is Normal)(T10 is Normal)(T11 is Falha $\left.+1^{\circ} \mathrm{C}\right)(\mathrm{T} 12$ is Normal) (1)

15. If (T3 is Normal) and (T4 is Normal) and (T7 is Normal) and (T8 is Normal) and (T9 is Normal) and (T10 is Normal) and (T11 is Normal) and (T12 is Falha$1^{\circ} \mathrm{C}$ ) then (T3 is Normal)(T4 is Normal)(T7 is Normal)(T8 is Normal)(T9 is Normal)(T10 is Normal)(T11 is Normal)(T12 is Falha- $\left.1^{\circ} \mathrm{C}\right)(1)$ 
16. If (T3 is Normal) and (T4 is Normal) and (T7 is Normal) and (T8 is Normal) and (T9 is Normal) and (T10 is Normal) and (T11 is Normal) and (T12 is Falha $+1^{\circ} \mathrm{C}$ ) then (T3 is Normal)(T4 is Normal)(T7 is Normal)(T8 is Normal)(T9 is Normal)(T10 is Normal)(T11 is Normal)(T12 is Falha $\left.+1^{\circ} \mathrm{C}\right)(1)$

17. If (T3 is Normal) and (T4 is Normal) and (T7 is Normal) and (T8 is Normal) and (T9 is Normal) and (T10 is Normal) and (T11 is Normal) and (T12 is Normal) then (T3 is Normal)(T4 is Normal)(T7 is Normal)(T8 is Normal)(T9 is Normal)(T10 is Normal)(T11 is Normal)(T12 is Normal) (1)

Como pode ser visto, a base de regras foi criada com o objetivo de indicar a ocorrência de falha de cada termopar, possibilitando identificar facilmente qual o sensor falho.

\subsection{Implementação do Sistema Fuzzy}

O Sistema Fuzzy foi implementado utilizando-se a toolbox Fuzzy do Matlab. Esta ferramenta possui uma janela de visualização das regras, onde é possível atribuir valores de entrada e verificar na mesma janela o resultado da inferência.

Na Figura 58 é mostrado o resultado de uma situação de falha onde o valor de T3 está a $-1^{\circ} \mathrm{C}$ abaixo do valor limite de erro para a calibração do termopar.Além disso, verifica-se que para as saídas dos outros termopares (T4, T7, T8, T9, T10, T11, T12), o resultado da inferência é de "Condição Normal". Através da movimentação do cursor vermelho, é possível simular diversas situações de falha, sendo necessário apenas escolher o termopar e o tipo de falha simulada, para que possa ser realizada a inferência. 
Aule Viewer: diagnostico

$-\mid[a|x|$

File Edit View Options

$T 3=-1 \quad T 4=0 \quad T 7=0 \quad T 8=0 \quad T 9=0 \quad T 10=0 \quad T 11=0 \quad T 12=0 \quad T 3=-0.7 \quad T 4=-0.06 \quad T 7=-0.06 \quad T 8=-0.06 \quad T 9=-0.06 \quad T 10=-0.06$

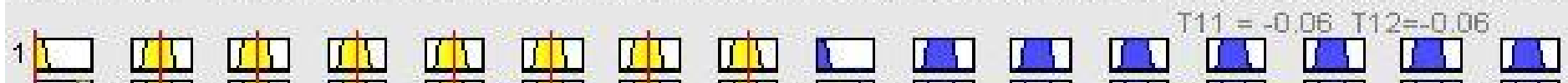

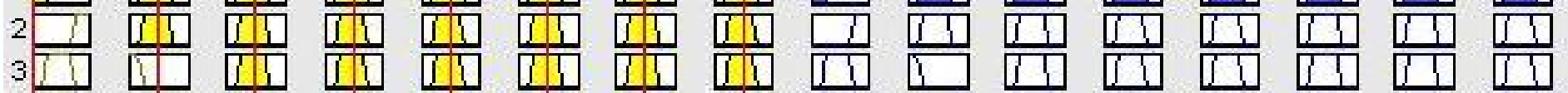

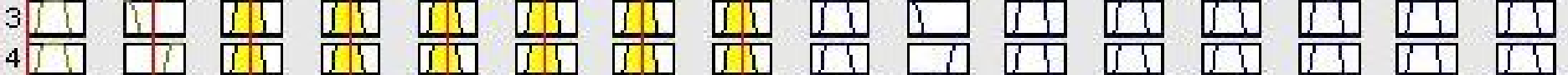

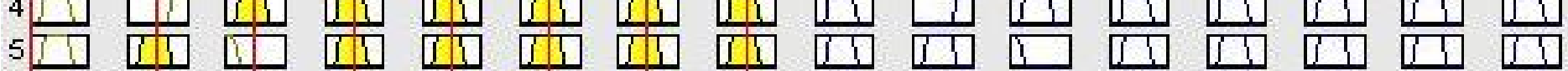

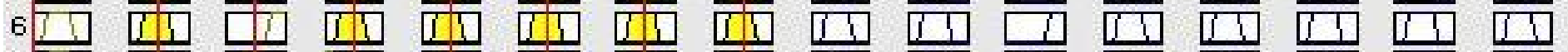

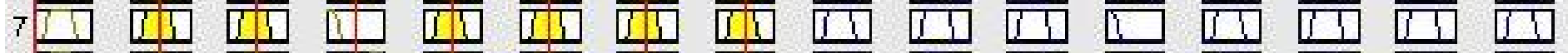

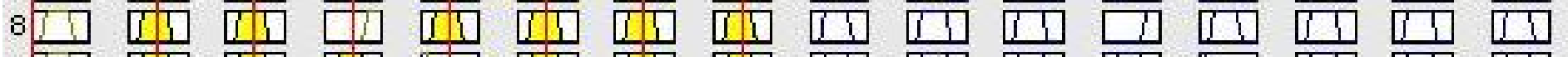

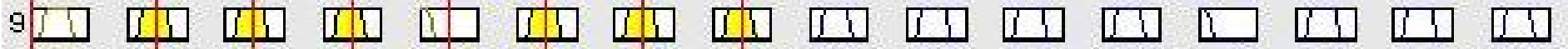

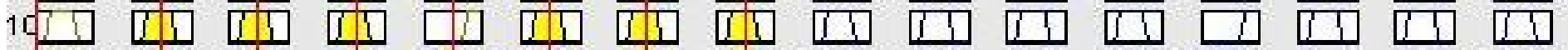

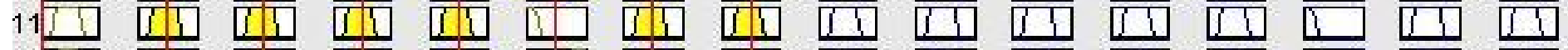

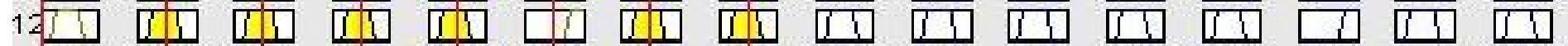

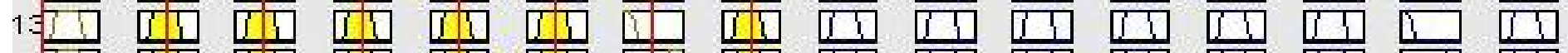

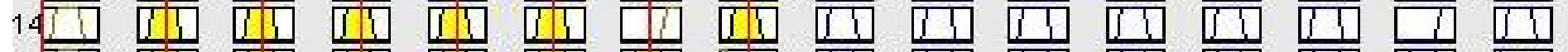

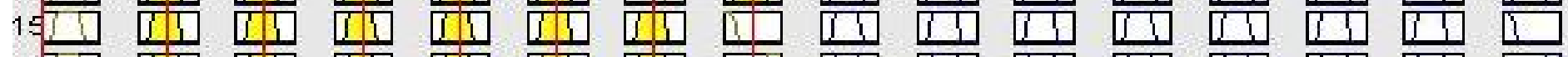

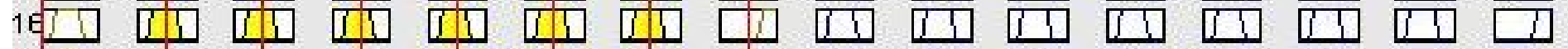

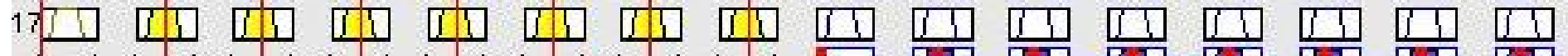

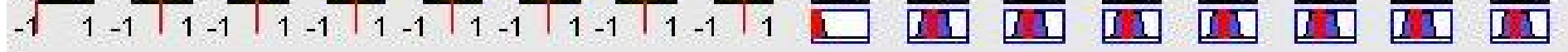

\begin{tabular}{|c|c|c|c|c|c|c|c|c|}
\hline Input: & {$\left[\begin{array}{llllllllllllllll}-1 & 0 & 0 & 0 & 0 & 0 & 0 & 0\end{array}\right]$} & Plot points: & 101 & Move: & left & right & down & up \\
\hline \multicolumn{4}{|c|}{ Opened system diagnostico, 17 rules } & \multicolumn{3}{|c|}{ Help } & Clos & \\
\hline
\end{tabular}

Figura 58. Simulação de falha no termopar responsável pela leitura de T3 


\section{CONCLUSÕES}

O objetivo desta dissertação é mostrar a viabilidade do emprego da metodologia de Redes Neurais Artificiais na monitoração e detecção de falhas em sensores de um processo. Para tanto foi desenvolvido um sistema de monitoração e diagnóstico de falhas utilizando duas bases de dados: uma contendo dados gerados por um modelo teórico, e outra contendo dados de uma semana típica de operação do reator IEA-R1.

O modelo teórico do reator foi desenvolvido utilizando-se a ferramenta GUIDE do Matlab. Este modelo possui uma interface que permite gerar dados de operação normal, dados com falhas e dados com diferentes níveis de ruído nas variáveis de entrada. $\mathrm{O}$ modelo teórico do reator possui um total de onze variáveis, onde a metodologia de Redes Neurais Artificiais foi utilizada no desenvolvimento de um sistema de monitoração, obtendo-se excelentes resultados, onde os valores das funções de Energia do Erro (En) foram da ordem de $10^{-5}$. Através deste estudo foi possível estabelecer qual a arquitetura da rede que fornecia o melhor resultado, e determinar o melhor algoritmo de treinamento.

Os resultados obtidos nos estudos da metodologia de Redes Neurais Artificiais para a monitoração e detecção de falhas usando dados gerados por um modelo teórico, propiciaram uma base para a aplicação desta metodologia usando dados referentes a uma semana típica de operação do reator.

Para o desenvolvimento do Sistema de Monitoração usando dados de operação, foi utilizada uma base de dados fornecida pelo Sistema de Aquisição de Dados (SAD), que é responsável pela monitoração de 57 variáveis de operação. Assim, utilizou-se dado de operação, referentes à terceira semana de Abril de 2004, cuja potência de operação foi de 4,3 MW. Foram consideradas as mesmas variáveis do modelo de monitoração usando dados gerados pelo modelo teórico, com exceção das variáveis de temperatura, pois o reator estava utilizando o trocador de calor B, nesta semana de operação. Os resultados obtidos na monitoração usando dados de operação foram excelentes, onde os valores das Funções de Energia do Erro (En) foram da ordem de $10^{-3}$. Também foi feita a monitoração da taxa de dose, sendo o valor da Função de Energia do Erro (En) da ordem de $10^{-2}$. 
Para a implantação do Sistema de Detecção de Falhas, foram utilizadas as redes treinadas na monitoração de falhas. Essas redes foram testadas com uma base de dados contendo falhas, onde foram inseridas falhas artificiais de $\pm 1^{\circ} C$, primeiramente na base de dados gerada pelo modelo teórico, e depois na base de dados contendo dados de operação do reator. $\mathrm{O}$ valor de $\pm 1^{\circ} \mathrm{C}$ foi utilizado, pois o limite máximo de erro de calibração dos termopares especiais é de $\pm 0,5^{\circ} C$. Uma falha é definida como uma diferença entre o valor lido pelo instrumento e o valor estimado pela RNA, e se esta diferença for superior ao valor limite de erro de calibração do termopar, há uma falha no termopar. Os resíduos obtidos na detecção de falha foram maiores do que os obtidos na monitoração, comprovando a presença de falha no sistema, sendo que foram testadas apenas as redes responsáveis pela monitoração das variáveis T3 e T4, com o propósito de verificar a capacidade de generalização das redes utilizadas no desenvolvimento do Sistema de Monitoração.

A última etapa deste trabalho foi o desenvolvimento de um Sistema Fuzzy para realizar o diagnóstico de falhas. As variáveis de entrada do Sistema Fuzzy foram as variáveis de temperatura, onde a falha foi definida como um valor superior a $\pm 0,5^{\circ} C$, que é o valor limite de erro de calibração dos termopares; e as variáveis de saída também foram as variáveis de temperatura, mostrando a possibilidade de ocorrência de falha nos termopares. Assim, foram realizadas algumas simulações de falha para verificar o desempenho do Sistema Fuzzy desenvolvido, onde os resultados obtidos mostraram que o mesmo apresentou excelentes resultados nas simulações realizadas.

\subsection{Recomendações para trabalhos futuros}

* Expandir o Sistema de Monitoração e Diagnóstico de falhas utilizando uma nova base de dados que contenha várias semanas de operação do reator, na mesma condição de potência.

* Elaborar um novo modelo para monitorar a vazão do primário, do secundário, além de incluir variáveis nucleares.

* Ampliar o estudo das falhas, através da simulação de falhas em outros sensores, além dos termopares.

* Elaborar um Sistema Neurofuzzy para realizar o diagnóstico de falhas, utilizando-se os resíduos obtidos na monitoração como entrada deste sistema. 
* Testar a implementação desta metodologia nas usinas nucleares brasileiras, pois a mesma não implica em nenhuma modificação na instrumentação existente.

* Atualização do banco de dados elaborado em Access, através da incorporação dos dados de operação de 2003 a 2005.

* Estudar métodos de seleção automática das variáveis de entrada para uma dada variável de saída (Análise de Componente Principal) e métodos de eliminação de variáveis colineares. 


\section{REFERÊNCIAS BIBLIOGRÁFICAS}

1. SIMANI, S.; FANTUZZI, C. Fault diagnosis in power plant using neural networks. Information Sciences, v. 117, p. 125-136, 2000.

2. PATTON, R. J.; CHEN, J.; NIELSEN, S. B. Model-Based Methods For Fault Diagnosis: Some Guidelines. IEEE Transactions of the Institute of Measurement and Control, v. 17, n. 2, 1995.

3. KALOGIROU, S. A. Applications of artificial neural networks for energy systems. Applied Energy, v. 67, n. 1, p. 17-35, Setembro 2000.

4. ZUPAN, J., NOVIC M., RUISANCHEZ I. Kohonen and counterpropagation artificial neural networks in analytical chemistry. Chemometrics and Intelligent Laboratory Systems, v. 38, n. 1, p. 1-23, Agosto 1997.

5. BROSSE, S., GUEGAN, J. F., TOURENQ, J. N., LEK, S. The use of neural networks to asses fish abundance and spatial occupancy in the littoral zone of a mesotrophic lake. Ecol. Model., v.120, p. 229-311, 1999.

6. BAXT, W. G., SHOFER, F. S., et. al. A neural computational aid to the diagnosis of acute myocardial infarction. Ann Emerg Med, v. 39, p. 366-373, Abril 2002.

7. CLARK, R. N. Instrument fault detection. IEEE Trans. Aerosp. Electron. Syst., v. 14, p. 456-465, Maio 1978.

8. ECHENDU, J. E. A., ZHU, H. Detecting changes in the condition of process instruments. in Conf. Rec. of IMCT, Irvine CA, USA, p. 515-518, 1993.

9. SYDENHAM, P. H., THORN, R. Strategies for sensor performance assessment. in Conf. Rec. of IMTC, Irvine CA, USA, p. 353-358, 1993.

10. CLARK, R. N., FOSTH, D. C., WALTON, V. M. Detecting instrument malfunctions in control systems. IEEE Trans. Aerosp. Electron. Syst., v. 11, p. 465-473, Julho 1975.

11. WILLSKY, A. S. A survey of design methods for failure detection in dynamic systems. Automatica, v. 12, p. 601-611, 1976.

12. PATTON, R., FRANK, P., CLARK, R. Fault diagnosis in dynamic systems theory and application. Prentice Hall, 1989.

13. FRANK, P. M. Fault diagnosis in dynamic systems using analytical and knowledge-based redundancy - A survey and some new results. Automatica, v. 26, n. 3, p. 459-474, 1990. 
14. BEARD, R. V. Failure Accommodation in Linear Systems Through SelfReorganization. Dept. MVT-71-1. Man Vehicle Laboratory, Cambridge, MA., 1971.

15. JONES, H. L. Failure detection in linear sustems. PhD Thesis, MIT, Cambridge, MA, 1973.

16. MEHRA, R. K.; PESHON, I. An innovation approach to fault detection and diagnosis in dynamic systems. Automática, v. 7, p. 637-640, 1971.

17. DECKERT, J. C.; DESAI, M. N.; DEYST, J. J.; WILLSKY A. S. DFBW sensor failure identification using analytic redundancy. IEEE Trans. Aut. Control., AC22, p. 795-809, 1977.

18. KITAMURA, M. Detection of sensor failures in nuclear plant using analytic redundancy. Trans. Am. Nucl. Soc., v. 34, p. 581-583, 1980.

19. HENLEY, E. J. Application of expert systems to fault diagnosis. In AIChE Annual meeting, San Francisco, CA, 1984.

20. CHESTER, D.; LAMB, D.; DHURJATO, P. Rule based computer alarm analysis in chemical process plant. In Proceeding of $7^{\text {th }}$ Micro-Delcom, p. 22-29, 1984.

21. RICH, S. H.; VENKATASUBRAMANIAN, V. Model-based reasoning in diagnostic expert systems for chemical process plants. Computers and Chemical Engineering, v.11, p. 111-122, 1987.

22. SORSA, T., KOIVO, N. H. Neural Networks in process fault diagnosis. IEEE Transactions on systems, Man and Cybernetics, v. 21, n. 4, Julho/Agosto 1991.

23. BERNIERI, A et al. A Neural Network approach to instrument fault detection and isolation. Instrument and Measurement Technology Conference, v. 1, p. 139144, 1994.

24. SELIGER, B. K., FRANK, P. M. Fault Detection and Isolation in Technical Processes with Neural Networks. Proceeding of the $34^{\text {th }}$ Conference on Decision \& Control, New Orleans, LA, Dezembro 1995.

25. KEYVAN, S., DURG, A., NAGARAJ, J. Application of artificial neural networks for the development of a signal monitoring system. Expert Systems, v. 14, n. 2, Maio 1997.

26. MAKI, Y., LOPARO, K. A. A Neural Network approach to fault detection and diagnosis in industrial processes. IEEE Transaction on control system technology, v. 5, n. 6, Novembro 1997.

27. ABO-SHOSHA A., et. al.Using Neural Network in fault diagnosis of nuclear power reactors. 1997. Disponível em:

http://www.icgst.com/biography/cse/robotics/Aboshosha/ICECS97.pdf 
28. ROSSI, R. H. P. S. Utilização de Redes Neurais na monitoração da potência do Reator IEA-R1. Dissertação (mestrado), Instituto de Pesquisas Energéticas e Nucleares - IPEN, 151 p., São Paulo, 2001.

29. SEKER, S. et al. Artificial neural networks for dynamic monitoring of simulated-operating parameter of high temperature gas cooled engineering teste reactor (HTTR). Annals of Nuclear Energey, v. 30, p. 1777-1791, 2003.

30. INSTITUTO DE PESQUISAS ENERGÉTICAS E NUCLEARES (IPEN). Relatório de Análise de Segurança do reator de pesquisas do IPEN IEA-R1 (RAS).

31. BUENO, E. I. Manual do Banco de Dados do reator IEA-R1. Relatório Técnico, IPEN, 2002.

32. GONÇALVES, I. M. P., TING, D. K. S. A theoretical model for the IPEN research reactor IEA-R1. INAC 2005 - International Nuclear Atlantic Conference Proceedings (Cdroom), Agosto 2005.

33. HAYKIN, S. Neural Networks - A Comprehensive Foundation. Prentice Hall, 1999.

34. BRAGA, A. P.; LUDERMIR, T. B.; CARVALHO, A. Redes Neurais Artificiais Teoria e Aplicações. Livros Técnicos e Científicos, São Paulo, 1999.

35. MCCULLOCH, W. S., PITTS, W. A logical calculus of the ideas immanent in nervous activity, Bulletin of Mathematical Biophysics, v. 5, p. 115-133, 1943.

36. HEBB, D. O. The Organization of behavior: a neuropsychological theory. New York: Wiley, 1949.

37. FAUSETT, L. Fundamentals of neural networks architectures, algorithms and applications. New Jersey, 1994.

38. RUMMELHART, D. E., MCCLELLAND, J. L. Parallel Distributed Processing: Explorations in the Microstructure of Cognition, v. 1, Cambridge, MA: MIT Press, 1986.

39. ZADEH, L. A. Fuzzy Sets. Inf. Control, 8, 388, 1965.

40. GUIMARÃES, A. C. F. Metodologia para análise de confiabilidade baseada em árvore de falhas Lógica Fuzzy. Tese (Doutorado), Coppe/Ufrj, Rio De Janeiro, 1997.

41. HINES, W. J. Introduction to Fuzzy Logic. The University Of Tennessee, Junho/2000.

42. GONÇALVES, I. M. P. Monitoração e diagnóstico para deteç̧ão de falhas de sensores utilizando a metodologia GMDH. Tese (Doutorado), IPEN, São Paulo, 2005 . 
43. Manual on the use of thermocouples in temperature measurement. ASTM STP 470B. American Society for Testing amd Materials, Fevereiro 1983.

44. Fuzzy logic toolbox for use GUIs with Matlab Version 5, the MATH WORKS Inc, MA, USA, 1997.

45. TANOMARU, N., HIROMOTO, M. Y. C. Manual de Instalação e Operação do SAD IEA-R1. NR22.10-3121-Ho-01/00, Ctmsp, Julho 1998.

46. MONTEIRO, P. R. B., GONÇALVES, I. M. P. Sistema de Aquisição de Dados do Reator IEA-R1. INAC 2002 - International Nuclear Atlantic Conference Proceedings (Cdroom), Outubro 2002.

47. BUENO, E. I., TING, D. K. S., GONÇALVES, I. M. P. A development of an artificial neural network for nuclear power monitoring and fault detection in the IEA-R1 research reactor at IPEN. INAC 2005 - International Nuclear Atlantic Conference Proceedings (Cdroom), Setembro 2005. 